\title{
aAba, Refrain, Chorus, Bridge, PreChorus - SONGFORMEN UND IHRE HISTORISCHE ENTWICKLUNG
}

\author{
Ralf von Appen und Markus Frei-Hauenschild
}

\section{Einleitung}

\subsection{Warum Formanalyse?}

In der Literatur zur Analyse populärer Musik werden Songformen nur peripher behandelt. Die wenigen existenten, weitgehend bezuglos nebeneinander stehenden Aufsätze und Kapitel zur Form von Popsongs beschränken sich darauf, eine pauschale Übersicht verbreiteter Formmodelle aufzustellen, ohne diese historisch oder stilistisch zu differenzieren. Tiefergehende Studien zur historischen Entwicklung und Verbreitung verschiedener Songformen gibt es bislang nicht, sodass der Eindruck entsteht, populäre Musik beschränke sich auf wenige konventionelle Standardformen. Dies hat möglicherweise zur Folge, dass die Analyse formaler Abläufe als banal und irrelevant für semantische Interpretationen angesehen wird.

Nach eingehender Untersuchung hat sich diese Einschätzung als unzutreffend erwiesen und es sind wichtige Desiderate für die intensivere Auseinandersetzung mit Songformen offenbar geworden:

Erstens weist die aktuell benutzte Nomenklatur unzählige interne Widersprüche auf (s. Abschnitt 1.2). Es fehlt eine kritische Diskussion der Terminologie mit dem Ziel, im Umlauf befindliche Begriffe hinsichtlich ihrer Ursprünge und Wandlungen zu untersuchen. Eine wissenschaftlich belastbare Terminologie ist als Grundlage für die Verständigung über Musik und ihre Analyse unerlässlich.

Zweitens sollte sich die Analyse von Song-Architekturen nicht in der bloBen Beschreibung erschöpfen, sondern es erscheint lohnenswert, die Songform als Gegenstand der Analyse - nicht nur als ihre Grundlage zur Orientierung im Song - zu betrachten, da sie auf semantischer, symbolischer und funktionaler Ebene Anlass zur Interpretation gibt: Zwar steht sie meist in 
keinem so engen semantischen Verhältnis zum Songtext wie Harmonik, Melodik oder Sound, doch sollte ein Bewusstsein dafür vorhanden sein, dass expressive Inhalte wie Spannung und Langeweile, Ausgeglichenheit und Ungeduld, Aufbruch und Heimkehr, Ordnung und Unangepasstheit oder Chaos, Veränderung, Überraschung, Befriedigung oder Verstörung auch durch die Gestalt der Songform unterstützt bzw. konterkariert werden können. Während solche Interpretationsmöglichkeiten auf einem unmittelbaren Ähnlichkeitsbezug von Form und Inhalt basieren, sind auch Interpretationen denkbar, die die Form symbolisch deuten, die also von Bedeutungen ausgehen, die einem bestimmten Formmodell mehr oder weniger willkürlich zugeschrieben worden sind und nun durch Konvention an ihm haften: So können Songformen als parodistisch, ironisch oder nostalgisch gehört werden, wenn sie in einen Kontext versetzt werden, der nicht ihrem ursprünglichen entspricht (s. Abschnitt 6), so wie überhaupt jeder bewusste Bruch mit Konventionen zur Interpretation herausfordert. Daneben kann die Form auch in Hinblick auf die Einbindung eines Songs in Funktionszusammenhänge interpretiert werden, denn aus der Form - z. B. aus der Länge und Art der Introduktion, der Textmenge, aus der Position und Häufigkeit des Auftretens von Refrains oder Choruses - lassen sich Rückschlüsse auf den anvisierten Einsatz bspw. im Radio, bei politischen oder bei Tanz-Anlässen ziehen.

Drittens braucht jeder, der Musik der Vergangenheit und der Gegenwart auf der Basis geschichtlicher Entwicklung verstehen möchte, Kenntnisse über die jeweiligen historischen Standards und Innovationen. Was ist zu einer bestimmten Zeit das allgemein Übliche, was das Besondere? Wie kam es zu Veränderungen, Einflussnahmen, Neuerungen, Anpassungen und Verschmelzungen?

Solche Fragen und Erkenntnisinteressen setzen terminologische und historische Grundlagen voraus, die wir im Folgenden legen möchten.

\subsection{Terminologische Basis}

Auf dem höchsten Verallgemeinerungsniveau lässt sich das Gros populärer Songs einem der drei folgenden Formmodelle zuordnen:

\section{Verse/Chorus-Form}

Verse/Chorus-Formen enthalten (neben optionalen Introduktionen, Soli oder Codas) zwei Formbausteine: einen Chorus, der harmonisch, melodisch und textlich (weitgehend) unverändert wiederholt wird, und mehrere Verses, die sich bei weitgehender harmonischer und melodischer Identität jeweils im Songtext unterscheiden. Innerhalb der Verse/Chorus-Form sollte man mit 
John Covach (2005: 73) die »simple« von der »contrasting " Verse/ChorusForm unterscheiden: In letzter unterscheiden sich Verse und Chorus in Harmonik und/oder Melodik, in der »simple verse/chorus «-Form folgen beide dem gleichen harmonischen Ablauf.

2. AAA- oder »simple verse $«-$ Form

In diesem Formmodell wird ein Formbaustein (A) mehrfach mit verändertem Songtext wiederholt. Dabei kann dieser A-Teil stets mit der gleichen Textzeile, dem Refrain, enden oder beginnen, es gibt jedoch keinen zweiten eigenständigen Formteil wie im Verse/Chorus-Modell. Zum AAA-Modell sind erzählende Balladen oder Folk Songs ebenso zu zählen wie Stücke, die aus der mehrfachen Wiederholung eines Bluesschemas bestehen. Eine einheitliche Benennung für die einzelnen A-Teile gibt es nicht: Je nach Genre und Autor ist von Verse, Chorus, "stanza« oder »strophe» die Rede.

\section{AABA- oder American Popular Song Form}

Dieses Formmodell basiert auf einem meist achttaktigen A-Teil, der zu Beginn oder am Ende oft die Titelzeile enthält und der unmittelbar nach seinem ersten Auftreten mit variiertem Text wiederholt wird. Es folgt ein kontrastierender, meist ebenfalls achttaktiger B-Teil, bevor die 32-taktige Einheit mit einer weiteren Wiederholung des (variierten) A-Teils schließt. Mitunter steht vor diesem AABA-Durchgang ein einleitender, oft rezitativischer Verse, der nicht wiederholt wird. In einigen Fällen folgt auf den ersten ein weiterer vollständiger AABA-Durchlauf, häufiger werden nur die letzten 16 Takte (BA) wiederholt, bevor der Song mit einer Coda schließt.

Für die einzelnen Formbausteine dieser drei Grundmodelle gibt es keine einheitliche Terminologie. Gängige Begriffe wie »Chorus", »Verse« oder "Bridge « sind historischen Wandlungen unterworfen, sie werden daher in der Literatur nicht selten gegensätzlich definiert. Aufgrund der Gewachsenheit der Begriffe sind endgültige Definitionen nicht möglich, sodass an einer historischen Betrachtung kein Weg vorbei führt.

Folgende Übersicht soll zunächst weniger für Klarheit sorgen, als den widersprüchlichen Gebrauch dokumentieren und so ein Bewusstsein für die zahlreichen Doppeldeutigkeiten schaffen.

\section{Chorus}

"Chorus « ist zunächst die Bezeichnung für jenen meist achttaktigen eigenständigen Formteil innerhalb der Verse/Chorus-Form, der mit identischem Songtext bei identischer harmonischer und melodischer Struktur wiederholt 
wird. Oft enthält er den Titel des Stückes oder einen anderen Text-Hook, der die Wiedererkennbarkeit erhöht und häufig zum Mitsingen animiert.

Innerhalb der AAA-Form wird als »Chorus« aber auch jeweils ein Durchgang der harmonischen und melodischen Struktur, also ein A-Teil bezeichnet, obwohl der Songtext hier nicht identisch wiederholt wird. Entsprechend wird die AAA-Form auch »Chorus-Form « genannt: »Blues form is a type of chorus form: the structural unit carrying one stanza (which musically may be referred to as a verse or chorus) is repeated for subsequent stanzas« (Middleton 2003: 503, vgl. auch 508).

Auch innerhalb der AABA-Form wird ein vollständiger 32-taktiger Durchlauf als »Chorus « tituliert, gerade im Jazz, wo über mehrere Wiederholungen solcher Choruses improvisiert wird (ebd.: 505). Mit Bezug auf die Popular Songs der Tin Pan Alley-Ära bezeichnet Allen Forte (1995: 38) allerdings nicht den ganzen Durchgang, sondern nur die A-Teile als »Chorus«. Die ersten beiden A-Teile fasst er zum »Chorus 1 « zusammen, den dritten A-Teil nennt er »Chorus $2 \ll$.

\section{Refrain}

»Refrain« wird v.a. im Deutschen, aber auch bei Richard Middleton (2003: 508) synonym mit »Chorus « benutzt, sofern es sich um einen Chorus innerhalb einer Verse/Chorus-Form handelt.

Innerhalb von AAA- und AABA-Formen ist mit »Refrain« meist das gemeint, was auf Deutsch genauer mit »Refrainzeile« zu bezeichnen wäre: eine am Anfang oder Ende eines Formteils stehende Textzeile, die bei jedem Auftreten wiederholt wird. In dieser Verwendung ist der Refrain kein eigenständiger Formteil.

Allerdings gibt es auch Autoren, die einen Durchlauf der 32-taktigen AABA-Form als einen »Refrain « bezeichnen, so Forte (1995: 36) oder Covach (2005: 70), der zur Vermeidung von Missverständnissen den Begriff »sectional refrain« vorschlägt. Üblich war diese Bezeichnung offenbar auch unter den Song-Autoren, denn im einleitenden Verse des Songs »|t's De-Lovely« von Cole Porter (1936) heißt es, bevor der erste AABA-Durchgang beginnt:

I feel a sudden urge to sing the kind of ditty that invokes the spring. So, control your desire to curse while I crucify the verse! This verse I've started seems to me the »Tin Pan-tithesis « of melody. So to spare you all the pain, I'll skip the darn thing and sing the refrain. 
Verse

Wie in diesem Beispiel wird im Rahmen der AABA-Form der dem ersten A oft vorangestellte rezitativische Teil als »Verse « bezeichnet. ${ }^{1}$ Covach (2005: 69f.) nennt solche Einleitungen »sectional verse«, denn »Verses« sind für inn wiederum die einzelnen A-Teile innerhalb der AABA-Form.

In AAA-Formen werden die einzelnen A-Teile manchmal als »Chorus«, manchmal als »Verse « bezeichnet. Was Middleton (2003: 508) »chorus-form nennt, heißt bei Covach (2005: 68f.) dementsprechend »simple verse «Form. Diese Verses können wiederum eine Refrainzeile beinhalten.

Innerhalb der Verse/Chorus-Form ist der Verse der eigenständige Formteil, der mit verändertem Text wiederholt wird.

\section{Bridge}

»Bridge « wird zunächst der B-Teil in AABA-Formen genannt. Daneben sind für diesen Teil allerdings auch die Bezeichnungen »Release «, »Channel « und »Middle Eight« verbreitet. Zudem bezeichnet »Bridge « in Verse/ChorusFormen einen dritten eigenständigen Formteil, der nach der Wiederholung von Verse und Chorus im letzten Drittel des Songs noch einmal neues, kontrastierendes Material bringt. Diese Bridge wird meist nicht wiederholt.

Vor allem unter Musikern wird »Bridge « noch in einem dritten Zusammenhang verwendet, und zwar zur Bezeichnung eines vom Verse zum Chorus überleitenden Parts, der alternativ als »PreChorus« bezeichnet wird (s. Abschnitt 5 und Fußnote 75). Um diese Begriffe auseinanderzuhalten, wurden die Termini »Transitional Bridge« (im Sinne von PreChorus) und »Primary Bridge« (im Sinne von Middle Eight) vorgeschlagen (vgl. Fritsch/Kellert/ Lonardoni 2010: 226f.), diese Differenzierung findet im praktischen Gebrauch allerdings sehr selten Verwendung. ${ }^{2}$

Nur in Ken Stephensons (2002: 138) Nomenklatur bezeichnet »Bridge « auch einen Formteil, der zwischen mehreren Verses steht.

Es wird deutlich, dass die Bezeichnungen von Forte, Covach und Middleton nicht miteinander vereinbar sind: Dieselbe 32-taktige AABA-Form bestünde bei Covach aus drei gleich langen Versen und einer Bridge, bei Forte aus

1 Vgl. auch den Verse von »Catch Em Young, Treat Em Rough, Tell Em Nothing « (Krantz/Colby 1951): »This verse is short / and so's this song / Follow my advice and you can't go wrong «).

2 Der Formteil PreChorus wird übrigens weder in Middletons (2003) noch in Stephensons (2002) Formen-Übersicht erwähnt. Selbst Covach hat keine Bezeichnung für diesen Formteil, obwohl er mit »Be My Baby« (Spector/Barry/ Greenwich 1963) einen Song analysiert, der PreChoruses enthält (s. Covach 2005: 71). 
zwei unterschiedlich langen Choruses und einer Bridge - während die Bridge bei Middleton Teil eines umfassenden Chorus' ist. Um diese Termini wissenschaftlich nutzen zu können, ist es also unerlässlich zu untersuchen, wie es zu dieser Begriffsverwirrung kommen konnte und wo die historischen Ursprünge dieser Formteile und ihrer jeweiligen Bezeichnungen liegen.

\subsection{Zur Gliederung}

Unsere zentrale These ist, dass das weitgehende Verschwinden des Verse in der American Popular Song Form der Tin Pan Alley-Zeit mit einer zunehmend differenzierten Binnengestaltung der AABA-Choruses einherging, aus der um 1960 eine neue, komplexere Verse-(PreChorus)-Chorus-Form mit der Bridge als nun formal isoliertem Mittelteil entstand.

Die nachfolgende Darstellung beginnt mit der Einführung des Begriffs Chorus für den Refrain in den Minstrelsongs von Stephen Foster (Abschnitt 2.1). Durch Ausweitung und textliche wie musikalische Separierung der Formteile entsteht in den 1890er Jahren die typische Verse/Chorus-Form der frühen Tin Pan Alley-Zeit, in der der Chorus meist als 16- oder 32taktige Periode ABAC auftritt (Abschnitt 2.2). Nach dem Ersten Weltkrieg setzt sich als Standard die 32-taktige AABA-Form durch, deren A-Zeilen nun mit einem Refrain beginnen oder enden (Abschnitte 2.3 und 2.4). Für die weitere Ausdifferenzierung der A-Zeilen sind die unterschiedlichen Arten der Harmonisierung innerhalb der Stilmelange »Tin Pan Alley« von maßgeblicher Bedeutung (Abschnitt 2.5). Abschnitt 2.6 stellt die Bridge als »Das Andere innerhalb der AABA-Form dar. Neue Arten die A-Zeile zu füllen wurden in der R\&B-Ballade und im Doo Wop der 1950er Jahre erprobt. Die im Doo Wop erfolgende Standardisierung harmonischer Loops stellt eine wesentliche Voraussetzung für die Emanzipierung eigenständiger Verses innerhalb der AABA-Form dar (Abschnitt 3).

Abschnitt 4.1 verfolgt, wie sich in den späten 1920er Jahren im Blues und später R\&B aus schließenden Refrainzeilen eigenständige Choruses entwickeln. Der gleiche Prozess findet dann auch innerhalb der AABA-Form statt (Abschnitt 4.2), sodass sich in den späten 1950er Jahren aus der AABAForm das Modell Verse - Chorus - Verse - Chorus - Bridge - Verse Chorus entwickelt. Abschnitt 5 betrachtet die Evolution des Formteils PreChorus. Seine Ursprünge liegen in 32-taktigen AABA-Formen des DooWop (Abschnitt 5.1), im Brill Building-Pop wird er dann zum festen Bestandteil umfangreicherer A-Teile innerhalb der AABA-Form (Abschnitt 5.2). Als eigenständiger Formteil etabliert sich der PreChorus um 1962, nun auch außerhalb der AABA-Form. In Abschnitt 6 werden die Renaissance von AABA- 
Formen in den frühen Songs der Beatles und der anschließende starke Rückgang dieses über 40 Jahre dominierenden Formmodells dargestellt. Seit den mittleren 1960er Jahren ist eine größere Vielfalt und Individualität von Songformen zu beobachten (Abschnitt 7). Hier endet unsere Betrachtung, da zu diesem Zeitpunkt alle gängigen Formteile etabliert sind und seitdem frei miteinander kombiniert werden.

Insgesamt wurden für diese Untersuchung Formanalysen von ca. 2500 Songs erstellt. Die Stichproben-Auswahl erfolgte zunächst nicht systematisch (also etwa anhand von Chart-Platzierungen bestimmter Jahre), sondern auf Basis der uns zugänglichen Sammlung des Instituts für Musikwissenschaft und Musikpädagogik der Justus-Liebig-Universität Gießen. Anschließend wurden gezielt weitere Beispiele gesucht, um aus der Arbeit erwachsene Thesen zu überprüfen. Für eine quantitative Validierung wurden zuletzt alle nichtinstrumentalen Billboard Top 100-Spitzenreiter aller geraden Jahre zwischen 1952 und 1982 analysiert und hinsichtlich des zugrunde liegenden Formmodells klassifiziert. Der Schwerpunkt liegt auf der populären Musik der USA, da alle wichtigen Entwicklungen hier zuerst zu beobachten sind. Bei den genannten Songbeispielen bemühen wir uns, jeweils möglichst frühe Manifestationen der beschriebenen Entwicklungen zu anzuführen; dass es sich um die tatsächlich ersten handelt, kann aufgrund der notwendig begrenzten Stichprobe nicht garantiert werden.

\section{Chorus und Refrain}

\subsection{Der Refrain wird zum Chorus}

Soweit zu sehen ist, beginnt die Konfusion um die Begriffe »Chorus « und »Refrain« Mitte des 19. Jahrhunderts zum einen in Liedausgaben für das häuslich-familiäre Singen sowie in den sogenannten Plantation Songs, wie sie z. B. Stephen Foster für die Minstrelbühne schrieb. ${ }^{3}$ Lieder wie »Old Folks At Home« oder »Oh! Susanna« weisen eine einfache Verse/Refrain-Form auf. Zwei achttaktige Perioden bilden die Verses, wobei die Halbsätze nur

3 Vgl. Hamm (1979: 255): »The verse-chorus pattern, one of the most distinctive features of these songs, had developed first in songs of the singing families of the 1840 s and ' 50 s and in minstrel songs of the same period. By this time it was an almost universal pattern and was one of the most uniquely American features of this body of song. It was equally appropriate for performance at home, where the better singers could take the solo verses and all others could join in the chorus, and on the minstrel stage, where the entire troupe could echo the verses sung by one of the stars." 
durch geringe Abweichungen zur Bildung von Halb- und Ganzschlüssen differieren. Auch der Refrain ist eine solche achttaktige Periode, deren Vordersatz jedoch neues Material bringt. In unserem Beispiel trägt er die Titelwörter »Oh! Susanna « und hebt sich harmonisch durch den Shift auf die Subdominante deutlich ab. Der Nachsatz greift die erste Strophenzeile auf (nun natürlich mit Ganzschluss). ${ }^{4}$

\begin{tabular}{|c|c|c|c|}
\hline \multicolumn{4}{|c|}{ Stephen Foster: »Oh! Susanna« (1848) } \\
\hline & Text & Textzeile & $\begin{array}{l}\text { mus. Halbsätze (je- } \\
\text { weils vier } 2 / 4 \text {-Takte) }\end{array}$ \\
\hline \multirow[t]{2}{*}{ Verse 1} & \multirow{2}{*}{$\begin{array}{l}\text { I came from Alabama } \\
\text { Wid my banjo on my knee, } \\
\text { I'm g'wan to Lousiana, } \\
\text { My true love for to see. }\end{array}$} & A & $a^{D}$ \\
\hline & & B & $a^{\top}$ \\
\hline \multirow[t]{2}{*}{ Verse 2} & \multirow{2}{*}{$\begin{array}{l}\text { It rain'd all night the day I left, } \\
\text { The weather it was dry, } \\
\text { The sun so hot I frose to death; } \\
\text { Susanna, don't you cry. }\end{array}$} & C & $a^{D}$ \\
\hline & & D & $a^{\top}$ \\
\hline \multirow[t]{2}{*}{$\begin{array}{l}\text { Refrain } \\
\text { (Chorus) }\end{array}$} & \multirow{2}{*}{$\begin{array}{l}\text { Oh! Susanna, } \\
\text { Oh! Don't you cry for me, } \\
\text { I've come from Alabama, } \\
\text { Wid my banjo on my knee. }\end{array}$} & $\mathrm{E}$ & $b^{S->D}$ \\
\hline & & A & $a^{\top}$ \\
\hline
\end{tabular}

Songs mit Refrainzeilen, die - manchmal unisono von der ganzen Minstreltruppe - zur selben Melodie wie die Verse-Zeilen gesungen wurden, gab es zuvor schon in vielen anderen Minstrel-Songs. Neu an Fosters Minstrel-Songs war, dass der Refrain in den um die Mitte des 19. Jahrhunderts erschienenen Notenausgaben durch vier- oder fünfstimmigen Satz abgehoben war (Hamm 1979: 210). ${ }^{5}$ Diese Differenzierung zwischen den solistisch vorgetragenen Strophen und dem chorisch vorgetragenen oder vierstimmig gesetzten Refrain trug diesem die Bezeichnung »Chorus « ein. Die Benennung hielt sich und führte schließlich zu einem Synonymgebrauch der Begriffe »Refrain« und »Chorus ${ }^{6}{ }^{6}$

4 Tawas Analyse von 230 Songs der Jahre 1866-1910 kommt zu dem Ergebnis, dass Verse und Chorus vor 1890 häufiger dieselben, nach 1890 meist unterschiedliche Melodien hatten (Tawa 1990: 97). Im zweiten Fall griffen die Refrains häufig eine der Phrasen aus dem Verse auf (ebd.: 110), nur in seltenen Ausnahmefällen boten sie komplett neues Material (ebd.: 117). Vgl. dazu auch Hamm (1979: 254f.).

5 Die Ausgaben sind online verfügbar unter http://levysheetmusic.mse.jhu.edu. In den Ausgaben, die sich auf die Aufführungen der Christy Minstrels beziehen, ist der Chorus fünfstimmig gesetzt, in der Ausgabe »As Sung by the Ethiopian Serenaders « vierstimmig.

6 Tawa (1990: 106) spricht bei chorisch gesungenen Refrains auch vom »chorus refrain«. Hoerburger (1998: 124) führt im MGG-Artikel »Refrain« - leider ohne Beleg - an, dass die Bezeichnung »Chorus « für den Refrain auch im englischen 


\subsection{Tin Pan Alley-Standard Nr. 1: ABAC}

Der erste Tin Pan Alley-Hit »After The Ball« (Harris 1891) weist mit einem 64-taktigen Verse und einem 32-taktigen Chorus gegenüber »Oh! Susanna« geradezu monströse Ausmaße auf. Zwar ist die Länge des zweiteiligen Verse auch für das neue Songzeitalter ungewöhnlich (vgl. Tawa 1990: 163, sowie Hamm 1979: 293), doch hat »After The Ball« in anderer Hinsicht durchaus Modellcharakter. Der Refrain heißt weiterhin »Chorus «, obwohl seine chorische Ausführung nun die Ausnahme ist. ${ }^{7}$ Im Gegensatz zu »Oh! Susanna « hat dieser Chorus mit dem Verse keinerlei melodische Substanzgemeinschaft, vielmehr kontrastiert seine schwelgerische Walzermelodik deutlich zum schlichteren Moritatentonfall des Verses. Der Chorus besteht aus einer 32taktigen Periode, die gegliedert ist in zwei 16-taktige Halbsätze, vier achttaktige Zeilen bzw. acht viertaktige Phrasen. Bis in die 1920er Jahre, als dieser Zuschnitt zum prägenden Modell wird, sind daneben auch verschiedene 16-taktige Chorusmodelle populär, welche ansonsten die übrigen Charakteristika des neuen Modells teilen.

Folk Song üblich war. Hamm (1979: 210) dagegen weist für Foster als offensichtlichstes Unterscheidungsmerkmal darauf hin, dass seine »Ethiopian melodies « immer einen Chorus hatten, seine » English< Songs « dagegen nie.

7 Die Terminologie ist hier noch lange nicht verbindlich. Selbst zwei Ausgaben von »After The Ball« von 1892 bei Harris' eigenen Verlagshäusern sind sich hierüber nicht einig. Die Ausgabe aus Milwaukee bezeichnet den Teil ab »After the ball... « als »Chorus«, die New Yorker Ausgabe als »Refrain« (vgl. dazu das gemeinsame Online-Sheet-Music-Archiv verschiedener Bibliotheken des USBundesstaats Indiana unter http://webapp1.dlib.indiana.edu/inharmony/ welcome.do). Zwar war bei den üblichen Aufführungen solcher Songs in Vaudeville-Shows die einstimmig-chorische Ausführung des Chorus' unter Beteiligung des Publikums durchaus üblich. Dies ist jedoch eine Frage der Aufführungspraxis, nicht der Komposition. Die mehrstimmige Aussetzung des Chorus' erfolgt nun allenfalls optional: »Although the chorus no longer sports a soprano-altotenor-baritone harmonization, an unaccompanied vocal-quartet harmonization of this section is sometimes included in the sheet music to accommodate the many amateur and professional quartets, particularly male ones, active during these years. In instances where optional harmony is omitted, the possibility of improvised vocal harmony was probably assumed« (Tawa 1990: 169f.). 
Charles K. Harris: »After The Ball« (1891) mit ABAC-Chorus

\begin{tabular}{|c|c|c|c|}
\hline & Text & Reime & $\begin{array}{l}\text { mus. Halbsätze } \\
\text { (jeweils } 8 \text { Takte) }\end{array}$ \\
\hline \multirow[t]{8}{*}{ Verse 1} & $\begin{array}{l}\text { A little maiden } \\
\text { climbed an old man's knee }\end{array}$ & $a$ & $\left\{A^{\text {Verse }}\right\}$ \\
\hline & $\begin{array}{l}\text { Begged for a story - } \\
\quad \gg \text { Do Uncle, please.« }\end{array}$ & a & $\left\{\mathrm{B}^{\text {Verse }}\right\}$ \\
\hline & $\begin{array}{l}\text { Why are you single; } \\
\text { why live alone? }\end{array}$ & b & $\left\{A^{\prime}\right.$ Verse $\}$ \\
\hline & $\begin{array}{l}\text { Have you no babies; } \\
\text { have you no home? }\end{array}$ & b & $\left\{C^{\text {Verse }}\right\}$ \\
\hline & $\begin{array}{l}\gg \text { had a sweetheart, } \\
\text { years, years ago; }\end{array}$ & C & $\left\{D^{\text {Verse }}\right\}$ \\
\hline & $\begin{array}{l}\text { Where she is now, pet, } \\
\text { you will soon know }\end{array}$ & c & $\left\{\mathrm{E}^{\text {Verse }}\right\}$ \\
\hline & $\begin{array}{l}\text { List to the story, } \\
\text { I'll tell it all, }\end{array}$ & $d$ & $\left\{A^{\prime}\right.$ Verse $\}$ \\
\hline & $\begin{array}{c}\text { I believed her faithless } \\
\text { after the ball.« }\end{array}$ & $d$ & $\left\{\mathrm{C}^{\text {Verse }}\right\}$ \\
\hline \multirow[t]{4}{*}{ Chorus } & $\begin{array}{l}\text { After the ball is over, } \\
\text { After the break of morn, }\end{array}$ & e & $A^{\text {Chorus }}$ \\
\hline & $\begin{array}{l}\text { After the dancers' leaving, } \\
\text { After the stars are gone; }\end{array}$ & e & $\mathrm{B}^{\text {Chorus }}$ \\
\hline & $\begin{array}{l}\text { Many a heart is aching, } \\
\text { If you could read them all; }\end{array}$ & $d$ & $\mathrm{~A}^{\prime}$ Chorus \\
\hline & $\begin{array}{l}\text { Many the hopes that have vanished } \\
\text { After the ball. }\end{array}$ & $d$ & $C^{\text {Chorus }}$ \\
\hline
\end{tabular}

Im Unterschied zur schlichten Periode von »Oh! Susanna« sind die beiden zweiten Hälften der Halbsätze im Chorus nicht nur durch ihren Schlussakkord differenziert, sondern weisen unterschiedliche harmonische und melodische Gestaltung auf. Die daraus resultierende Chorusform ABAC wird bis um 1920 vorherrschen und auch später noch für einige Hits gut sein. ${ }^{8}$

8 Beispiele: "Alexander's Ragtime Band « (Berlin 1911), "Swanee« (Caesar/ Gershwin 1919), »Tea For Two (Caesar/Youmans 1924), »I Can't Give You Anything But Love« (Fields/McHugh 1928), »White Christmas« (Berlin 1942), »Ev'ry Time We Say Good Bye (Porter 1944), »Cry« (Kohlman 1951), »Mr. Sandman« (Ballard 1954), „Spanish Eyes« (Kaempfert/Singleton/Snyder 1965/66). Noch 1952 waren sieben Songs in diesem Format unter den ersten 20 Songs der Billboard Year End-Charts. Populär war ABAC in dieser Zeit auch in der Country Music, etwa in Hank Williams' »Half As Much« (Curley Williams 1951) oder Pee Wee Kings »Slow Poke« (Price 1951). 


\begin{tabular}{|c|cc|cc|cc|cc|}
\hline & \multicolumn{2}{|c|}{$\begin{array}{c}\text { Sentimental } \\
\text { Songs } \\
\end{array}$} & \multicolumn{2}{|c|}{ Waltz Songs } & \multicolumn{2}{c|}{$\begin{array}{c}\text { Coon and Rag } \\
\text { Songs }\end{array}$} & \multicolumn{2}{c|}{$\begin{array}{c}\text { March and other } \\
\text { Rhythmic Songs }\end{array}$} \\
Verse & Chorus & Verse & Chorus & Verse & Chorus & Verse & Chorus \\
\hline ABAC & $>50 \%$ & $27 \%$ & $31 \%$ & & $60 \%$ & $40 \%$ & $53 \%$ \\
\cline { 2 - 8 } AABA & & $34 \%$ & $13 \%$ & & & $20 \%$ & $20 \%$ \\
\hline
\end{tabular}

Tabelle 1: Verteilung der Verse- und Chorus-Formen in verschiedenen Songtypen der Jahre 1890-1910 nach Tawa (1990: 170, 179, 190 u. 196);

leere Felder = keine Angabe

Abhängig von der harmonischen und melodischen Komplexität der 32-taktigen Periode ist die Wahrnehmung der musikalischen Form des Chorus' mitunter durchaus anspruchsvoll. So finden etwa auf der Ebene der viertaktigen Phrasen häufig Variantenbildungen statt. Insbesondere betrifft dies die zweite A-Zeile, was also - wie schon bei »After The Ball $«$ zu ABA'C-Formen führt. ${ }^{9}$ Die Trennlinie zwischen variierter $A B A C$-Form und ungewöhnlichen Formen wie $A B B^{\prime} A$ oder $A B C D$ ist dabei durchaus unscharf. Zur besseren Fasslichkeit dieser Form trägt jedoch der Text bei, der gerade bei musikalisch differenzierten Gestaltungen durch Wiederholungen oder Analogien formale Orientierungspunkte bietet. Das am häufigsten vorkommende Modell textlicher Formgebung findet sich bereits bei »After The Ball«; es besteht in der simplen Umklammerung des Chorustextes durch den Titelhook. Auch das Zitat eines Hookbestandteils - hier des Wortes »After « - zu Beginn der ersten vier Phrasen ist ein verbreitetes Mittel der Formbildung. ${ }^{10}$

Wichtig am »After The Ball«-Modell ist schließlich, dass der Text des Chorus' keinerlei direkten Bezug auf die rührende Geschichte nimmt, die in den drei Verses erzählt wird und andererseits diese Geschichte auch nicht benötigt. Er kann durchaus für sich alleine stehen und genau dies wird später für die Aufführung von Songs abseits der Bühne oder des Musikfilms die Regel sein.

9 In »Come Rain Or Come Shine (Mercer/Arlen 1946) wird bspw. die zweite Phrase der zweiten A-Zeile (T. 21-24) gegenüber der ersten Zeile in die Obersekunde transponiert. In »Who (Harbach/Hammerstein II/Kern 1925) ist die erste Phrase der zweiten A-Zeile (T. 17-20) in die Oberquarte transponiert.

10 Beispiele: »For Me And My Gal« (Meyer/Leslie/Goetz 1917), »Who« (Harbach/ Hammerstein II/Kern 1925), »If « (Evans 1934), »Because Of You« (Hammerstein/Wilkinson 1940). Besonders beliebt ist dieses Mittel im list song, dessen Text - meist in mehr oder weniger freiem Bezug zum Titelhook - Belege, Beispiele oder Assoziationen auflistet. Diese Technik eignet sich insbesondere für comedy songs (z.B. »Always True To You (In My Fashion)«, Porter 1948), findet aber auch in der love ballad Anwendung. 


\subsection{Tin Pan Alley-Standard Nr. 2: AABA}

Wie die folgende Graphik zeigt, wird ABAC als wichtigste Chorusform in den 1920er Jahren abgelöst (wenn auch keineswegs völlig verdrängt) durch die später als klassisch geltende Tin Pan Alley-Form AABA. ${ }^{11}$

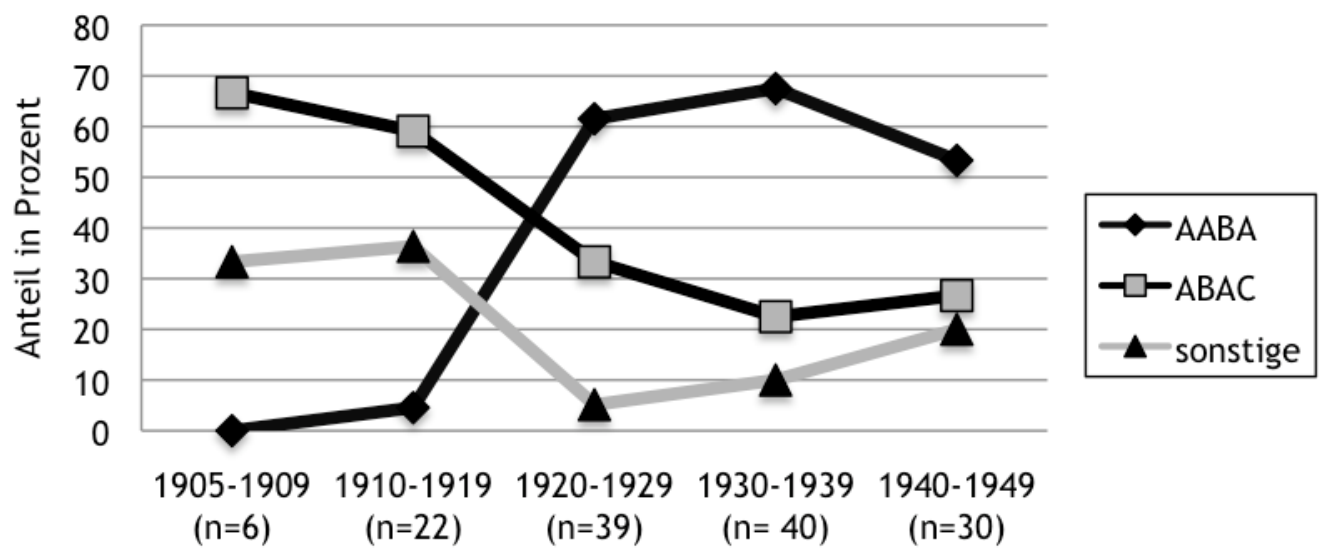

Abbildung 1: Chorus-Formmodelle in der Kernstichprobe »Tin Pan Alley-Songs«

Die früheste AABA-Chorusform unserer Kernstichprobe weist der Song "Someday, Sweetheart « der Brüder Benjamin und John Spikes von 1919 auf. Frühere AABA-Formen ohne Verse gibt es bereits im 19. Jahrhundert, etwa bei Friedrich Silcher (»Muss i denn«, 1827) oder Foster (»I Dream Of Jeannie With The Light Brown Hair«, 1854). Einen AABA-Verse bietet »Silver Threads Among The Gold« (Rexford/Danks, 1873), AABA-Choruses finden sich in den Songs »| Love My Wife, But Oh You Kid« (Harry von Tilzer 1909) und »Let's

11 [1] Dieser Graphik liegt die Untersuchung von 137 Songs aus den Jahren 1905 bis 1949 zugrunde. Die Kernstichprobe folgt drei Rankinglisten in Charles Hamms (1979) Buch Yesterdays, die diese Songs als Hits ausweisen. Die Zusammenstellung dieser Stichprobe mag anfechtbar sein, gleichwohl dürfte die sich klar abzeichnende Tendenz zur Verteilung der Formmodelle durchaus die Entwicklung zumindest im Tin Pan Alley-Mainstream abbilden. [2] Die Bezeichnung »Tin Pan Alley« wird von uns sehr weit gefasst. Eine Differenzierung etwa nach der Bestimmung der Songs für den Sheet Music-Markt, den Rundfunk bzw. die Entstehung im Zusammenhang mit einer Broadwayshow oder einem Hollywoodfilm wurde nicht unternommen. Nähme man die Broadwaysongs aus der Untersuchung heraus, so kämen Songwriter wie Cole Porter, Richard Rodgers oder Lorenz Hart schlichtweg nicht vor. Broadwayshows des "Goldenen Zeitalters" disponierten mit ca. zwei bis vier Hits in der American Popular Song Form (also mit einem AABA-Chorus), die auf der Bühne vom pit orchestra begleitet gesungen, als Sheet Music (auf der Tin Pan Alley!) verlegt, zuhause am Klavier geklimpert, für Tanzorchester bearbeitet, mit großem Orchester oder kleiner Combo auf Platte aufgenommen und von Bebop-Musikern als Improvisationsund Kompositionsgrundlage benutzt wurden. 
Go Into A Picture Show« (Albert von Tilzer/McCree 1909) sowie Mitte der 1910er Jahre bei Irving Berlin. ${ }^{12}$ Gleichwohl ist der Durchbruch dieser Form im American Popular Song erst um 1920 evident (so auch Middleton 2003: 515). Einiges spricht zudem dafür, dass diese neue 32-taktige Form mehr mit der 32-taktigen Periodenform ABAC zu tun hat als mit dem deutlich überschaubareren »Muss i denn «.

Sollte in der Folge die AABA-Form gerade in Abgrenzung zu Bluesderivaten aller Art für den Popsong schlechthin stehen, so erstaunt, dass diese »neue « Chorusform zunächst häufig in afroamerikanischen Zusammenhängen auftaucht. So nahm Jelly Roll Morton die Autorenschaft für »Someday, Sweetheart « für sich in Anspruch (vgl. Pastras 2001: 125 und Schafer 2008: 54). Irving Berlins AABA-Song »Everybody Step« von 1921 galt seinen Zeitgenossen - darunter George Gershwin - als explizit »jazzy« (vgl. Magee 2006: 698ff.). Und auch Jerome Kern verknüpft in den 1920er Jahren afroamerikanische Musikidiome mit der AABA-Form. Einer seiner ersten Songs in dieser Form war der »Left All Alone Again Blues « von 1920, ein blues song ${ }^{13}$ im Ragtimesound, der mit I-IV-Shuttle im A-Teil und dem Alternieren von reiner und übermäßiger Quarte in der Melodiebildung zwei Merkmale bluesiger Färbung aufweist. Im epochalen Musical Show Boat von 1927 behalten Kern und Oscar Hammerstein II die AABA-Form der Sphäre der Schwarzen vor. »Ole Man River« wird vom Hafenarbeiter Joe gesungen und beklagt bekanntlich - wiederum zwischen I und IV pendelnd - das harte Dasein und die Diskriminierung der Schwarzen im Süden. Der zweite Song in AABAForm, »Can't Help Lovin' Dat Man«, wird von der Vaudeville-Künstlerin Julie gesungen, die sich mit diesem blue notes-gespickten Song unfreiwillig als

12 Z.B. »Araby« 1914, und »From Here To Shanghai « 1917. Zu dieser Zeit nutzte Berlin häufiger auch die Zwitterform AABC (z.B. »The Syncopated Walk« 1914, »'m Going Back To The Farm« 1915, »I Lost My Heart In Dixieland« 1919), die in der Folge allerdings keine große Rolle mehr spielte.

13 Blues songs sind Tin Pan Alley-Songs, in deren Titel und Lyrics das Wort »Blues" genannt wird. Text und Musik weisen mehr oder weniger deutliche Blues-Topoi auf, formal entsprechen Sie jedoch den üblichen Verse/Chorus-Verläufen. Für einen ersten Eindruck dieses Repertoires sei auf die Seite »parlorsongs « verwiesen (http://parlorsongs.com/issues/2007-4/thismonth/feature.php; letzter Zugriff 3.4.2011). Die hier nachgewiesenen, zwischen 1919 und 1922 entstandenen Songs haben sämtlich ABAC-Choruses. Drei der Songs enthalten zudem einen sogenannten patter-Teil, wie er vor allem für komische Vaudeville-Acts typisch war. Für die allgemeine Begriffsverwirrung ist bezeichnend, dass diese textreichen, parlando vorgetragenen und damit deutlich Verse-haften Teile gelegentlich als »patter chorus« bezeichnet wurden (vgl. z. B. »Wabash Blues«, Ringle/Meinken 1921). 
Mulattin outet, ein Umstand, der wenig später für das Ende ihres Engagements auf dem Show Boat sorgen wird. ${ }^{14}$

\subsection{Der AABA-Chorus bekommt einen Refrain}

Bezeichnete der Begriff Chorus zunächst einen von einem - wie auch immer gearteten - »Chor « vorgetragenen Refrain und wurde er dann zu einem Synonym für einen mehrzeiligen Refrain schlechthin, so steht bei »Someday, Sweetheart « (und vielen anderen Songs der Zeit seit dem Ersten Weltkrieg) die Bezeichnung Chorus für den Song selbst. Zwar gibt es auch bei diesem neuen Typus einen einleitenden Verse, der im Musical die Funktion erfüllt, vom Sprechtext zum »eigentlichen Song«, dem Chorus, überzuleiten, und in anderen Formen der Livedarbietung als eine Art auskomponierte Anmoderation fungieren kann, doch wird dieser bei Plattenaufnahmen meist weggelassen. ${ }^{15}$ Wäre da nicht das zweite Dasein des Tin Pan Alley-Chorus' als harmonische Improvisationsgrundlage im Jazz, so wäre der Begriff genau genommen obsolet, da deckungsgleich mit »Song«. Ein Refrain ist dieser Chorus im Falle der meisten Plattenaufnahmen per definitionem jedenfalls nicht mehr, da dieser sich als etwas Wiederkehrendes von etwas Veränderlichem absetzen muss. Ad absurdum geführt wird die Terminologie, wenn der Chorus mehrere Texte aufweist. ${ }^{16}$ Dies macht jedoch zugleich deutlich, dass Verse und Chorus nicht nur syntaktische Funktionen sind, sondern dass ihnen auch unterschiedliche Charaktere zugeschrieben werden: Es gibt offenbar etwas Verse-haftes, das sich von Chorus-artigem unterscheidet.

Wie belastbar die Form Verse/AABA-Chorus sein kann, zeigt sich im Musical, wo die Form gelegentlich zur Musical Scene ausgebaut wird. So hat "Ole Man River « in der Bühnenfassung von Show Boat die Form: Verse AABA' - Verse2 - B2 - Verse3 - AABA'. Die einzelne, neu textierte Bridge (B2) sowie die A-Teile des letzten Chorus' - nicht aber dessen Bridge -

14 Julies zweiter Song »Bill« hat zwar einen Chorus in ABAC-Form, stammt jedoch aus einer älteren Show von 1918, aus einer Zeit also, als Kern noch nicht in der neuen Form schrieb.

15 [1] Von dieser Regel abgewichen ist vor allem Ella Fitzgerald, deren Aufnahmen häufig den Verse enthalten. Obwohl der Verse insbesondere in Broadway-Songs häufig die Funktion erfüllt, vom Sprechtext zum »eigentlichen Song« (dem Chorus) überzuleiten, finden sich bei den Songs der besten Songwriter viele textlich wie musikalisch - durchaus hörenswerte Verses. [2] Neben dieser neuen Form hielt sich in den 1920er Jahren auch die ältere mit meist zwei Verses und häufig kürzerem (16-taktigen) abac-Chorus.

16 Auf der Bühne und in gedruckten Ausgaben ist dies keine Seltenheit, in das begrenzte Plattenformat schafften es mehrtextige Choruses nur in rascherem Tempo. 
werden hier vom Chor gesungen, die ursprüngliche Bedeutung des Begriffs spielt hier also gar keine Rolle mehr. Plattenaufnahmen tendieren ihrerseits dazu, die vorn um den Verse verkürzte Form hinten durch (Teil-)Wiederholungen zu erweitern; einerseits um - abhängig vom Tempo - auf die nötige Dauer zu kommen, andererseits weil Wiederholungen und der Einstieg mit dem Chorus zum Erzielen eines Hits zweckdienlicher sind als ein musikalisch unauffälliger Verse, der ohnehin nicht wieder aufgegriffen wird. Verbreitet ist vor allem die Form AABA - A(instrumental) - BA - Coda.

Der Wert eines klaren, einprägsamen und exponierten Hooks für die Merkbarkeit und damit Markttauglichkeit eines Songs war den Komponisten und Textautoren seit Beginn der Tin Pan Alley-Marktkonzentration bewusst, sodass kaum ein AABA-Song (bzw. -Chorus) ohne Refrain auskommt. ${ }^{17}$ Die Lösung von »Some Day Sweetheart « taugte hierfür freilich nicht. Sie nutzt die in der ABAC-Form bewährte Klammertechnik, indem sie den Titelhook als Beginn und als Ende des Textes verwendet $\left({ }_{x} A A_{0} B_{0} A_{x}\right)$. Einige wenige Nachfolger hat diese Lösung gefunden - z.B. »The Man I Love« (Gershwin/ Gershwin 1924) und »Symphony« (Alstone 1945) -, durchsetzen konnte sie sich jedoch nicht.

\begin{tabular}{|c|c|c|c|}
\hline \multicolumn{4}{|l|}{ "Someday, Sweetheart« (Spikes/Spikes 1919) } \\
\hline Someday, sweetheart, you may be sorry... & Hook & $A^{1}$ & \\
\hline And you may regret... & & $A^{2}$ & \\
\hline Oh, you're happy now... & & B & \\
\hline ...make you weep, someday, sweetheart. & & $A^{3}$ & Hook \\
\hline
\end{tabular}

Die große Mehrzahl der AABA-Songs der Kernstichprobe nutzt eines von zwei anderen Modellen. Als Beispiel für das erste sei »Over The Rainbow« (Harburg/Arlen 1939) genannt. In diesem Song sind die drei A-Teile melodisch und harmonisch identisch (ein Halbschluss nach der ersten Zeile wird »künstlich « durch eine angehängte ii-V-Kadenz erzielt) und werden jeweils durch den Hook »Somewhere Over The Rainbow « eröffnet. ${ }^{18}$ Die Bridge ist in aller Regel Hook- bzw. Refrain-frei. ${ }^{19}$ Auch hier enthält sie den Hook nicht,

17 Wie Tawa (1990: 107) feststellt, wurde dem Songtitel in Songtexten vor 1890, als die kommerzielle Verwertbarkeit also noch nicht so professionell organisiert war, noch keine besondere Beachtung geschenkt: Mal stand er zu Beginn des Verses, mal zu Beginn oder am Ende des Chorus', mal führte er beide Teile an. Auch konnte er sowohl den Verse beginnen als auch den Chorus beenden oder er war an mehreren unauffälligen Stellen des Textes »versteckt «.

18 Nicht von ungefähr wird dieser Hook oft als Titel genannt, obwohl das "Somewhere eigentlich nicht dazu gehört.

19 Zu den Ausnahmen zählt »What'll I Do« (Berlin 1923). 
wenngleich es sicher kein Zufall ist, dass er im eröffnenden »Some« (»Some day I wish upon a star...«) immerhin anklingt.

\begin{tabular}{|l|ll|}
\hline »Over The Rainbow« (Harburg/Arlen 1939) & \multicolumn{3}{l|}{} \\
\hline Somewhere, over the rainbow, way up high... & Hook & $A^{1}$ \\
\hline Somewhere, over the rainbow, skies are blue... & Hook & $A^{2}$ \\
\hline Someday l'll wish upon a star... & & B \\
\hline Somewhere, over the rainbow, bluebirds fly... & Hook & $A^{3}$ \\
\hline
\end{tabular}

Diesem Modell ( $\left.{ }_{x} A{ }_{x} A B_{0} A\right)$ steht ein zweites zur Seite, in dem der Hook die A-Zeilen schließt $\left(A_{x} A_{x} B_{0} A_{x}\right)$. Als spätes Beispiel hierfür soll der Song »Till There Was You« aus Meredith Willsons Musical The Music Man stehen. Die beiden ersten A-Zeilen unterscheiden sich nur im letzten Ton (Halb-/ Ganzschluss).

\begin{tabular}{|l|ll|}
\hline »Till There Was You« (Willson 1957) \\
\hline There were bells... till there was you. & $A^{1}$ & Hook \\
\hline There were birds... till there was you. & $A^{2}$ & Hook \\
\hline Then there was music... & $\mathrm{B}$ & \\
\hline There was love... till there was you. & $\mathrm{A}^{3}$ & Hook \\
\hline
\end{tabular}

Nur selten verzichten AABA-Songs auf einen Refrain wie z.B. »My Funny Valentine« (Hart/Rodgers 1937). Der Titel erklingt hier wörtlich nur einmal direkt am Anfang und wird am Ende in der bekannten Verklammerungstechnik durch zweifache Nennung des Hookwortes »Valentine zitiert. $^{20}$

Hatte der Chorus seine Existenz als Refrain begonnen, so ist aus ihm nun selbst ein Formteil mit eigenem Refrain geworden. Freilich sind seine Refrains von ganz anderem Charakter als der Chorus von »After The Ball«. Sie sind nicht nur ausgesprochen kurz (in der Regel ein oder zwei Takte) sondern auch syntaktisch in die Melodie- und Textzeilen eingebunden: Textlich handelt es sich bei den »Hook-Refrains « der genannten Beispiele um adverbiale Bestimmungen (einmal des Ortes und einmal der Zeit), die um Subjekt, Prädikat und dergleichen erst noch ergänzt werden müssen, melodisch sind die Refrains als Phrasen in den Zeilenbau integriert. Diese »Ganz-

20 Ein weiterer großer Hit ohne Refrain ist Nat King Coles Signature Song »Stardust« (Parish/Camichael 1927/29). Hier ist der Titel dreimal an nichtexponierter Stelle, quasi en passant zu hören und zwar im Verse und in den Choruszeilen A1 und A3. Es sei dahingestellt, ob Parish diesen Verzicht auf einen wirklichen Texthook ironisieren wollte, in dem er seinen Chorus mit dem Wort »refrain« enden ließ (»... the memory of love's refrain«). 
heit « der Zeile ist typisch für die klassische AABA-Love Ballad der Tin Pan Alley-Zeit. Ein einziger Satz (oder zwei Sätze, die - etwa durch Wiederholung des Hooks - deutlich aufeinander bezogen sind), eine meist durch klassische Techniken wie Transposition, Sequenz, Motivvariation und -ableitung etc. gestaltete Melodie sorgt für die Geschlossenheit der Zeile, die durch den Refrain lediglich eröffnet oder beendet wird. Für Textdichter wie für Komponisten dieses Stils scheint es geradezu einen Ehrgeiz gegeben zu haben, diese Refrains immer wieder wie zufällig sich ergeben zu lassen.

\subsection{Harmonik der A-Zeile}

Bei der Ausbildung verschiedener Stile und Song-Genres der Tin Pan AlleyZeit spielen verschiedene Konzepte harmonischer Organisation eine wesentliche Rolle. Da diese auch für die weitere Entwicklung der A-Zeile von entscheidender Bedeutung sind, seien sie hier kurz vorgestellt. Ausdrücklich hingewiesen sei dabei auf die Feststellung, dass nicht nur unterschiedliche Akkordformen und -folgen zur Differenzierung beitragen. Mindestens ebenso wichtig sind hier Instrumentierung und Arrangement sowie das Verhältnis von Harmonik und Melodiebildung.

a) Schweifende Harmonik

In diesem ersten Typ unterstützt die Harmonik die Einheit der Zeile. Sie ist in aller Regel der Melodie deutlich untergeordnet, ergibt sich aus ihr oder tritt mit ihr in ein Wechselspiel und färbt sie. Bei »Till There Was You« beispielsweise ist die Melodie der A-Zeile durch den Zentralton g (in C-Dur) geprägt, den die schweifende Harmonik nacheinander als reine Quinte (I), verminderte Quinte $\left(\# i^{\circ}\right)$, Quartvorhalt $\left(\mathrm{ii}^{7}\right)$ und Nonvorhalt $\left(\mathrm{iv}^{7}\right)$ auftreten lässt. Die Harmonik wirkt dabei selten als etwas Präexistentes. Dies gilt insbesondere für die klassische, orchesterbegleitete Love Ballad, deren typische schweifende Harmonik reich an Nebenklängen ist, Wiederholungen meidet, den harmonischen Rhythmus variiert und chromatische Gänge sucht.

\begin{tabular}{|c|c|c|c|c|c|c|c|c|c|c|c|c|c|}
\hline \multicolumn{14}{|c|}{ »Till There Was You« $\left(\mathrm{A}^{1}\right)$ (Willson 1957) } \\
\hline Takte & 1 & 2 & 3 & \multicolumn{2}{|c|}{4} & \multicolumn{2}{|c|}{5} & \multicolumn{2}{|c|}{6} & & 7 & \multicolumn{2}{|c|}{8} \\
\hline Text & $\begin{array}{l}\text { (There } \\
\text { were) } \\
\text { bells }\end{array}$ & $\begin{array}{l}\text { (on } \\
\text { the) } \\
\text { hill, }\end{array}$ & $\begin{array}{l}\text { (but I) } \\
\text { never } \\
\text { heard } \\
\text { them }\end{array}$ & \multicolumn{2}{|c|}{ ringing, } & $\begin{array}{l}\text { (No, } \\
\text { neve } \\
\text { hear } \\
\text { them }\end{array}$ & & \multicolumn{2}{|c|}{ all, } & \multicolumn{4}{|c|}{$\begin{array}{l}\text { (Till there was) } \\
\text { you. }\end{array}$} \\
\hline Motive & $a$ & $a$ & \multicolumn{3}{|c|}{ B } & \multicolumn{4}{|c|}{$B^{\prime}$} & \multicolumn{4}{|c|}{ Y } \\
\hline Harmonien & $\mathrm{I}^{\mathrm{maj} 7}$ & $\# i^{\circ 7}$ & $\mathrm{ii}^{7}$ & iv $^{7}$ & $\mathrm{bVII}$ & $I^{\text {maj7 }}$ & $\# \mathrm{ii}^{\circ 7}$ & $\mathrm{ii}^{7}$ & $\mathrm{~V}^{7}$ & $\mathrm{iii}^{7}$ & $\mathrm{blII}^{7}$ & $\mathrm{ii}^{7}$ & $\mathrm{~V}^{7}$ \\
\hline \multirow{2}{*}{$\begin{array}{l}\text { Chromati- } \\
\text { sche Gänge }\end{array}$} & $h$ & $b$ & $a$ & as & & & dis & $d$ & & $h$ & $b$ & & \\
\hline & c & cis & $d$ & & $b$ & $h$ & $c$ & & & $e$ & es & $d$ & \\
\hline
\end{tabular}


Orchestratoren wie Robert Russell Bennett verschleiern in einem stark kontrapunktischen Satz die harmonischen Fortschreitungen zusätzlich, indem sie die Akkorde in instrumentale Linien auflösen und mit reichlich Vorhalten, Durchgängen und Alterationen ausstatten, die in der Jazzakkordschrift der Lead Sheets schließlich zu den typischen Tensions erstarren.

Das fließende Orchesterarrangement der Broadwayversion wird in Peggy Lees Version ${ }^{21}$ von »Till There Was You« auf ein um Holzbläser erweitertes Combo-Format reduziert und mit einem durchgehenden Rumba-Groove unterlegt. Die A-Zeilen werden hier noch unterschiedlich instrumentiert, die Harmonik ergibt sich weitgehend noch immer aus melodischen Linien. Bei den Beatles bleiben davon als einziges melodisches Element neben dem Gesang die Gitarrenlicks George Harrisons übrig, das sonstige harmonische Geschehen ist in die von John Lennon geschlagenen Griffe zusammengeschmolzen. Nicht unbedeutend dürfte sein, dass die Beatles von der Herkunft des Songs zunächst nichts wussten. So hielten sie auch »Over The Rainbow « für einen Song von Gene Vincent. ${ }^{22}$ Diese Art der Kolportage verlieh den Songs nicht nur ein anderes Image, auch die ursprüngliche Soundvorstellung ging unterwegs verloren.

Somit ist die Harmonik in Versionen mit Broadway- oder Studioorchester einerseits und Versionen, in denen die Hits der Broadway- oder Hollywoodproduktionen in der Folge mit Combo- oder Bigband-Begleitung eingespielt wurden andererseits also nicht wirklich identisch, auch wenn die selben harmonischen Stufen verwendet werden.

\section{b) Loops / »Rhythm Changes«}

Dies gilt ebenso für die zweite wichtige, gänzlich andere Art der Harmonisierung einer A-Zeile, auf der die allmähliche Ausdifferenzierung der A-Zeile zu einer neuen Verse/Chorus-Form beruhen wird. Im Tin Pan Alley-Repertoire findet sie vorzugsweise in schnellerem Tempo Anwendung, wie z. B. in charm-, comedy- und novelty songs. Hierbei wird die Harmonik in überschaubare, sich wiederholende Folgen von meist zwei Takten gegliedert. Philipp Taggs (2009: 199) Terminologie folgend, bezeichnen wir diese Folgen (die in Überschneidung mit anderen Phänomenen häufig auch als Pattern, Turnarounds oder Vamps bezeichnet werden) als »Loops«. Taggs Bild der Schleife betont die öffnende, motorische Qualität dieser Akkordfolgen, die

21 Sie erschien zuerst auf dem Album Latin à la Lee!, aufgenommen August 1959, erschienen Januar 1960 bei Capitol Records.

22 »I didn't know that was from the musical The Music Man until many years later « (McCartney in The Beatles 2000: 22). Zu dem in der Frühzeit der Beatles von John Lennon gesungenen »Over The Rainbow« vgl. ebd.: 67. 
Fortsetzung, ja Wiederholung fordert. Da die AABA-Form geschlossene AZeilen erfordert, muss diese Motorik am Ende der Zeile unterbrochen werden. Dies geschieht durch eine Kadenz, sei sie plagal oder authentisch, ganz- oder halbschließend. Herkömmlichen Wendungen wie I-V(-I), I-IV-I und vor allem ii-V(-I) werden dabei häufig durch Quintfallerweiterungen und/oder chromatische Linien zu Turnarounds ausgebaut, die im Unterschied zu den Loops schließende Wirkung haben. Prototyp dieser Art der Harmonisierung sind die so genannten Rhythm Changes. Sie verdanken ihren Namen George und Ira Gershwins Song »| Got Rhythm« (1930), in dem sie allerdings in ihrer standardisierten Form gar nicht vorkommen:

\begin{tabular}{|l|c|c|c|c|c|c|c|c|}
\hline & \multicolumn{2}{|c|}{ Loop } & \multicolumn{2}{c|}{ Loop } & \multicolumn{4}{c|}{ Turnaround } \\
\hline $\begin{array}{l}\text { Rhythm } \\
\text { Changes }\end{array}$ & $\mathrm{I}^{\mathrm{maj}^{7}}-\mathrm{vi}^{7}$ & $\mathrm{ii}^{7}-\mathrm{V}^{7}$ & $\mathrm{I}^{\mathrm{maj}^{7}}-\mathrm{vi}^{7}$ & $\mathrm{ii}^{7}-\mathrm{V}^{7}$ & $\mathrm{I}-\mathrm{I}^{7}$ & $\mathrm{IV}-\# \mathrm{iv}^{\circ 7}$ & $\mathrm{I}-\mathrm{V}^{7}$ & $\mathrm{I}-[\mathrm{ii}-\mathrm{V}]$ \\
\hline $\begin{array}{l}\gg \mathrm{I} \text { Got } \\
\text { Rhythm }\end{array}$ & $\mathrm{I}-\mathrm{I}^{6} / 5$ & $\mathrm{ii}^{7}-\mathrm{V}^{7}$ & $\mathrm{I}-\mathrm{i}^{\circ 7} / 5$ & $\mathrm{ii}^{7}-\mathrm{V}^{7}$ & $\mathrm{I}-\mathrm{I}^{6} / 5$ & $\mathrm{ii}^{7}-\mathrm{V}^{7}-\mathrm{i}^{\circ 7}$ & $\mathrm{I}-\mathrm{V}^{7}$ & $\mathrm{I}$ \\
\hline & \multicolumn{2}{|c|}{ Loop } & \multicolumn{2}{|c|}{ Loop } & \multicolumn{3}{c|}{ Loop" } & \multicolumn{2}{c|}{ Kadenz } \\
\hline
\end{tabular}

Zweifellos ist hier nicht von einer Vereinfachung der variantenreicheren Harmonik Gershwins zu einer griffigeren Formulierung auszugehen. Vielmehr dürfte Gershwin (oder wer auch immer die Harmonik in die Form gebracht hat, in welcher der Song schließlich aufgeführt und gedruckt wurde) ein gewissermaßen in der Luft liegendes harmonisches Muster verwendet und nach bester (Jazz-)Musikerart reharmonisiert haben. Interessant ist dabei, dass der zweite Akkord in T. 1 und 5 sich in seiner Klangsubstanz in beiden Versionen gar nicht unterscheidet. In F-Dur kommen in beiden Akkorden die Töne $d-f-a-c$ vor, nur die Lage ist anders. Bei Gershwin liegt als Wechselbass die Tonikaquinte $c$ im Bass, in den üblichen Rhythm Changes klingt an dieser Stelle der $\mathrm{ii}^{7}$. Dieser Unterschied ist insofern von Bedeutung, als in der weiteren Entwicklung der Loop-Harmonik die Basslinie enorm an Bedeutung gewinnen wird.

c) Akkordschemata

Die dritte (und seltenste) Art der Harmoniebildung im Tin Pan Alley-Song ist das Akkordschema. Damit ist hier eine durch Konvention gefestigte und daher vorherhörbare Harmoniefolge gemeint, die - im Unterschied zum Loop - ganze Zeilen oder sogar Zeilengefüge harmonisch festlegt. Bekanntestes Beispiel für solche Folgen sind die diversen Bluesschemata, aber auch Standardperioden wie I-I-I-V V-V-V-I fallen hierunter. Als Füllung der A-Zeile kommen achttaktige Bluesschemata vor allem im Swing gelegentlich vor, wie z.B. in Glenn Millers »Blueberry Hill« (Lewis/Stock/Rose 1940), das als 
A-Zeile ein achttaktiges Grundakkordschema mit Bluesanklang verwendet (IV-IV-I-I V-V-I-IV-I). ${ }^{23}$ Andere Grundakkordschemata sind als deutliche Allusionen an Country- oder Folkstile erkennbar, wie z. B. in »Don't Fence Me In (Porter 1944), »Vaya Con Dios« (Russell/James/Pepper 1953) oder »Buttons And Bows« (Livingstone 1948). Die Frage, ob es sich bei letzterem um einen Country-Song im AABA-Format oder um einen Tin Pan Alley-Novelty-Song im Countrysound handelt, wird weniger über musikalische Eigenschaften zu klären sein als über das Image seiner Interpretin Dinah Shore.

\subsection{Varianten der A-Zeile}

Die Dramaturgie der AABA-Form ist schlicht, aber wirkungsvoll. Die erste Wiederholung der A-Zeile bestätigt die Bedeutung des in den ersten acht Takten exponierten Materials und festigt es - nicht zuletzt mithilfe des Refrains - beim Zuhörer. Die Bridge bringt Abwechslung und Kontrast und $\mathrm{A}^{3}$ schließlich die erfreuliche Wiederkehr des bereits Bekannten. Einem geflügelten Wort zufolge besteht das Komponieren eines Tin Pan Alley-Songs in der Kunst »to say ,I love you' in thirty-two bars«. Und tatsächlich gibt es jede Menge Songs (und darunter viele gute), die sich streng an die einfache AABA-Form halten. Das Konzept hält aber einiges an Variationen aus:

Das erste Zeilenpaar folgt in der Regel der klassische Periodenform, auf der ja auch die ABAC-Form basiert; die meisten $A^{1}$-Zeilen enden im Halbschluss, $A^{2}$ dann entsprechend im Ganzschluss. Die Ausgestaltung dieser ersten, in der Regel 16-taktigen Periode kann unterschiedlich erfolgen. So sind in »Over The Rainbow« beide Zeilen melodisch identisch, der Halbschluss wird lediglich durch eine angehängte Kadenz (hier ii-V) erzielt. In anderen Fällen (wie z.B. »Till There Was You«) wird die letzte Phrase harmonisch angeglichen; in beiden Fällen unterscheiden wir bei der genaueren Analyse zwischen $A^{D}$ und $A^{\top} .{ }^{24}$ Das erste Zeilenpaar kann in sich aber auch die bewährte ABAC-Form enthalten, nun jedoch verkleinert, wir bezeichnen solche Viertaktgebilde entsprechend mit kleinen Buchstaben, hier also abac. »Someday, Sweetheart « weist eine solch variierte Form auf, deren erstes Zeilenpaar also genauer als $A A^{\prime}$ zu bezeichnen ist. ${ }^{25} A^{3}$ kann nun entweder dem schließenden $A^{2}$ entsprechen (AA'BA') oder im Sinne einer durchkompo-

23 Vgl. hierzu jedoch auch unten Abschnitt 3.1.

24 Weitere Beispiele: »It's Only A Paper Moon« (Harburg/Arlen 1933), »The Lady Is A Tramp« (Hart/Rodgers 1937).

25 Weitere Beispiele: »From Here To Shanghai « (Berlin 1917), »In The Still Of The Night (Porter 1937), »Old Black Magic (Mercer/Arlen 1942); eine ausgewachsene 32-taktige ABAC-Form als $A A^{\prime}$ eines (56-taktigen) AA'BA"-Chorus' findet sich in »The Man That Got Away« (Gershwin/Arlen 1954). 
nierten AA'BA"-Form zum Beispiel eine emphatische Finalwirkung entfalten. Beispiel hierfür ist die Ballade »So In Love« aus Kiss Me Kate (Porter 1948), in welcher der Spitzenton in den A-Zeilen um jeweils einen Halbton ansteigt. Zudem ist die dritte A-Zeile um die Hälfte länger als die ersten beiden. Letzteres gilt auch für »All The Things You Are (Hammerstein II/Kern 1938) und »My Funny Valentine « (Hart/Rodgers 1937), dessen A-Zeilen zudem durch Transpositionen variiert werden. Schlusswirkungen durch Erweiterungen oder melodische Variation der $\mathrm{A}^{3}$-Zeile finden sich aber auch in ansonsten weniger durchkomponierten Songs, z.B. »They Can't Take That Away From Me« (Gershwin/Gershwin 1937).

\subsection{Die Bridge}

Während die A-Zeilen variieren können, ist in der Bridge Veränderung die wesentliche Aufgabe. Dass an dieser Stelle, der dritten Zeile innerhalb des Chorus', Kontrast möglich und notwendig ist, stellt den wesentlichen Unterschied zur ABAC-Form dar. Zwar ist die C-Zeile der Konkurrenzform ebenfalls durch »Anderssein« geprägt, doch muss sie zugleich für die Geschlossenheit der Form sorgen, die Möglichkeiten der Kontrastierung sind also deutlich eingeschränkt. Das die Form schließende $A^{3}$ gibt Komponisten wie Textern in der Bridge deutlich größere Freiheiten. Textinhaltlich kann dieser Kontrast durch Perspektiv- oder Subjektwechsel ${ }^{26}$, durch Kommentierung aller Art, durch Exemplifizierung, Ironisierung ${ }^{27}$ usw. erfolgen. In narrativen Songs kann die Bridge die entscheidende Wendung bringen ${ }^{28}$, in list songs das Tempo der Aufzählung steigern ${ }^{29}$, diese reflektieren ${ }^{30}$ oder erklären ${ }^{31}$.

26 »Smoke Gets In Your Eyes« (Harbach/Kern 1933): $A^{1} »$ They asked me..., $A^{2}$ »They said someday...«, Bridge "So I chaffed...«, $A^{3} »$ Now laughing friends...«. In »Ole Man River « ändert die Bridge die Perspektive nachhaltig: $A^{1}$ und $A^{2} \gg$ Ole Man River...«, Bridge »You and me...«, $A^{3} » \mid$ get weary...«.

27 Zugleich ironisch und exemplifizierend die Bridge von »Ac-Cent-Tchu-Ate The Positive (Mercer/Arlen 1944): »To illustrate my last remark, / Jonah in the whale, Noah in the ark...«.

28 »Rudolph The Rednosed Reindeer « (Marks 1949): »Then one day at christmas eve...«.

29 »Anything Goes « (Porter 1934): »The world has gone mad today, / And good's bad today, / And black's white today, / And...«.

30 »Let's Call The Whole Thing Off« (Gershwin/Gershwin 1936): »But, oh, if we call the whole thing off...«.

31 »It's All Right With Me« (Porter 1953): »...there's someone I'm trying so hard to forget...«. 
Die Bridge ist der Ort für Rückfragen ${ }^{32}$, Konjunktive ${ }^{33}$, Detailbeschreibungen $^{34}$ und Tagträume ${ }^{35}$. Sie kann eintrüben ${ }^{36}$ und aufhellen ${ }^{37}$.

Bridges tendieren dazu, prosaischer zu sein als die A-Zeilen und so deren lyrische Qualitäten deutlicher hervortreten zu lassen. Bridges mit ausgesprochenem Chorus-Charakter, wie wir sie später etwa bei den Beatles finden werden ${ }^{38}$, sind im Tin Pan Alley-Song rar. ${ }^{39}$

Auch für die Komponisten bietet die Bridge zahlreiche Gestaltungsmöglichkeiten. Die Bewegung (und damit für den Texter die Silbenzahl) kann erhöht werden ${ }^{40}$, kantablen A-Zeilen kann eine eher rezitierende Deklamation gegenüberstehen und so weiter. Alle Möglichkeiten klassischer Kontrastbildung können hier Anwendung finden. Ein entscheidender Moment innerhalb der AABA-Form ist der Beginn der Bridge, der in den meisten Fällen durch eine öffnende Harmonie signalisiert wird. Während die schweifende Harmonik der A-Teile fließende Übergänge und kontrapunktisch scheinbar »sich ergebende« Harmoniefolgen bevorzugt und auch die Quintfallsequenzen der Loop-Harmonisierung weiche Übergänge bilden, ist der Schritt in die Bridge in der Regel ein sehr bewusstes, deutlich wahrnehmbares Abheben, weshalb wir hier den Begriff des »Take off « anwenden. Verbreitet - wenn auch noch längst nicht so vorherrschend wie später etwa im Doo Wop - ist der Anschluss auf der IV oder der ii (funktionsharmonisch also der Subdominante bzw. Subdominantparallele). Die Take off-Wirkung der IV wird dadurch verstärkt, dass diese Stufe im A-Teil selten exponiert -

32 »Who Do You Love I Hope« (Berlin 1946): »Is it the baker who gave you a cake? I I saw that look in his eye...".

33 »Just One Of Those Things« (Porter 1935): »If we'd thought a bit, at the end of it...«.

34 »The Surrey With The Fringe On Top« (Hammerstein II/Rodgers 1943): »The wheels are yeller, the upholstery's brown...«.

35 »Over The Rainbow «: »Some day I'll wish upon a star...«.

36 »They Can't Take That Away From Me« (Gershwin/Gershwin 1937): »We may never, never meet again...«.

$37 \gg$ Didn't Know What Time It Was « (Hart/Rodgers 1939): »Grand to be alive to be young..."

38 »Thank You Girl« (1963), »Can't Buy Me Love« (1964), »Eight Days A Week (1964, alle Lennon/McCartney).

39 Zu diesen Ausnahmen zählt »You Can't Get A Man With A Gun« aus Irving Berlins Musical Annie Get Your Gun (1946) mit der seltenen Form $A_{x} A_{x} B_{x} A_{x}$. Die nur viertaktige Bridge hat den Text »With a gun, / With a gun, / No, you can't get a man with a gun «. In diesem comedy song folgen einem vierzeiligen Verse drei textreiche Chorus-»Strophen«, die knappe Bridge hat hier auflockernde und gliedernde Release-Funktion.

40 Einige Beispiele für ungleiches Verhältnis der Silbenzahlen von $A^{1}$-Zeile und Bridge: »Over The Rainbow« 23:40; »Body And Soul« (Heyman/Sour/Eyton/ Greene 1930) 30:40; »Top Hat, White Ties And Tails« (Berlin 1935) 18:33. 
etwa zu Beginn eines Zwei- oder Viertakters - erklingt, also gewissermaßen für den Take off zur Bridge aufgespart bleibt. ${ }^{41}$ Wie die Beispiele in der Tabelle zeigen, finden sich neben der IV und der ii in diesen Take offs jedoch auch andere Stufen. Der Grad der Take off-Wirkung hängt dabei nicht nur von der harmonischen Distanz ab. Auch charakteristische Dissonanzen, die den Take off-Akkord etwa als neue Tonika oder Zwischendominante einordnen oder aber seine Funktion und damit die harmonische Zielrichtung offen lassen ${ }^{42}$, können die Wirkung maßgeblich beeinflussen. Der demonstrative Schritt aus dem bisherigen harmonischen Feld heraus wird häufig begleitet und verstärkt durch satztechnische bzw. orchestratorische Kontrastbildungen. Der Take off ist also ein vorrangig, aber nicht ausschließlich harmonisches Moment.

\begin{tabular}{|c|c|c|c|}
\hline Stufe & Titel & Autor(en) & Jahr \\
\hline $\mathrm{I}^{7}$ & »They All Laughed« & Gershwin/Gershwin & 1937 \\
\hline ii & »| Love You« & Porter & 1943 \\
\hline $\mathrm{bii}^{7}$ & »All The Things You Are« & Hammerstein II/Kern & 1939 \\
\hline bll & »Body And Soul« & Heyman/Sour/Eyton/Greene & 1930 \\
\hline blll & »The Way You Look Tonight« & Field/Kern & 1936 \\
\hline $\mathrm{iii}^{7}$ & »I Hear A Rhapsody« & Fragos/Baker/Gasparre & 1941 \\
\hline III (in Moll) & »My Funny Valentine « & Hart/Rodgers & 1937 \\
\hline IV & »Oh, Lady Be Good« & Gershwin/Gershwin & 1924 \\
\hline iv $^{7}$ (in Dur) & »Lost In The Stars« & Anderson/Weill & 1946 \\
\hline V & »Let It Snow!« & Cahn/Styne & 1945 \\
\hline$v^{7}$ (in Dur) & »Crazy Rhythm« & Caesar/Meyer/Kahn & 1928 \\
\hline $\mathrm{v}$ (in Moll) & »Cry Me A River « & Hamilton & 1953 \\
\hline $\mathrm{vi}$ & »Dinah « & Lewis/Young/Akst & 1925 \\
\hline bVI & »Smoke Gets In Your Eyes« & Harbach/Kern & 1933 \\
\hline bVII & »My Defenses Are Down« & Berlin & 1946 \\
\hline
\end{tabular}

Tabelle 2: Beispiele für Take off-Harmonien zum Bridge-Beginn in Tin Pan AlleySongs

41 Eine doppelte Ausnahme ist hier »Over The Rainbow«: Der zweite Zweitakter der A-Zeilen beginnt auf der IV, dafür setzt die Bridge auf der I ein, was wirklich sehr außergewöhnlich ist. Die umso wirkungsvollere harmonische Öffnung erfolgt hier erst in T. 5 der Bridge.

42 Ein Beispiel: Die Bridge in "All The Things You Are Mollseptakkord auf $a$, also dem enharmonisch verwechselten bii $^{7}$ zur Tonika AsDur. Dass der Akkord eine Kadenz nach G-Dur eröffnet, ist in dem Moment des Take off ungewiss, daher wird dieser hier als bii, und nicht mit der Zielstufe VII bezeichnet. 


\section{Neue Füllungen für die A-Zeile}

In der Zeit nach dem Zweiten Weltkrieg bleibt die AABA-Form weiter im Rennen. Zwar läuft für den Tin Pan Alley-Song alter Prägung die Zeit ab, doch findet die Form im Swing und bei Vocal Groups weiter Verwendung. Im Folgenden sollen zwei neue Varianten der A-Zeilen-Gestaltung vorgestellt werden. Die R\&B-Ballade beschert der Form einen neuen Sound, der den Blues nicht mehr nur zitiert. Sie bildet - aufbauend auf älteren Stücken eigene harmonische Formeln aus und löst die »klassische Melodiebildung der Tin Pan Alley-Ballade durch Bluesintonation ab (Kap. 3.1). Im Doo Wop wird die Grundlage für die Aufspaltung der A-Zeile bereitet, indem die Loop-Harmonik in den Vordergrund tritt und so die Zeile zergliedert (Kap. 3.2).

\subsection{Die R\&B-Ballade}

Bereits oben wurde erwähnt, dass im Tin Pan Alley-Repertoire der Zeit nach dem Ersten Weltkrieg die AABA-Form in unerwarteten afroamerikanische Konnotationen und Zusammenhängen auftrat. In der nächsten Nachkriegszeit entsteht mit der R\&B-Ballade ein Genre, das nun umgekehrt vom Blues auszugehen scheint und sich der Popular Song Form bedient. Für die Ausdifferenzierung der A-Zeile zu einem neuen Verse/Chorus-Modell spielt dieses Genre eine untergeordnete Rolle, da ihre Syntax der üblichen Refrainform des Tin Pan Alley-Songs mit seinen ganzen Zeilen folgt. Dennoch soll es hier erwähnt werden, da es eine eigenständige und keineswegs randständige Gestaltung der AABA-Form entwickelt. Zudem warnt das Genre vor der Konstruktion allzu scharfer Dichotomien wie »schwarz/weiß«, »Pop/Blues« etc. Tatsächlich ist schon die eben geäußerte Anfangsannahme fragwürdig, nach der die R\&B-Ballade vom Blues ausgeht. Vor allem zwei Aspekte machen die Sache kompliziert: Zum einen waren die Grenzen zwischen Tin Pan Alley-Pop, Jazz und Blues schon lange vor dem Zweiten Weltkrieg durchlässig. Für genauere Analysen ist hier nicht der Ort, doch seien immerhin einige signifikante Nummern genannt, die sich einer eindeutigen stilistischen Zuordnung entziehen: »Gee, Baby, Ain't I Good To You« (Razaf/Redman 1929), »Ain't Misbehavin'« (Razaf/Waller 1929), »Stormy Weather« (Koehler/Arlen 1933), »| Ain't Got Nothing But The Blues« (George/Ellington 1937), »Don't Get Around Much Anymore (Russell/Ellington 1940).

Zum anderen taucht dasselbe Repertoire in den unterschiedlichsten Bearbeitungen und Performance-Situationen auf. Theaterbühne, Tanzsaal, 
Studio, Club oder Juke Joint - jede Besetzung, jeder Ort und Anlass gibt einem Song ein anderes Gepräge. So ist hier einmal mehr darauf hinzuweisen, dass auch Bluesmusiker in der Regel eben nicht »Nur-Bluesmusiker « waren. ${ }^{43}$ Und auch im Jazz war das Beherrschen verschiedener Stile letztlich eher die Regel als die Ausnahme. Ella Fitzgerald konnte Tin Pan Alley-Songs notengetreu interpretieren, >jazzig f frei phrasieren und schließlich als Basis ihrer Scat-Improvisationen verwenden, und im Orchester der Broadwayproduktion von Gershwins Musical Girl Crazy (1930) spielten unter anderem Benny Goodman, Glenn Miller, Jack Teagarden und Gene Krupa.

Unsere folgende Darstellung unterscheidet zwei harmonische Konzepte, die hier als »Blues«- und »Jazzharmonik« bezeichnet sind. Es sei ausdrücklich darauf hingewiesen, dass diese Konzepte als prototypisch zu verstehen sind und keineswegs als hinreichende analytische Instrumente zur Stilbestimmung. Als typisch für die Bluesharmonik erscheint die Beschränkung auf Dur-Grundstufenakkorde (bis in die 1960er Jahre sind Blues in Moll überaus selten) und deren Überblendung mit mollgefärbten Melodieelementen, aus denen einerseits die typischen Reibungen zwischen Moll- und Durterzen resultieren und die andererseits auf allen Stufen »funktionslose «, d.h. nicht-dominantische kleine Septimen auftreten lassen. Bereits in den um 1920 beliebten Blues Songs wurde als Bluesmerkmal gerne die exponierte d.h. durch einen deutlichen harmonischen Schritt erreichte, an betonter Stelle stehende - vierte Stufe eingesetzt. Jazzharmonik ist dagegen - es wurde bereits darauf hingewiesen - eng mit der klassischen Funktionsharmonik verwandt. Quintfalllogik und Mediantik als deren Gegenspielerin, zu Tensions erstarrte Dissonanzen, chromatische Guide Tone Lines und leitereigene Septimakkorde als Grundform sind ihre Charakteristika.

Nochmal: Ob in einem Stück die eine oder andere Art der Harmonik vorkommt, entscheidet nicht darüber, was das Stück ist. Andere Kriterien

43 Zwei Belege mögen an dieser Stelle genügen: So schreibt Peter Townsend (2007: 196) über die frühen Jahre von Muddy Waters, der späteren Ikone des Chicago Blues: $\gg$ His repertoire contained [...] songs like $\rightarrow$ Red Sails In The Sunset<, >Dinah < and >Bye Bye Blues< as well as cowboy or hillbilly tunes like >Home On The Range<, >You Are My Sunshine<, >Boots And Saddles<, and [...] >Deep In The Heart Of Texas . [...] Waters sang traditional blues numbers, his own compositions, and those of Walter Davis, but also sDark Town Strutters' Ball<, and [...] >Chattanooga Choo-Choo [...]. Waters also told Lomax that his favorite artist on the radio was Fats Waller « (2007: 196). Und Lonnie Johnson bemerkte zu seiner »Blueskarriere «, die mit einem Plattenvertag als erstem Preis eines Musikwettbewerbs begann: »I guess I would have done anything to get recorded - it just happened to be a blues contest, so I sang the blues« (http://www. musicianguide.com/biographies/1608004726/Lonnie-Johnson.html, Zugriff am 1.4.2011). 
wie Melodiebildung, Intonation, Rhythmus, Besetzung, Tempo und Tonbildung sind ebenso wichtig wie Harmonik oder Form. Gleichwohl ist anzunehmen, dass ein Stück von einer ausgewiesenen Bluessängerin wie Bessie Smith sehr viel schneller als >Vaudeville-Nummer c gewertet wird, wenn ein mediantisch einsetzender Quintfallloop oder -turnaround darin vorkommt (vgl. z.B. unten »Nobody Knows You, When You're Down And Out«).

1949 bescherte Ruth Brown mit ihrer ersten Aufnahme »So Long « dem jungen Label Atlantic Records auf Anhieb einen Hit. Der Song steht in AABAForm und klingt in Browns Interpretation auf den ersten Eindruck durchaus nach R\&B. Tatsächlich ist er jedoch eine Tin Pan Alley-Komposition der Songwriter Harris, Melsher und Morgan von 1940. Ella Fitzgeralds Aufnahme aus dem Entstehungsjahr präsentiert eine in klassischer Weise komponierte Korrespondenzmelodik, die klar im Vordergrund steht und aus der sich die Harmonisierung mit dem Loop der Rhythm Changes eher zufällig zu ergeben scheint (ebenso zufällig vielleicht wie die unüberhörbaren Anklänge der Komposition an Rodgers und Harts »Blue Moon« von 1934). Obwohl der Rhythm-Loop mit seiner Major7-Tonika, seinen Mollnebenklängen und seiner Quintfalllogik all das hat, was die Bluesharmonik gerade nicht auszeichnet, obwohl die Bläser in Browns Aufnahme nicht weniger mellow klingen als bei Fitzgerald und obwohl eine AABA-Form vorliegt, vermutet Arnold Shaw (1983: 500) in diesem Song eine »alte Bluesballade«. Diese Einschätzung wird kaum dem Umstand geschuldet sein, dass der jazzige Turnaround, der dem Grundloop mittels Alteration und Substitutsdominante eine zum

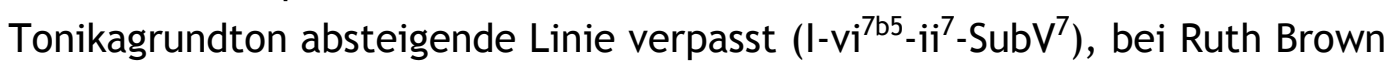
durch einen bluesigeren, über die IV laufenden mit aufsteigender chromatischer Linie ersetzt wird $\left(\mathrm{I}-\mathrm{I}_{3}-\mathrm{IV}-\# i \mathrm{~V}^{07}-\mathrm{I}_{5}-\mathrm{ii}^{7}{ }_{5}-\mathrm{V}\right)$. Eher tragen das langsamere Tempo, der ausgeprägtere Shuffle-Rhythmus und der höhere Improvisationsanteil in der Begleitung dazu bei. Vor allem aber ist es Ruth Browns Gesang, der dem Song seinen Tin Pan Alley-Charakter nimmt. Die Sängerin schert sich nicht im Geringsten um die wohlgesetzte Korrespondenzmelodik; statt auf den im Dreiklang absteigenden Zentraltönen der Komposition enden ihre jeweils frei gebildeten Phrasen mit weiblichen, melodisch fallenden Schlussformeln. In Hinblick auf den Gesang hat die Nummer alles, was eine R\&BBallade braucht, das Arrangement und vor allem die »Füllung « der A-Zeile bleiben jedoch dem Pop-Stil der 1940er Jahre verhaftet.

Vorbilder für eine eigene Variante der A-Zeile gab es durchaus. ${ }^{44}$ Fünf Jahre nach »So Long« nimmt Ruth Brown mit »Oh What A Dream« (Willis

44 Die Autoren danken Thomas Phleps für die Einsicht in seine umfangreichen, bislang unveröffentlichten Forschungsergebnisse zur Form im Pre War-Blues. 
1954) eine R\&B-Ballade auf, deren A-Zeile mit eben diesem Material auskommt. Tatsächlich zeigt sich hier das harmonische Gerüst der sich um 1950 herausbildenden R\&B-Ballade, das freilich in solch »sauberer« Form die große Ausnahme bleibt.

\begin{tabular}{|l}
\hline$»$ Oh What A Dream« (Willis 1954) \\
\begin{tabular}{|c|c|c|c|c|c|c|c|c|}
\hline $\begin{array}{c}\text { Ruth Brown } \\
\text { (1954) }\end{array}$ & I & I $^{7}$ & IV & IV & I & V & I & V \\
\hline
\end{tabular}
\end{tabular}

In der Standard A-Zeile der R\&B-Ballade (in der Folge »R\&B-Zeile«) gibt es zwei wichtige harmonische Ereignisse. Im ersten Viertakter wechselt die Harmonik zur vierten Stufe, ein Wechsel, der üblicherweise nicht als neutraler Shuttle eintritt, sondern durch einen Zwischendominantseptakkord vorbereitet wird. ${ }^{45}$ Die zweite Hälfte beschreibt eine Bewegung von der Tonika zur Dominante, die entweder einmal viertaktig oder - wie in »Oh What A Dream« - zweimal zweitaktig abläuft. Diese grundlegende harmonische Bewegung wird - im Unterschied zu »Oh What A Dream« - in aller Regel in einem Quintfallturnaround auskomponiert. Der mediantische Sprung von der Tonika zum Beginn des Turnarounds (in den folgenden Beispielen in T. 5 bzw. T. $5 \rightarrow 6$ ) ist das zweite markante Ereignis in der Harmonik der R\&B-Zeile.

Phleps unterscheidet dort sechs Klassen achttaktiger Schemata, die fast ausnahmslos mit den drei Grund(sept)akkorden auskommen.

45 Dieser $\gg 1^{7}$ «-Akkord hat zunächst einmal nichts mit Bluesharmonik zu tun, sondern wirkt eindeutig im Sinne funktionaler Harmonik. Dieser Eindruck kann freilich verschoben werden, etwa durch Licks oder Riffs, die auf der Bluesskala basieren und so die kleine Septime als dem tonikalen Tonraum der ersten Stufe zugehörig erscheinen lassen. Man vergleiche etwa »Need Your Love So Bad « in den Versionen von Little Willie John und Fleetwood Mac. John spielt im Intro die Bluesskala und bettet den Eintritt der kleinen Septime im zweiten Takt des Gesangs organisch in ein Begleitriff ein. Peter Greens Intro verwendet dagegen (fast) ausschließlich eine Durpentatonik, spart also die kleine Septime aus. Im ersten A-Teil des Gesangs tritt in der Orgel vor dem Wechsel die kleine Septime als (sehr leise, aber deutliche) harmonische Funktionsbestimmung hinzu. Die Originalversion klingt entsprechend mehr >nach Blues<, das Cover mehr >nach Ballade<. 


\begin{tabular}{|c|c|c|c|c|c|c|c|c|}
\hline \multicolumn{9}{|c|}{ »Please, Send Me Someone To Love« (Mayfield 1950) } \\
\hline $\begin{array}{l}\text { Percy May- } \\
\text { field (1950) }\end{array}$ & I & $1^{7}$ & IV & $\# i v^{\circ} 7$ & $1-v i^{\circ 7}$ & $\mathrm{ii}^{7}$ & $\mathrm{~V}^{7}-\mathrm{bVl^{7 }}$ & $V^{7}$ \\
\hline \multicolumn{9}{|c|}{ »Drown In My Own Tears« (Glover 1951) } \\
\hline $\begin{array}{l}\text { Lula Reed } \\
\text { (1951) }\end{array}$ & $1^{8-\mathrm{maj} 7}$ & $\mathrm{I}^{7}$ & IV & iv & I & $\mathrm{vi}^{7}$ & $\|^{7}$ & $\mathrm{~V}^{7}$ \\
\hline $\begin{array}{c}\text { Ray Charles } \\
\text { (1956) }\end{array}$ & $\mathrm{I}-\mathrm{V}^{\# 5}$ & $\mathrm{I}^{7}$ & IV & $\# i v^{\circ} 7$ & $\mathrm{I}-\mathrm{III}$ & $\mathrm{vi}^{7}$ & $\mathrm{II}^{7}$ & $V^{7}-V^{\# 5}$ \\
\hline \multicolumn{9}{|c|}{ »Need Your Love So Bad« (John 1955) } \\
\hline $\begin{array}{l}\text { Little Willie } \\
\text { John (1955) }\end{array}$ & I & $\mathrm{I}^{7}$ & IV & $\# i v^{\circ} 7$ & I & $\mathrm{Vl}^{7}$ & $\mathrm{II}^{7}-\mathrm{V}^{7}$ & $\mathrm{I}-\mathrm{V}^{7}$ \\
\hline \multirow[t]{2}{*}{$\begin{array}{l}\text { Fleetwood } \\
\text { Mac (1968) }\end{array}$} & I & $\mathrm{I}^{7}$ & IV & $\# i v^{\circ} 7$ & $\mathrm{I}-\mathrm{vi}^{7}$ & $\mathrm{ii}^{7}-\mathrm{V}^{7}$ & I - IV & $\mathrm{I}-\mathrm{V}$ \\
\hline & 1 & 2 & 3 & 4 & 5 & 6 & 7 & 8 \\
\hline
\end{tabular}

Diese beiden Ereignisse prägen jeweils unterschiedliche Varianten aus, aus denen im Wesentlichen das harmonische Formelrepertoire des Genres besteht.

1. Die üblicherweise im dritten Takt erreichte IV wird - im Unterschied zu »Oh What A Dream« - meist im vierten Takt entweder vermollt oder zur \#iv ${ }^{\circ}$ verschärft. In diesem Kontext fungiert dieser verminderte Septakkord nicht im Sinne des »verkürzten Dominantseptnonakkords « der funktionalen Harmonielehre, da die Fortschreitung unter Missachtung möglicher Leittonfunktionen mit einem Tritonusfall des Basses zurück zur I. Stufe geht. Der Basston ist hier wohl vielmehr als der typische chromatische Zwischenschritt zwischen dem vierten und fünften Ton der Bluesskala zu verstehen, was die Eigenständigkeit der R\&B-Zeile unterstreicht.

2. Beim mediantischen Schritt der zweiten Zeilenhälfte variiert zum einen die Richtung des Terzsprungs - aufwärts zur iii oder abwärts zur vi - und zum anderen Gestalt und Geschlecht der Mediante. Neben den leitereigenen Akkorden $\mathrm{iii}^{(7)}$ und $\mathrm{vi}^{(7)}$ kommen verminderte Septakkorde $\left(\mathrm{vi}^{\circ}{ }^{7}\right)$ und verdurte Medianten $\left(\mathrm{VI}^{(7)}\right.$ und $\left.\mathrm{III}^{(7)}\right)$ vor. Im Rahmen der Quintfallsequenz sind diese verdurten Stufen funktionsharmonisch leicht als Zwischendominanten erklärbar. Gleichwohl hat sich insbesondere der Schritt I-III ${ }^{7}$ als eigenständige harmonische Formel durchgesetzt. Sie ist die markante Wendung im Klassiker »Nobody Knows You When You're Down And Out « sowie in den Vorreitern der R\&B-Zeile »'Tain't Nobody's Business If I Do « und »Georgia On My Mind «, in denen sie bereits die erste Zeilenhälfte prägen. 


\begin{tabular}{|c|c|c|c|c|c|c|c|c|}
\hline \multicolumn{9}{|c|}{ „'Tain't Nobody's Business If I Do« (Grainger/Robins 1922) } \\
\hline $\begin{array}{c}\text { Anna Meyers } \\
(1922)\end{array}$ & I & $\mathrm{III}^{7}$ & vi & $\# i v^{\circ 7}$ & 1 & V & I - IV & $\mathrm{I}-\mathrm{V}$ \\
\hline $\begin{array}{c}\text { Jimmy } \\
\text { Witherspoon } \\
(1949)\end{array}$ & I & $\mathrm{III}^{7}$ & IV & iv & I- vi & ii - V & 1 & ii - V \\
\hline $\begin{array}{l}\text { Freddie King } \\
\text { (Studio 1970) }\end{array}$ & I & $\mathrm{III}^{7}$ & IV & iv & I - vi & ii - V & I - IV & $\mathrm{I}-\mathrm{V}$ \\
\hline $\begin{array}{c}\begin{array}{c}\text { Freddie King } \\
\text { (Live 1975) }\end{array} \\
\end{array}$ & I & $\mathrm{III}^{7}$ & IV & $\# i v^{\circ}$ & I - vi & ii - V & I-IV & $\mathrm{I}-\mathrm{V}$ \\
\hline \multicolumn{9}{|c|}{ »Georgia On My Mind« (Gorrell/Carmichael 1930) } \\
\hline $\begin{array}{c}\text { Hoagy } \\
\text { Carmichael } \\
(1930)\end{array}$ & I & $1 \mathrm{II}^{7}$ & $\mathrm{vi}^{7}$ & $\# i v^{07}-i v^{7}$ & I- biii $^{\circ}$ & $\mathrm{ii}^{7}-\mathrm{V}^{7}$ & $\mathrm{I}-\mathrm{vi} \mathrm{i}^{7}$ & $\mathrm{ii}^{7}-\mathrm{V}^{7}$ \\
\hline \multirow[t]{2}{*}{$\begin{array}{c}\text { Ray Charles } \\
(1960)\end{array}$} & 1 & $1 \mathrm{II}^{7}$ & $\mathrm{vi}^{7}$ & $I V^{7}-\# i v^{\circ}{ }^{7}$ & $\mathrm{I}-\mathrm{VI}^{7}$ & $\mathrm{II}^{7}-\mathrm{V}^{7}$ & $\mathrm{III}^{7}-\mathrm{VI}^{7}$ & $\| I^{7}-\mathrm{bll}^{7}$ \\
\hline & 1 & 2 & 3 & 4 & 5 & 6 & 7 & 8 \\
\hline
\end{tabular}

»'Tain't Nobody's Business If I Do « fällt in Hinblick auf die Form doppelt aus dem Rahmen: Zum einen durch seinen eigentümlichen 16-taktigen Blues»Verse ${ }^{46}{ }^{6}$, der das Stück in die Nähe der Popular Song Form stellt, zum anderen durch das »Fehlen« einer Bridge, das es wieder von dieser entfernt. ${ }^{47}$ In unserem Zusammenhang ist der Song trotz der fehlenden Bridge wichtig, da er als sehr frühes Beispiel die Charakteristika der R\&B-Zeile ausprägt. Jimmy Witherspoons erfolgreiches Cover von 1949 behält den markanten Schritt zwar bei, folgt dann aber nicht dem Quintfallmodell sondern entledigt die $\mathrm{III}^{7}$ durch den Schritt zur >bluesigeren< IV gänzlich ihrer Zwischendominantfunktion. Dafür ersetzt Witherspoon die Grundstufenkadenz der zweiten Zeilenhälfte durch den für die R\&B-Zeile typischen Quintfallturnaround. ${ }^{48}$ Diese Harmoniefolge verwendet unter anderem auch Freddie King in seiner Studioaufnahme von 1969, während dessen

46 Vgl. die frühen Aufnahmen mit Anna Meyers (Uraufnahme 1922) oder Bessie Smith (1923). Dieser Verse wird, wie seine Tin Pan Alley-Gegenstücke, im Laufe der Zeit auf der Strecke bleiben.

47 Ob es der Verse, der mediantische Schritt oder Anna Meyers albern anmutendes »doo-doo-doo-doodelam-doo-doo« am Zeilenende der Uraufnahme ist, durch das sich das Stück als »vaudeville blues song « auszeichnet, sei dahingestellt (vgl. http://en.wikipedia.org/wiki/Ain\%27t_Nobody\%27s_Business; letzter Zugriff 3.4.2011).

48 Die Verwendung des Terminus' Turnaround steht hier im Widerspruch zu Taggs Definition. Zwar stimmen wir Tagg zu, wenn er den Turnaround vom Loop unterscheidet und feststellt, »its original meaning is a short progression of chords played at the end of one section « (Tagg: 2009: 200, Herv. i. 0.), gleichwohl ist der Bluesturnaround als ursprünglich primär melodische, zur fünften Stufe auf- oder absteigende Linie so signifikant, dass er auch im Verlauf eines Teils - also ohne formschließende Funktion - als solcher erkannt wird. 
Liveversion von 1975 schließlich die von Witherspoon eingeführte Moll-IV wieder durch die ursprüngliche $\# i v^{\circ}$ ersetzen wird. Die Basslinie der ersten vier Takte ergibt nun einen aufsteigenden, unvollständigen Bluesturnaround (Notenbeispiel 1a). ${ }^{49}$

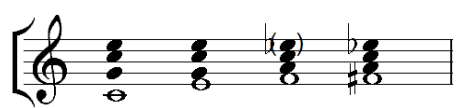

Notenbeispiel $1 \mathrm{a}$

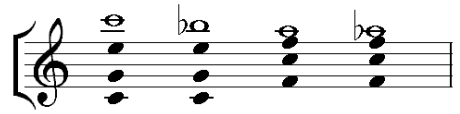

$1 \mathrm{~b}$

Auch die in R\&B-Zeilen verbreitete Harmoniefolge $\mid-I^{7}-I V-i v[-I]$ enthält einen - diesmal absteigenden - Bluesturnaround (Notenbeispiel 1b). Die R\&BZeile besteht also aus der Montage eines über die IV laufenden Bluesturnarounds mit einem auf der klassischen Quintfallsequenz basierenden Jazzturnaround. Die Auswahl bei der Ausgestaltung dieser Turnarounds zwischen den harmonischen Bausteinen $\gg \mid V-i V \ll$ oder $\gg \mid V-\# i v^{\circ 7}$ « einerseits und $\gg|-v i \ll, »|-V \mid \ll$ oder $\gg|-||| \ll$ (samt Alterationen und Substitutionen) andererseits besteht nicht nur bei der Neukomposition, auch verschiedene Versionen desselben Stücks können darin variieren. ${ }^{50}$ Bemerkenswerterweise fehlt in den untersuchten Beispielen der für Bluesschemata so typische Schritt V-IV, der gerade in achttaktigen Bluesschemata - im Unterschied zum zwölftaktigen »Standardschema« - keineswegs auf den Schlussabschnitt festgelegt ist. ${ }^{51}$

Die Norm der Zweiteilung der R\&B-Zeile wird besonders deutlich, wenn sie gebrochen wird. In Lonnie Johnsons Hit »Tomorrow Night« von 1948 erfolgt der Schritt von der IV zur iv an völlig unüblicher Stelle zwischen dem vierten und fünften Takt, wodurch die Zweiteilung der Zeile überspielt

49 Die Linie liegt auch der ersten A-Zeilenhälfte von Ray Charles' »Hallelujah, I Love Her So « (Charles 1956) zugrunde - eine der selteneren schnellen R\&BNummern in AABA-Form -, hier wird die 3 jedoch durch den Tonikaakkord in Terzstellung harmonisiert.

50 Neben der beschriebenen Versionengeschichte von »It Ain't Nobody's Business If I Do « vgl. auch in der Tabelle die beiden Versionen von »Drown In My Own Tears«. In der Uraufnahme mit Lula Reed geht die IV zur iv, bei Ray Charles zur $\# i v^{\circ 7}$. Der Quintfallturnaround setzt bei Reed mit vi ein, bei Charles mit der vorgeschalteten iii.

51 Die von Phleps (s. Fußnote 44) aufgestellte Systematik unterschiedlicher Bluesschemata nennt vier Klassen solcher achttaktiger Schemata, in denen der Schritt $V^{7}-I^{[7]}$ in der ersten Hälfte vorkommt. Der (heute) bekannteste Blues dieses Typs ist wohl »Key To The Highway« (Jazz Gillum 1940): I-V $V^{7}-I V^{7}-I V^{7}-$ $I-V^{7}-I-I$. 
wird. ${ }^{52}$ In der Aufnahme mit LaVern Baker von 1954 sorgt eine Reharmonisierung für größere Klarheit:

\begin{tabular}{|c|c|c|c|c|c|c|c|c|}
\hline \multicolumn{9}{|c|}{ »Tomorrow Night« (Coslow/Grosz 1939), A'-Zeile } \\
\hline $\begin{array}{c}\text { Lonnie Johnson } \\
(1948)\end{array}$ & $\mathrm{I}$ & $1^{7}$ & IV & IV & iv & $\mathrm{V}^{7}$ & I-vi-ii & $V^{7}$ \\
\hline $\begin{array}{l}\text { LaVern Baker } \\
\quad(1954)\end{array}$ & I & $1^{7}$ & IV & $\mathrm{IV}-\mathrm{iij}^{\circ 7}$ & $11^{7}$ & $V^{7}$ & $I-1 I^{9}$ & $V^{7}$ \\
\hline
\end{tabular}

Die Bildung der R\&B-Zeile durch zwei aufeinanderfolgende Turnarounds teilt die "ganze Zeile« der Tin Pan Alley-Form in zwei Teile. Wie stark diese Teilung wahrgenommen wird, ist - wie üblich - von verschiedenen Faktoren abhängig, von denen die Qualität des mediantischen Schritts nur einer ist. Textumfang und -form, Tempo, Arrangement, Agogik sowie der Verlauf der Gesangsmelodie tragen ebenso dazu bei, ob die Zeile trotz des zweigeteilten harmonischen Aufbaus als Eine gehört wird oder ob etwa in Takt 5 eine Art Take off, vergleichbar mit dem Einsatz der Bridge, stattfindet. »Wenn mir danach ist in den Ozean zu springen, dann geht das niemanden etwas an « lässt sich ohne weiteres in einer Zeile sagen, und Anna Meyers tut es (bei einem Tempo von ca. 130 bpm). ${ }^{53}$ Bessie Smith vereinzelt die Textphrasen schon deutlich (ca. 80 bpm) und bei Jimmy Witherspoon, der (bei ca. 65 bpm) über Existentielleres singt ${ }^{54}$, wird die Zeile bei gleicher Textlänge beinahe schon als ausgewachsene »Strophe « wahrgenommen. In Little Willie Johns »Need Your Love So Bad« (72 bpm) ist dies ganz entschieden der Fall. In 37 Silben und sieben Textzeilen, deren erste und dritte durch den gleichen Beginn korrespondieren, wird die A-Zeile deutlich gegliedert und so zum »A-Teil«:

I need someone's hand

To lead me through the night.

I need someone's arms

To hold and squeeze me tight.

When the night begins

And the dew remains,

I need your love so bad.

52 In der zweiten A-Zeile wird der Schritt zwar an die übliche Stelle (T. 3/4) verlagert, durch den ausbleibenden Akkordwechsel zu T. 5 bleibt jedoch die Zweiteilung verwischt.

53 »'Tain't Nobody's Business If I Do «: »If I should take a notion / To jump into the ocean, / It ain't nobody's business if I do."

54 »One day, we got ham and bacon, / Next day ain't nothing shakin', / Ain't nobody's business if I do.« 
Der Beginn des zweiten Abschnitts bildet hier - und noch stärker in der mit 50 bpm erheblich langsameren Version von Fleetwood Mac - schon einen deutlichen Take off-Charakter aus, der den Titelrefrain vorbereitet. Das für die britische Bluesband ungewöhnliche Streicherarrangement unterstreicht das Anderssein der Ballade gegenüber dem Blues. In der Frühzeit des Genres fällt die Unterscheidung nicht immer ganz so deutlich aus. So gibt es bei Ray Charles zwischen ausgeprägten langsamen Blues ${ }^{55}$ und der R\&B-Ballade ${ }^{56}$ auch bridgelose achttaktige Blues resp. Balladen mit für die R\&B-Zeile typischen Harmonieverläufen. ${ }^{57}$

Noch in den 1960er Jahren sollte die AABA-Form bei R\&B-Balladen als Norm geläufig sein. ${ }^{58}$ So wurde Sam Cookes unübliche Variante einer AAABAForm in seiner Bürgerrechtshymne »A Change Is Gonna Come« (Cooke 1964), deren zusätzlicher A-Teil einem erhöhten Textbedarf dieser politischen Ballade geschuldet sein mag, in den Coverversionen der Supremes (1965) sowie von Otis Redding (1966) und Aretha Franklin (1967) auf eben diese Norm zurückgestutzt. Aretha Franklin setzt dem Song sogar eine kurze Einleitung voran, die freilich nur sehr entfernt an den Tin Pan Alley-Verse erinnert.

\subsection{Doo Wop}

Die entscheidende Voraussetzung dafür, dass aus der geschlossenen A-Zeile ein komplexer A-Teil und aus dem bisherigen Refrain ein neuer Chorus werden konnte, ist eine gegenüber den Tin Pan Alley-Songs deutlichere Unterteilung der A-Zeile. Ausgangspunkt hierfür ist die Loop-Harmonisierung, wie wir sie bereits bei den Rhythm Changes beobachtet haben. Die schweifende Harmonik, die in der Love Ballad für die Ganzheit der Zeile sorgte, spielt in den neuen Stilen der 1950er Jahre so gut wie keine Rolle mehr und bleibt

55 Z.B. »Ray's Blues« (Charles 1953), »Black Jack« (Charles 1954).

56 Neben dem in der Tabelle aufgeführten »Drown In My Own Tears « seien hier genannt »Funny But I Still Love You« (Charles 1953) und »The Midnight Hour« (Sweet 1952).

57 »The Sun's Gonna Shine Again« (Charles 1952; hier vertritt ein Klaviersolo die Bridge. Inwiefern die im Blues sich als Standard etablierende Positionierung eines Instrumentalsolos im - harmonisch freilich nicht veränderten - dritten Formteil auf das Vorbild der AABA-Form rekurriert, sei einstweilen dahingestellt), »Come Back Baby« (Charles 1954).

58 Mitunter freilich mit einigen Modifikationen, von denen z.T. später noch die Rede sein wird. Vgl. z. B. James Carr: »The Dark End Of The Street « (Moman/ Oldham/Penn 1967), Percy Sledge: »When A Man Loves A Woman« (Lewis/Write 1966) oder Brook Benton: »Rainy Night In Georgia« (White 1962; Bentons Aufnahme stammt von 1970). 
mit jenem nun als altmodisch empfundenen Sound verbunden, von dessen Folie sich die zunehmend von jugendlichen Hörern gefragte Musik abhebt.

Die über die Zweiteilung der R\&B-Zeile hinausgehende Segmentierung der A-Zeile wird vollzogen im Doo Wop, genauer: in jener Doo Wop-Richtung, die mit der Verwendung der AABA-Form, harmonischer Zweitakt-Loops und einer weitgehend auf der Durheptatonik basierenden Melodiebildung eher dem Pop nahesteht ${ }^{59}$ und dessen Spätphase zuweilen als »milksap music « ${ }^{60}$ bezeichnet wird. Die entscheidende Voraussetzung für diese Segmentierung ist die Emanzipation der Basslinie und damit das Hervortreten des harmonischen Loops. Tritt in einer Jazzcombo der durchgängig gezupfte Kontrabass stärker als harmonisch-rhythmische Grundlage aus dem Klangbild heraus als der gestrichene Bass in einem Orchesterarrangement, so wird der Bass Man im Doo Wop vielen ungeübten Hörern die Basslinien jenseits der schon vorher auffälligeren Walking- und Boogiebässe überhaupt erstmals erkennbar machen. Der Vergleich dreier Versionen von »Blue Moon« (Hart/ Rodgers 1934) - der vielleicht bekanntesten Tin Pan Alley-Ballade mit LoopHarmonisierung - mag dies verdeutlichen.

Die A-Teile von Rodgers' Komposition basieren auf dem I-vi-ii-V-Loop der Rhythm Changes. Die Melodie besteht aus einer zweitönigen, den Titelhook tragenden Intonation, auf die eine dreimal erklingende und dabei tonal in absteigenden Terzen sequenzierte Phrase folgt. Die Zentraltöne dieser Sequenz ( $b, g$ und es) ergeben den Tonikadreiklang, als ausgehaltene Zieltöne der drei Phrasen fallen sie aufgrund der Loopharmonisierung jeweils auf den Tonika-Akkord (Eb ${ }^{\text {maj7 }}$ bzw. Eb ${ }^{6}$ ). Auf eine Kadenz zum Ende der AZeile kann hier verzichten werden, da die fallende Sequenz der Melodie mit dem Zielton es in T. 7 hinreichend schließende Wirkung hat. ${ }^{61}$

59 Im Unterschied zu der eher am Boogie, Jump Blues bzw. R\&B orientierten Richtung, die auf Bluesschemata aufbaut, im Leadgesang Bluesintonation verwendet und deren Arrangements an bläserdominierte Combos wie Louis Jordans Tympany Five erinnert.

60 Tagg (2009: 204) benutzt diese Bezeichnung unter Berufung auf ein Jerry Lee Lewis zugeschriebenes Zitat und weist darauf hin, dass es korrekt milksop (Milchgesicht, Milchbubi) heißen müsste.

61 Aufschlussreich ist dagegen die im verwendeten Notenbeispiel vorgeschlagene Reharmonisierung der beiden letzten Loops zu einem chromatischen Turnaround. Bei der Verwendung des Chorus' als Harmoniegrundlage für Jazz-Improvisationen - und für diesen Zweck sind die real books in erster Linie gedacht würde die durchgehende Loop-Harmonisierung die AABA-Form schwer erkennbar machen. 

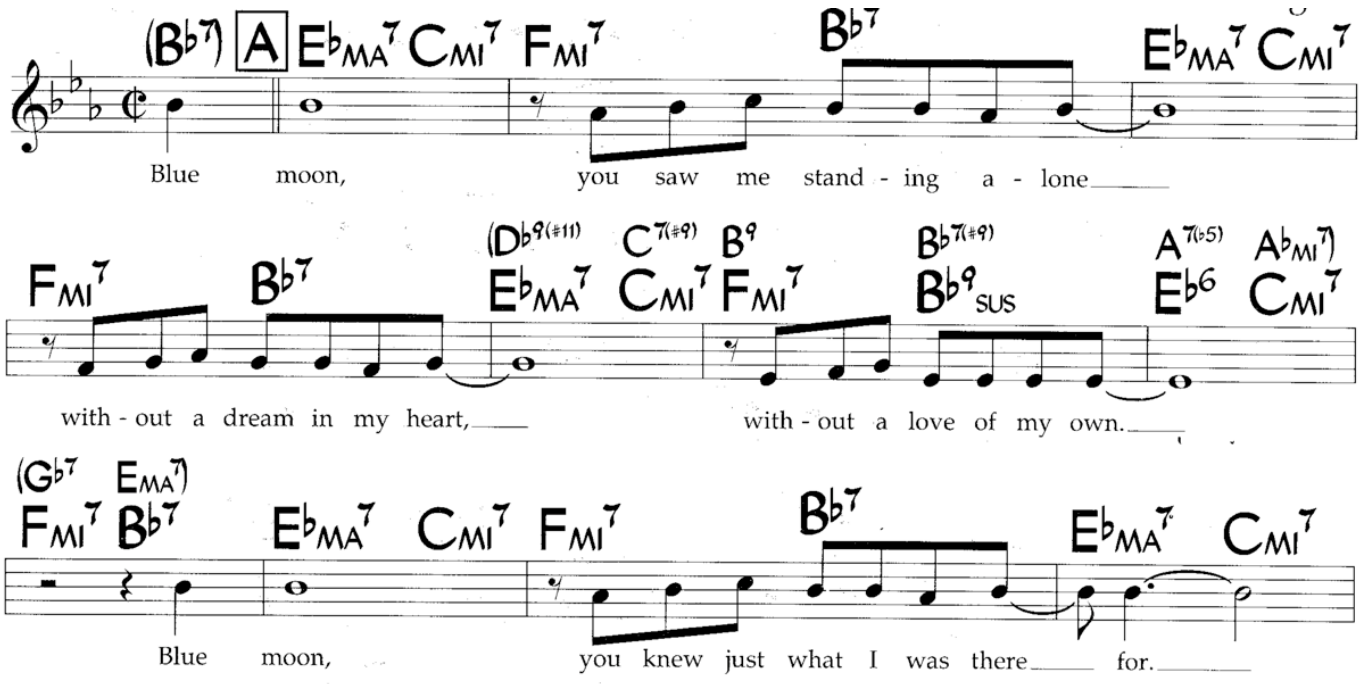

Notenbeispiel 2: Lorenz Hart / Richard Rodgers: »Blue Moon«, erste A-Zeile und Beginn der zweiten A-Zeile. Aus: The New Real Book, Vol. 3. Hg. v. Chuck Sher. Petaluma 1995, S. 47

In der Uraufnahme mit Connee Boswell und dem Victor Young Orchestra von 1935 ist die Rhythmusgruppe und damit auch der harmonische Loop vergleichsweise gut zu hören. Dieser wird aber durch die mit dem Gesang korrespondierenden Riffs der Streicher und Bläser überlagert, unangefochten im Vordergrund steht die Gesangsmelodie. In der erfolgreichen Version von Mel Tormé von 1949 verschwindet der Loop dagegen weitgehend hinter einem dichten, kontrapunktisch durchsetzten Orchesterarrangement. In der (späten) Doo Wop-Version der Marcels von 1961 schließlich wird der Loop einleitend zuerst vom (Vokal-)Bassisten und dann vom Satzgesang in einem mit dem Titelhook textierten Vamp deutlich exponiert und bleibt auch nach Einsatz des Leadgesangs präsent und beinahe gleichberechtigt zur Gesangsmelodie. ${ }^{62}$ Obwohl sich an der harmonischen und melodischen Substanz nichts Wesentliches geändert hat, hat sich doch das Verhältnis zwischen Melodie und Harmonik umgekehrt. Scheint sich in der Interpretation von Mel Tormé die (durch das Arrangement verschleierte) Harmonik aus der Sequenzierung der Phrase zu ergeben, so gibt bei den Marcels der präexistente Loop - »präexistent « ganz konkret in Form des vorangestellten Vamps ${ }^{63}$ -

62 Eine Vorstufe findet sich in der Aufnahme von Ivory Joe Hunter von 1951. Hier wird als Intro der Loop vom die Basslinie exponierenden Baritonsaxophon und nachschlagenden Akkorden des Saxophonsatzes vorangestellt. Als Background zum Gesang spielen die Bläser ein zweitaktiges Pattern, das die Loop-Harmonisierung unterstreicht.

63 Im bereits erwähnten Song »Oh What A Dream« von Ruth Brown (1954) geschieht dasselbe mit einer >Balladen-A-Zeile`, in dem der harmonische Verlauf 
den Klangraum vor, in dem sich die Melodie zu bewegen hat. Über den Akt der Komposition - ob also Richard Rodgers eine Phrase sequenziert und dann harmonisiert oder aber eine schon damals populäre harmonische Wendung mit einer eingängigen Melodie versehen hat - braucht hier nicht spekuliert zu werden.

Fand der I-vi-ii-V-Loop der Rhythm Changes auch in Neukompositionen des Doo Wop Verwendung, so schuf dieser sich mit einer kleinen Veränderung dieses Erfolgmodells sein eigenes, unverwechselbares Erkennungszeichen, die I-vi-IV-V-Formel. ${ }^{64}$ Der Grad der Identifizierung dieses Loops mit dem Stil selbst ist wohl nur vergleichbar mit dem Blues und eben diese Prominenz der Akkordfolge trug maßgeblich dazu bei, die acht Takte der AZeile in $4 \times 2$ Takte zu untergliedern und die Harmonik zum vorgegeben Gerüst zu machen, in die sich die Gesangslinie einzufügen hat. Nachdem die Vocal Harmony-Gruppen der 1940er Jahre und auch die frühen Doo WopFormationen noch mit unterschiedlichen harmonischen Abläufen (schweifende Tin Pan Alley-Harmonik, Blues-Topoi, einfache T-D-T-Perioden etc.) arbeiteten, kommen ab der Mitte der 1950er Jahre zahllose Doo Wop-Songs in ihren A-Teilen mit der bewussten Formel aus, die allenfalls in den letzten beiden Takten durch eine (häufig plagale) Kadenz aufgebrochen wird. ${ }^{65}$

\subsection{Titelhook und Refrain im Doo Wop}

Viele Doo Wop-Songs folgen dem Usus der Tin Pan Alley-Ballade, nach dem der Zeilenendrefrain identisch mit dem Titel ist bzw. diesen enthält. Andere jedoch suchen auf zwei Weisen die Wiedererkennbarkeit dieser nun wesent-

des Achttakters (I-IV-I-V) von den begleitenden Drifters in einem viertaktigen Intro vorgegeben wird.

64 Tatsächlich tendiert Tagg (2009: 205) dazu, diesen Loop lediglich als Variante aufzufassen, zumal durch die häufige Erweiterung der Dreiklänge nicht selten ein identisches Tonmaterial bei den fraglichen Klängen vorliege $\left(\mathrm{ii}^{7} \approx \mathrm{IV}^{6}\right)$, die sich dann snur < durch den Grundton unterschieden. Eine - auch genetische Verwandtschaft der beiden Formeln steht außer Frage, doch sprechen drei Gründe für die Eigenständigkeit der neuen Formel: [1] I-vi-ii-V kann Tin Pan Alley sein oder Jazz, I-vi-IV-V ist (sicher und ausschließlich) Doo Wop, [2] die neue Formel durchbricht die Quintfalllogik der alten, ersetzt eine Nebenfunktion durch eine Hauptfunktion und baut so die klare IV-V-I-Kadenz ein und [3] der neue Stil definiert sich eben nicht zuletzt durch die exponierte Bassführung, eine Änderung der Basslinie ist daher keineswegs akzidentiell.

65 Tagg (2009: 206) gibt an, er habe 137 Songs mit I-vi-ii-V- oder I-vi-IV-V-Loop in den Billboard Hot 100-Charts der Jahre 1957 bis 1963 gefunden, 57 davon führt er als Beispiele an. Als frühes Beispiel eines im A-Teil ganz mit dem I-vi-IV-VLoop auskommenden Doo Wop-Songs sei The Mello-Moods: »Where Are You (Now That I Need You) (1951) genannt. Komponiert wurde dieser Song ausgerechnet von dem vor allen als Broadway-Songwriter bekannten Frank Loesser. 
lich durch das Radio verbreiteten Musik zu steigern. Zum einen werden hier auch andere Möglichkeiten erprobt den Titel unterzubringen, zum anderen kommt neben dem Titelhook gelegentlich ein zweiter Refrain zum Einsatz. Ersteres wird durch die Textierung der für den Doo Wop typischerweise textlosen Lautsilben des Satzgesangs im Backgroundgesang oder im einleitenden Vamp erreicht. ${ }^{66}$ In Stücken, die dem R\&B näher stehen, wie etwa Leiber \& Stollers Bluesschema-Kompositionen »Mainliner (für Little Esther 1952), »Whadaya Want« (für Jack Cardwell 1955), »Smokey Joe's Cafe« (für The Robins 1955) und »Ruby Baby« (für The Drifters 1956) lässt der respondierende Background direkte Einflüsse der Bläserbehandlung im R\&B und Swing erkennen. Im eher poporientierten Doo Wop kommt die Textierung vor allem in einleitenden Vamps zur Anwendung und trägt so zusätzlich zur Merkbarkeit der Titel bei. Beispiele hierfür sind etwa »Adorable« der Drifters (Ram 1955), »Lily Maebelle« der Valentines (Briggs/Barrett 1955) und »Mary Lee« der Rainbows (Robinson/Robinson 1955). Der wohl prominenteste Vertreter für diese Methode ist der Song "Lollipop«, der in der Aufnahme der Chordettes 1958 eine Top Ten Crossover-Platzierung in den USamerikanischen Pop- und R\&B-Charts erreichte. ${ }^{67}$

Die Trennung von Refrain und Titelhook durch eine Art »Doppelrefrain« findet sich unter anderem im Song »Been So Long« der Pastels von 1958. Hier werden die beiden Refrainmodelle der Tin Pan Alley-Ballade kombiniert: Die A-Zeilen der AABA-Form beginnen mit dem - vom Backgroundchor wiederholten - Titelhook und enden mit der Refrainzeile »the blues are mine ${ }^{68}{ }^{68}$ Neben solch strengen Doppelrefrains tritt eine Variante auf, bei der einer der beiden »Refrains« variiert wird und dennoch als Refrain er-

66 Umgekehrt schaffen es die Lautsilben des Satzgesangs mitunter auch in den Titel: The Chords: »Sh-Boom« (Keyes/Feaster/Feaster/McRae/Edwards 1954), The Charms: »(Bazoom) I Need Your Loving « (Leiber/Stoller 1954), Lewis Lymon \& The Teenchords: »I'm So Happy (Tra-La-La-La-La-La)《 (Robinson 1956), The Edsels: »Rama Lama Ding Dong« (Jones 1957).

67 Tatsächlich ist der auf der halbtaktig wechselnden Doo Wop-Kadenz basierende, den Text »Lollipop, lollipop, ooh lolli-lolli-lolli« repetierende Satzgesang die eigentliche Substanz des Songs, der eine Rondoform aus jeweils achttaktigen Zeilen aufweist (»T« steht hier für den Titel-Vamp): T T A T B T A T T. Vor allem der typische harmonische Shift des B-Teils auf die IV. Stufe lässt hierbei das übliche AABA-Modell durchscheinen, auch wenn dieses einen seiner A-Teile an den eingängigen »Vamp-Refrain « abtreten musste.

68 Weitere Beispiele sind: The Moonglows: »Sincerely« (Fuqua 1954), Refrainende: »please, say you'll be mine«; The Danleers: »One Summer Night« (Webb 1958), Refrainende: »under the moon of love . Ein Sonderfall ist die Platzierung des Titelhooks am Anfang und am Ende der Zeilen: The Spaniels: "Goodnite, Sweetheart, Goodnite « (Carter/Hudson 1953) und Norman Fox \& The Rob Roys: »Tell Me Why« (Martinée 1957). 
kennbar ist. So beginnt jede A-Zeile des Songs »Devil Or Angel« der Clovers (Carter 1956) mit dem Titelhook, während die Zeilenenden trotz variierten Texts deutlichen Refraincharakter aufweisen:

A1: »Devil or angel [...] I miss you, I miss you, I miss you. «

A2: »Devil or angel [...] I need you, I need you, I need you.« [Bridge]

A3: »Devil or angel [...] I love you, I love you, I love you.«

Der umgekehrte Fall liegt etwa bei Sam Cookes »You Send Me« (Paul/Townsend/Cooke 1957) vor. Hier wird der Titelhook in A2 variiert, der Refrain lautet gleichbleibend »Honest you do .

\section{Die Refrainzeile wird zum eigenständigen Chorus}

Ohne Refrainzeilen kommt die AABA-Form also nicht aus: sie stiften Einheit, verbinden bei der Wiederholung des A-Teils die Prinzipien Variation und Wiederholung, sorgen für Eingängigkeit und Wiedererkennbarkeit und sie geben dem Song ein leicht erinnerbares Label, damit der Kunde im Geschäft weiß, wonach er suchen oder fragen muss. Diese Vorteile des Refrains machten sich Songwriter (nicht nur innerhalb der AABA-Form) innerhalb unseres Untersuchungszeitraums mehr und mehr zunutze, wie dieses Kapitel zeigen wird. So wurde die Refrainzeile im Laufe der 1950er Jahren immer weiter ausgebaut und erweitert, bis daraus ein eigenständiger Chorus innerhalb der AABA-Form wurde (Abschnitt 4.2). Ein entscheidender Anstoß für diese Entwicklung ist im Blues und insbesondere Rhythm \& Blues zu sehen, wo schon zuvor umfangreichere Refrains in Bluesschemata integriert worden waren (Abschnitt 4.1).

\subsection{Vom Refrain zum Chorus im Blues-Schema}

Blues folgen überwiegend einer »simple verse«- oder AAA-Großform. Die einzelnen A-Teile gliedern sich dabei in unterschiedlichste Akkord- und Textschemata, die im Detail zu betrachten hier nicht der Raum ist. Die heute prominenteste Harmoniefolge, das zwölftaktige Bluesschema, findet sich vor allem im Band-Kontext, wo weniger Spontaneität möglich ist und Absprachen bezüglich des formalen Ablaufs getroffen werden müssen; Solisten variieren dagegen reichlich, auch innerhalb eines Songs (vgl. z. B. das Formschema zu »Blue Yodel No. 1«, S. 96. Auch zur aab-Organisation von 
Text und Gesangsmelodik, die heute am engsten mit dem Blues assoziiert ist, gab und gibt es zahlreiche Alternativen. Während beim aab-Textschema der Text in jedem A-Teil unterschiedlich ist, gibt es unter den frühen BluesAufnahmen auch acht-, zehn-, zwölf- oder 16-taktige Formen mit Refrain (achttaktig z.B. »Papa's Lawdy Lawdy Blues«, Papa Charlie Jackson 1924; »Sitting On Top Of The World«, Mississippi Sheiks 1930). Die für unseren Kontext einflussreichste Variante ist ein Modell, in dem sich der Songtext nur jeweils in den ersten vier Takten der A-Teile verändert und über die Takte 5 bis 12 ein Refrain gesungen wird. Der zwölftaktige harmonische Rahmen bleibt dabei unverändert. Nach dem gleichnamigen Hokum-Blues von Tampa Red und Georgia Tom (1928) wird dieser Ablauf als »Tight Like That-Modell« bezeichnet (Middleton 2003: 504), obwohl das Modell schon früher, in Papa Charlie Jacksons »Shake That Thing « (Jackson 1925) auftritt. Durch den großen Erfolg des Originals und zahlloser Coverversionen verbreitete sich das Model rasant. ${ }^{69}$

\begin{tabular}{|l|l|l|l|l|l|l|l|l|l|l|l|l|l|}
\hline & & \multicolumn{3}{|c|}{ Verse-artig } & \multicolumn{1}{|c|}{ Refrain } \\
\hline $\begin{array}{l}\text { »It's Tight } \\
\text { Like That« }\end{array}$ & $\begin{array}{l}\text { Tampa Red \& } \\
\text { Georgia Tom (1928) }\end{array}$ & I & I & I & I & IV & IV & I & I & V & V*5 & I & I \\
\hline
\end{tabular}

Verse:

Listen here, folks, I'm gonna sing a little song;

Don't get mad, we don't mean no harm.

Refrain:

You know, it's tight like that, beedle-um-bum,

Boy, it's tight like that, beedle-um-bum,

Don't you hear me talkin' to you?

I mean, it's tight like that. ${ }^{70}$

69 Allein die Originalversion soll sich Shaw (1983: 12) zufolge 750.000-fach verkauft haben, weitere Verbreitung fand das Modell durch vier weitere Versionen von Tampa Red sowie durch Adaptionen u.a. von Jimmie Noone (»Tight Like That« 1928), McKinney's Cotton Pickers (»It's Tight Like That« 1928), Walter Barnes' Royal Creolians (»It's Tight Like That« 1928), Lonnie Johnson \& Spencer Williams (»It Feels So Good « Parts 1 bis 4, alle 1929), Cow Cow Davenport \& The Southern Blues Singers (»lt's Tight Like That «1929), Alura Mack (»Loose Like That « 1929), Slim Barton \& Eddie Mapp (»It's Tight Like That« 1929), Jim Jackson (»Hey, Mama, It's Nice Like That « 1929), Clara Smith (»Tight Like That « 1929, und »What Makes You Act Like That «1930), Bogus Ben Covington aka Ben Curry (»It's Tight Like That «1929), Charlie McKoy (»It's Hot Like That« 1930) sowie Ed Bell ( $\gg 1$ Don't Like That « 1930).

70 Eigene Transkription der ersten Aufnahme vom 24. Oktober 1927. Die vier späteren Aufnahmen bringen bei gleich bleibendem Refrain andere Verszeilen. 
Ausgehend vom Blues findet sich das Tight Like That-Modell im Jump Blues bzw. Rhythm \& Blues der 1940er und 1950er Jahre (Sister Rosetta Tharpe: »That's All«,1941; Louis Jordan: »Caldonia« 1945), aber auch im Western Swing (z.B. Bob Wills and His Texas Playboys: „What's The Matter At The Mill«, die Coverversion eines Memphis Minnie \& Kansas Joe-Songs 1930) und im Country (Hank Williams: »Move It On Over«,1947; Hank Snow: »l'm Moving On« 1950).

Im Rhythm \& Blues und später im Rock'n'Roll sind drei Modifikationen des Tight Like That-Modells sehr populär, die alle dazu beitragen, Verse und Refrain stärker voneinander abzusetzen:

- Erstens wird der Verse-Teil auf acht und das gesamte Schema damit auf insgesamt 16 Takte erweitert; der Refrain beginnt, wie gewohnt, mit dem Wechsel zur vierten Stufe, der dann in Takt 9 erfolgt. Zwar wird dabei der Verse und nicht der Refrain verlängert, doch dürfte diese Ausweitung Einfluss auf die spätere Eigenständigkeit und Trennung beider Formteile gehabt haben. Frühe Beispiele für dieses Vorgehen finden sich schon 1929 in Clara Smiths »Tight Like That«-Version sowie im Song »Dirty Butter« der Memphis Jug Band, bei dem die Refrains zudem chorisch gesungen und die Verse-Parts teilweise durch Stop Time abgesetzt werden. Neben dem achttaktigen Verse-Teil finden sich später auch zwölftaktige (Ray Charles' »Greenbacks«, Charles/Richard 1954) oder von Verse zu Verse zunehmende Längen (z.B. 8, 10 und 16 Takte in Willie Mabons »| Don't Know«,1952; auffällig ist hier die vollständige Unterbrechung des Metrums, bevor der Refrain einsetzt). Chuck Berry weitet den Verse-Teil später durchgängig auf 16 Takte aus, bevor das Bluesschema fortgesetzt wird und der Refrain beginnt (»No Money Down« 1956). Von Verse zu Verse zunehmende Längen weist auch sein »You Can't Catch Me« (1955) auf, dessen dritter Verse dann volle 48 Takte in Anspruch nimmt, bevor der Refrain einsetzt.

- Die zweite Modifikation betrifft nur den einleitenden A-Teil eines Songs: Um den Refrain besonders deutlich herauszustellen, wird er zu Beginn als Intro-Chorus gesungen. Erst ab dem zweiten Durchgang erhalten die Takte 1-4 durch wechselnden Text dann Verse-Charakter. Bereits Charley Pattons »Going To Move To Alabama« (1929) nutzt diesen Trick, indem Patton über die ersten vier Takte des Songs nicht singt, um dann in Takt 5 mit dem Refrain zu beginnen. »Whiskey Head Woman« von Tommy McClennan (1939) und »Rock Me Mama« von Arthur Crudup (1944) sind Beispiele für Songs, in denen der Text des Refrains im einleitenden 
A-Teil über alle zwölf Takte gesungen wird. Auch dies trägt zur Eigenständigkeit und späteren Abspaltung des Refrains vom Verse bei.

- Drittens wird die Trennung in Verse- und Refrain-Teil nicht selten dadurch verstärkt, dass die Verse-Takte in Stop Time gespielt werden so bereits in Clara Smiths »Tight Like That « und »Dirty Butter « der Memphis Jug Band, besonders häufig dann im Jump Blues, R\&B und Chicago Blues, z.B. in Sister Rosetta Tharpes »That's All« (1941), Lionel Hamptons »Hey! Ba-Ba-Re-Bop« (1946), Willie Mabons Answer-Song »l'm Mad« (1953) und Willie Dixons »Hoochie Coochie Man« (1954).

Alle drei Varianten kombinieren Arthur Crudup in seiner 1946er Aufnahme von »That's All Right« und Gene Vincent in »Be-Bop-A-Lula« (Vincent/ Graves 1956).

Parallel wurden im Country Möglichkeiten jenseits des Tight Like ThatModells gefunden, das Bluesschema mit einem Refrain zu kombinieren. Während die eben angeführten Beispiele den Refrain in das 12- bzw. 16taktige Bluesschema integrieren, wird in folgenden Beispielen erst nach Abschluss des Bluesschemas ein Refrain angehängt:

\begin{tabular}{|l|c|c|c|c|c|c|c|c|c|c|c|c|c|c|c|c|c|c|c|}
\hline & \multicolumn{10}{|c|}{} & \multicolumn{10}{|c|}{$\begin{array}{c}\text { Yodel- } \\
\text { Refrain }\end{array}$} \\
\hline \begin{tabular}{l}
\hline No. 1 \\
No
\end{tabular} & $\begin{array}{c}\text { Jimmie } \\
\text { Rodgers } \\
(1927)\end{array}$ & I & I & I & I & IV & IV & I & I & $V^{7}$ & $V^{7}$ & $V^{7}$ & $V^{7}$ & I & I & I & V & I & I \\
\hline & & 1 & 2 & 3 & 4 & 5 & 6 & 7 & 8 & 9 & 10 & 11 & 12 & 13 & 14 & 15 & 16 & 17 & 18 \\
$6 / 4$
\end{tabular}

\begin{tabular}{|l|c|c|c|c|c|c|c|c|c|c|c|c|c|c|c|c|}
\hline & & \multicolumn{1}{|c|}{ Verse-artig } & \multicolumn{3}{c|}{ Refrain } \\
\hline »TB Blues & $\begin{array}{c}\text { Jimmie } \\
\text { Rodgers } \\
(1931)\end{array}$ & I & I & $I^{7}$ & $I^{7}$ & IV & IV & I & I & $V^{7}$ & $V^{7}$ & I & I & V & I & I \\
\hline & & 1 & 2 & 3 & 4 & 5 & 6 & 7 & 8 & 9 & 10 & 11 & 12 & 13 & 14 & 15 \\
\hline
\end{tabular}

\begin{tabular}{|c|c|c|c|c|c|c|c|c|c|c|c|c|c|c|c|c|c|c|c|}
\hline & & \multicolumn{12}{|c|}{ Verse } & \multicolumn{6}{|c|}{ Refrain/Chorus } \\
\hline $\begin{array}{l}\text { "Long Gone } \\
\text { Lonesome } \\
\text { Blues« }\end{array}$ & $\begin{array}{c}\text { Hank } \\
\text { Williams } \\
(1950)\end{array}$ & I & I & 1 & I & $\mathrm{IV}^{7}$ & $\mathrm{IV}^{7}$ & I & I & $v^{7}$ & $\mathrm{~V}^{7}$ & 1 & I & 1 & IV & 1 & $V^{7}$ & I & I \\
\hline & & 1 & 2 & 3 & 4 & 5 & 6 & 7 & 8 & 9 & 10 & 11 & 12 & 13 & 14 & 15 & 16 & 17 & 18 \\
\hline
\end{tabular}

Es sind dies offenbar Zwitter-Formen, die sich bemühen, die in der Country Music (anders als im Blues) seit jeher stark verbreitete Verse/Chorus-Form mit dem Bluesschema zu verknüpfen. Überhaupt verdanken sich Vielfalt und 
Innovation im Bereich der Songformen stark der Begegnung und gegenseitigen Beeinflussung »schwarzer« und »weißer «, ruraler und urbaner Musiken, die allen puristischen Bestrebungen zum Trotz den US-amerikanischen Alltag prägten: in Minstrel- und Vaudeville-Shows, durch die Dominanz der Tin Pan Alley-Songs im Radio und in reisenden Shows, durch das enge Zusammenleben von schwarzen und weißen Musikern im Süden der USA, durch Migrationen von schwarzen Musikern und Musikhörern in die Städte des Nordens und durch die Verbreitung von Blues und Country durch Schallplatten und Radios. So verwundert es nicht, dass auch die »weißeste « Songform - AABA - mit der »schwärzesten« Binnengliederung - dem Bluesschema - verschmolzen wurde. Und dies von weißen Musikern ebenso wie von Schwarzen: andeutungsweise etwa in »That's The Stuff You Gotta Watch (Buddy \& Ella Johnson 1944) und »Route 66« (Troup 1946) bzw. konsequent ausgeführt (d.h. mit stärker kontrastierendem B-Teil) in »Chattanoogie Shoe Shine Boy« (Stone/Stapp), dessen formaler Crossover 1950 in der Interpretation von Red Foley auch mit einem kommerziellen Crossover-Erfolg, nämlich ersten Plätzen in den Billboard Pop- und Country-Charts einher ging sowie in der R\&B-Nr. 1 »One Mint Julep« (Toombs 1952) der Clovers.

\begin{tabular}{|c|c|c|c|c|c|c|c|c|c|c|c|c|}
\hline \multicolumn{13}{|c|}{ »One Mint Julep« (Toombs 1952; Bridge und $\mathrm{A}^{3}$ werden variiert wiederholt) } \\
\hline & & & & & & & & & \multicolumn{4}{|c|}{ Refrain } \\
\hline$A^{1}$ & $\mathrm{I}^{7}$ & $\mathrm{IV}^{7}$ & $\mathrm{I}^{7}$ & $\mathrm{I}^{7}$ & IV & $\mathrm{IV}^{7}$ & $1^{7}$ & $1^{7}$ & $\mathrm{~V}^{7}$ & $\mathrm{~V}^{7}$ & $1^{7}$ & $\mathrm{ii}^{7}-\mathrm{V}^{7}$ \\
\hline$A^{2}$ & $\mathrm{I}^{7}$ & IV & $\mathrm{I}^{7}$ & $\mathrm{I}^{7}$ & $\mathrm{IV}^{7}$ & $\mathrm{IV}^{7}$ & $\mathrm{I}^{7}$ & $1^{7}$ & $\mathrm{~V}^{7}$ & $\mathrm{~V}^{7}$ & I & 1 \\
\hline Bridge & III & III & blll & blll & II & II & V & V & & & & \\
\hline$A^{3}$ & $1^{7}$ & IV & $\mathrm{I}^{7}$ & $\mathrm{I}^{7}$ & $I V^{7}$ & $\mathrm{IV}^{7}$ & $\mathrm{I}^{7}$ & $1^{7}$ & $V^{7}$ & $V^{7}$ & I & I \\
\hline
\end{tabular}

In den frühen 1950er Jahren erreichte die Vielfalt an Songformen eine neue Qualität und zwar namentlich in den Stücken der weißen, jüdischen, urbanen Songwriter Jerry Leiber und Mike Stoller, die sie gezielt für afroamerikanische Interpreten produzierten. Ihr Interesse galt zunächst ausschließlich der black music (»We were two guys looking to write songs for black artists with black feelings in black vernacular «, Leiber/Stoller 2009: 94f.). Entsprechend verwendeten sie für ihre ersten Songs ein breites Repertoire verschiedener Bluesmodelle: zwölftaktige Bluesschemata ohne Refrain, mit Refrain ab Takt 5 oder ab Takt 9 sowie 16 -taktige Schemata mit Refrain ab Takt 9: 


\begin{tabular}{|c|c|c|}
\hline 迹 & $\begin{array}{l}A=12 \text {-taktiges Bluesschema, } \\
\text { ohne Refrain }\end{array}$ & $\begin{array}{l}\text { »Real Ugly Woman« (1951) } \\
\text { »Gloom \& Misery All Around« (1951) } \\
\text { »Mainliner« (1952) } \\
\text { »Lovin' Jim« (1952) }\end{array}$ \\
\hline & $\begin{array}{l}\text { A=12-taktiges Bluesschema, } \\
\text { Refrain ab Takt } 5 \\
\text { (Tight Like That-Modell) }\end{array}$ & $\begin{array}{l}\text { »Hard Times« (1952) } \\
\text { »Wailin' Daddy« (1952) } \\
\text { »Flesh, Blood And Bones« (1952; erstes A als } \\
\quad \text { Intro-Chorus) } \\
\text { »Kansas City« (1952; Ref nur im 1.,3. und 5. A- } \\
\quad \text { Teil) }\end{array}$ \\
\hline & $\begin{array}{l}\mathrm{A}=12 \text {-taktiges Bluesschema, } \\
\text { Refrain ab Takt } 9\end{array}$ & »That's What The Good Book Says« (1951) \\
\hline & $\begin{array}{l}A=16 \text {-taktiges Bluesschema, } \\
\text { Refrain ab Takt } 9\end{array}$ & $\begin{array}{l}\text { »Nosey Joe« (1952) } \\
\text { »Riot In Cell Block \#9« (1954, mit Stop Time) } \\
\text { »Jailhouse Rock« (1957, mit Stop Time) } \\
\text { »I'm A Hog For You« (1959, erstes A als Intro- } \\
\text { Chorus) }\end{array}$ \\
\hline & $\begin{array}{l}A=32 \text {-taktiges Bluesschema, } \\
\text { Refrain ab Takt } 17\end{array}$ & »Searchin'« (1957) \\
\hline
\end{tabular}

Tabelle 3: Unterschiedliche Bluesschemata und Refrainanteile in Songs von Leiber/ Stoller

In »Riot In Cell Block \#9 « wird der durch Stop Time erzielte Kontrast von Verse- und Refrain-Part noch gesteigert, indem die Verse-Zeilen gesprochen, die Refrainzeilen dagegen chorisch gesungen werden. Die Trennung ist so deutlich, dass man den Refrain auch als eigenständigen Formteil, als Chorus, ansehen kann. Leiber und Stoller selbst bezeichnen die Formteile entsprechend: »The chorus was sung by all the Robins, but the verses were spoken« (Leiber/Stoller 2009: 70). Zugleich sorgt die Integration beider Formteile in ein gemeinsames 16-taktiges Bluesschema für Einheit.

Neben diesen Tight Like That-Formen und ihren drei Modifikationen erprobten Leiber und Stoller noch weitere Möglichkeiten, den Refrain innerhalb des Bluesformats herauszustellen. »Nosey Joe« (1952) verdoppelt den Abschnitt der Takte 5-8 des konventionellen Bluesschemas, sodass eine 16taktige Form entsteht. ${ }^{71}$ Dabei bilden die ersten acht Takte den narrativen, paargereimten Verse. Auch bei diesem Song wirken die Takte 9 bis 16 vorbereitet durch Stop Time in Takt 7 und 8 - mit Background-Gesang, unverändertem Text und Nennung der Titelzeile eher als eigenständiger Chorus denn als Refrain.

71 Der gleiche 16-taktige Harmonieverlauf findet sich bereits in »Midnight Blues « (William (Bill) Moore 1928, allerdings ohne Refrain) und »Try Me One More Time« (Marshall Owens 1931, mit Refrain ab Takt 5). 


\begin{tabular}{|c|c|c|c|c|c|c|c|c|c|c|c|c|c|c|c|c|c|}
\hline \multicolumn{2}{|c|}{} & \multicolumn{5}{c|}{ Verse } & \multicolumn{5}{c|}{ Refrain / Chorus } \\
\hline$\gg$ Nosey Joe & $\begin{array}{c}\text { Leiber/Stoller } \\
(1952)\end{array}$ & I & I & I & I & IV & IV & I & I & IV & IV & I & I & V & V & I & I \\
\hline
\end{tabular}

Eindeutige Verse/Chorus-Formen gibt es bei Leiber und Stoller allerdings recht selten: "The Chicken And The Hawk 1955 für Big Joe Turner geschrieben, bleibt durchgängig beim 12-taktigen Bluesschema, nutzt dieses aber - wie zuvor schon Turners Hit »Shake, Rattle And Roll« (Calhoun 1954) sowohl für den Verse als auch für den Chorus (in Covach's Terminologie ergibt sich eine »simple verse/chorus«-Form). Der Verse folgt dem aab-Textformat, der Chorus setzt sich durch den mehrfach chorisch wiederholten Refrain »up, up, and away « ab. ${ }^{72}$ Vollständig vollzogen ist die Trennung in Verse und (mehr oder weniger kontrastierenden) Chorus auch bei »I Want To Do More« (für Ruth Brown 1955). Der achttaktige Verse in Stop Time lässt zunächst eine Tight Like That-Variante erwarten, es folgt dann aber der vollständige 16-taktige Chorus, mit dem das Stück auch eröffnet wurde:

\begin{tabular}{|c|c|c|c|c|c|c|c|c|c|c|c|c|c|c|c|c|c|c|c|c|c|c|c|}
\hline & & \multicolumn{7}{|c|}{ Verse } & \multicolumn{15}{|c|}{ Chorus } \\
\hline $\begin{array}{l}\text { »I Want } \\
\text { To Do } \\
\text { More« }\end{array}$ & $\begin{array}{l}\text { Leiber/ } \\
\text { Stoller } \\
\text { (1955) }\end{array}$ & I & & $1 \mid 1$ & 1 & 1 & $\begin{array}{l}\dot{\check{C}} \\
\end{array}$ & بُ & 1 & V & I & I & I & I & V & V & I & I & IV & IV & I V V & 1 & I \\
\hline
\end{tabular}

\subsection{Vom Refrain zum Chorus innerhalb der AABA-Form}

Die AABA-Form setzten Leiber und Stoller zunächst nur selten und ausschließlich für langsame Balladen ein. »Love Me« war 1953 vermutlich der erste Song, für den sie auf die bis dahin gemiedene AABA-Form zurückgriffen. Der Grund war offenbar ein ironischer: »Actually we'd written it as a parody of a corny hillbilly ballad« (Leiber/Stoller 2009: 105) - und für diese Pastiche bot sich die AABA-Form an. Doch das Stück wurde von zahlreichen schwarzen wie weißen Interpreten erfolgreich gecovert und so boten sie es - »corny or not« (ebd.) - halb im Scherz auch Elvis Presley an,

72 Bezeichnend ist, dass Turner seinen »Shake, Rattle And Roll «-Chorus erst hinter dem dritten Verse bringt, während die ungleich erfolgreichere Version des weiBen Bill Haley (ebenfalls 1954) inn gleich nach dem ersten und zweiten Verse vorstellt. Bei Leiber/Stoller findet sich diese »simple verse/chorus «-Form zuvor schon in »Hound Dog « (1952) und »Yeah, Yeah, Yeah« (1954). Das Prinzip, Verse und Chorus über das gleiche Akkordschema zu singen, war in Folk-Balladen schon lange vorher nichts Ungewöhnliches (etwa »Ain't It Hard«, Guthrie 1940), auch im frühen Doo Wop ist es, nun in Verbindung mit dem Bluesschema, zu finden (The Ravens: »Bye Bye Baby Blues«, Biggs 1946; ohne Bluesschema: The Larks: »I Ain't Fattening Frogs For Snakes«, Perryman/Snead 1951). 
der damit 1956 Top 10-Platzierungen in den Pop- und den R\&B-Charts erreichte.

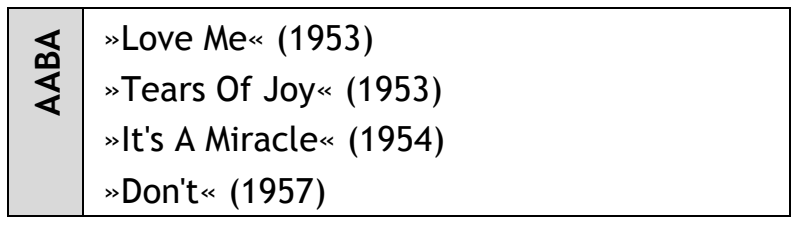

Tabelle 4: Leiber/Stoller-Stücke im AABA-Format

Die AABA-Form war also nachweislich geeignet für das Bemühen, Hits zu erzielen, die sich nicht auf eine schwarze Käuferschaft beschränkten. Dies mag ein Grund gewesen sein, warum Leiber und Stoller nach der anfänglichen Konzentration auf unterschiedlich gegliederte AAA-Formen Mitte der 1950er begannen, auch für schnellere R\&B-Songs Bridges zu komponieren. Als A-Teile setzten sie dabei gern die etablierten Blues-Binnengliederungen ein, sodass sie (wie Stone und Stapp einige Jahre zuvor im Country) R\&Bund Pop-Songformen miteinander verbanden:

\begin{tabular}{|l|l|l|}
\hline \multirow{2}{*}{$\begin{array}{l}\text { A=14-takt. Bluesschema } \\
\text { mit Refrain ab T. 9 }\end{array}$} & »Bazoom (I Need Your Lovin')« (1954) \\
\cline { 2 - 3 } $\begin{array}{l}\text { A=12-takt. Bluesschema } \\
\text { ohne Refrain }\end{array}$ & »Smokey Joe's Café« (1955) \\
\cline { 2 - 3 } $\begin{array}{l}\text { A=12-takt. Bluesschema, } \\
\text { Chorus ab T. 5 }\end{array}$ & »Charlie Brown« (1959) \\
\hline
\end{tabular}

Tabelle 5: AABA/Bluesschema-Kombinationen in Songs von Leiber/Stoller

Die verschiedenen Bluesschemata waren nur eine Möglichkeit der Ausfüllung des A-Teils. In ihren größten kommerziellen Erfolgen, vor allem den Songs für The Coasters, setzten Leiber und Stoller stattdessen auf A-Teile, die in der Harmonik zwar klar Blues-beeinflusst waren, sich aber zumindest für den abgesetzten Refrain zunehmend vom Bluesschema entfernten. Ein erster Versuch in diese Richtung war »Ten Days in Jail« (The Robins 1954), dessen A-Teil aufgrund der typischen Akkordwechsel (s. Tabelle 6) zunächst ein 12-taktiges Bluesschema erwarten lässt; statt des Wechsels zur V. Stufe in Takt 9 folgen dann aber weitere Takte auf der I. Stufe, die durch das wiederholte chorische Singen der Titelzeile Refrain-Wirkung erhalten. Ähnlich funktionieren »Bazoom (I Need Your Lovin')« - mit der weißen Band »The Cheers « Leiber/Stollers erste Nr. 1 in den Pop-Charts - sowie die für Elvis Presley geschriebenen Songs »Treat Me Nice und »(You're So Square) Baby I Don't Care « (beide 1957, s. Tabelle 6). Den Verse-Parts, die nur 
zwischen I. und IV. Stufe wechseln, stellen sie dabei kontrastierende Refrain-Parts mit größerer harmonischer Bewegung gegenüber. Die Nennung des Songtitels fällt jeweils mit dem schlussbildenden Erreichen der I. Stufe zusammen.

\begin{tabular}{|c|c|c|c|c|c|c|c|c|c|c|c|c|c|c|}
\hline & \multicolumn{8}{|c|}{ Verse-artig } & \multicolumn{6}{|c|}{ Refrain } \\
\hline $\begin{array}{l}\text { »en Days In Jail« } \\
\text { (1954) }\end{array}$ & I & 1 & I & 1 & IV & IV & I & 1 & 1 & I & I & V & & \\
\hline $\begin{array}{l}\text { "Bazoom (I Need } \\
\text { Your Lovin')《 } \\
(1954)\end{array}$ & I & I & I & 1 & $\mathrm{IV}^{7}$ & $\mathrm{IV}^{7}$ & I & 1 & $\begin{array}{l}\text { V-bV- } \\
\text { IV-bV }\end{array}$ & $\begin{array}{l}\text { V-bV- } \\
\text { IV-iii }\end{array}$ & I & V & I & $\mathrm{V}^{7}$ \\
\hline $\begin{array}{l}\text { »Baby I Don't Care« } \\
(1957)\end{array}$ & I-IV & I & I-IV & I & I-IV & I-IV & I-IV & 1 & IV & V & I & I & & \\
\hline $\begin{array}{l}\text { »Treat Me Nice } \\
(1957)\end{array}$ & I & I & I & I & IV & IV & IV & $\# i v^{\circ} 7$ & V & I & ii & V & I & I \\
\hline
\end{tabular}

Tabelle 6: Beispiele für A-Teile mit Refrain in AABA-Songs von Leiber/Stoller

Noch deutlicher exponierte Refrains und größere Entfernung vom Bluesschema weisen die Coasters-Songs »Down In Mexico (1956), »Young Blood« (Leiber/Stoller/Pomus 1957), »Poison Ivy« und »Love Potion No. 9« (beide 1959) auf. In den ersten acht Takten ihrer A-Teile wird jeweils die Erzählung vorangetrieben; harmonisch verbleiben sie größtenteils auf der I. Stufe. Es folgen jeweils acht weitere Takte mit größerer harmonischer Bewegung, in denen die ganze Band wiederholt den Songtitel singt. Besonders deutlich wird dieser Part in »Young Blood« abgesetzt, indem alle Instrumente zuvor für zwei Takte pausieren; zudem tritt im Refrain als zusätzliches Instrument das Saxophon hinzu. Bei »Poison Ivy« wird für den kontrastierenden Refrain in die parallele Moll-Tonart gewechselt. Diese Teile sind bereits mit gleichem Recht als eigenständige Choruses anzusehen, die AABA-Form bleibt dabei immer noch deutlich wahrnehmbar. ${ }^{73}$ Ausgehend vom Bluesschema finden Leiber und Stoller hier eine - in Abgrenzung zur schweifenden Harmonik der Tin Pan Alley-Ballade, den Doo WopLoops und dem doppelten Turnaround der R\&B-Ballade - vierte Gestaltungsweise für den A-Teil. Die erste Stufe ist hier nicht mehr »Tonika« im Sinne eines tonalen Zentrums, von dem die harmonische Bewegung ausgeht

73 Nach einem ähnlichen Muster erhalten kurz darauf auch die Songs anderer Songwriter sechs-, acht- und zehntaktige Refrains innerhalb der AABA-Form, etwa »A Lover's Question« (Benton/Williams 1958), »Please Don't Touch« (Kidd/ Robinson 1959), »Angel Face« und »Hushabye (beide Pomus/Shuman 1959), "Save The Last Dance For Me« und »Hound Dog Man« (beide Pomus/Shuman 1960) sowie »Kiddio« (Benton/Otis 1960). 
und zu dem sie zurückkehrt, sondern eher ein harmonisches »Null-Niveau«, von dem sich »das Andere durch harmonisches Abheben unterscheidet.

\begin{tabular}{|c|c|c|c|c|c|c|c|c|c|c|c|c|c|c|c|c|}
\hline & \multicolumn{8}{|c|}{ Verse-artig } & \multicolumn{8}{|c|}{ Refrain / Chorus } \\
\hline $\begin{array}{l}\text { »Down In } \\
\text { Mexico« (1956) }\end{array}$ & $\mathrm{i}$ & $\mathrm{i}$ & $\mathrm{i}$ & $\mathrm{i}$ & $\mathrm{i}$ & $\mathrm{i}$ & V & V & $i$ & $\mathrm{i}$ & iv & iv-i & $i$ & iv & iv & $\mathrm{i}$ \\
\hline $\begin{array}{l}\text { »Young Blood « } \\
(1957)\end{array}$ & 1 & I & I & I & I & 1 & I & 1 & IV & IV & 1 & 1 & IV & IV & V & V \\
\hline $\begin{array}{l}\text { Poison Ivy« } \\
\text { (1959) }\end{array}$ & 1 & I & I & I & 1 & 1 & I & 1 & vi & vi & $\mathrm{III}^{7}$ & $\mathrm{III}^{7}$ & vi & ii & vi & $V^{7}$ \\
\hline $\begin{array}{l}\text { "Love Potion } \\
\text { No. } 9 \ll(1959)\end{array}$ & & & & & & & & $v$ & III & III & iv & V & $\mathrm{i}$ & $\mathrm{i}$ & & \\
\hline
\end{tabular}

Tabelle 7: A-Teile mit Refrains bzw. Choruses in AABA-Songs von Leiber/Stoller

Die Ausdifferenzierung der A-Teile bei Leiber und Stoller korrespondiert in einigen Stücken mit einer Aufwertung der sonst den A-Teilen bzw. den Verse/Chorus-Paaren untergeordneten Bridge zum »narrative climax«, zum Höhepunkt der in ihren »Mini-Dramen« (»playlets«) erzählten Geschichten, etwa in »Smokey Joe's Cafe« (1955), »Down In Mexico« (1956) und »Little Egypt « (1961; s. Covach 2010: 7, Covach bezeichnet diese Form daher als »dramatic AABA form«).

1957 waren Leiber und Stoller mit elf, 1959 mit zwölf Hit-Singles in den Pop-Charts und zahlreichen weiteren Platzierungen in den R\&B-Charts die erfolgreichsten Songwriter der USA (Emerson 2005: 1 u. 63). Selbstverständlich waren für diese Crossover-Erfolge neben wichtigen außermusikalischen Faktoren auch der humorvolle und kreative Umgang mit Sprache, die Instrumentierung, Harmonik, Melodik etc. wichtig. Doch bereits auf der formalen Ebene, auf die wir uns hier konzentrieren, lassen sich mit der starken Betonung von Refrains bzw. Choruses und der größtmöglichen Verschmelzung »schwarzer« und »weißer« Formmodelle Erklärungsansätze für die große Popularität der Leiber/Stoller-Songs finden. Ökonomische Interessen spielten bei dieser Verschmelzung gewiss eine Rolle:

»No matter how much they prided themselves on being >race they identified with white teenagers, they recognized rhythm \& blues was beginning to appeal to a larger audience that it would be folly to ignore especially as they began to settle down and assume adult responsibilities. They had a record company to run, partners to please [...], pressing plants to pay, and distributors to dun [...]. Leiber and Stoller's greatest contribution to Atlantic Records was to make black music more alluring to white kids, and to help make the transition from an R\&B-specialty label to a rock ' $n$ ' roll powerhouse. Leiber 
and Stoller staddled and synthesized both strains of music« (Emerson 2005: $13 \mathrm{u}$. 15).

Mit der Erweiterung des Refrains zum Chorus im Rahmen von Blues-basierten AAA-Formen und der Übertragung dieser Idee auf die AABA-Form legten Leiber und Stoller den Grundstein für die bis heute populäre Kombination aus Versen, Choruses und Bridges.

Zu Beginn der 1960er übernahmen dann andere Songwriter die in Songs wie »Poison Ivy« vorgenommene starke Trennung von Verse und Chorus innerhalb der AABA-Form, sodass sich die Großform Verse - Chorus - Verse - Chorus - Bridge - Verse - Chorus ergab. Dass diese Struktur sich aus der AABA- und nicht etwa aus der Verse/Chorus-Form entwickelt hat, erscheint abgesehen von der dargestellten Formengeschichte auch deshalb plausibel, weil sich die frühen Beispiele stets exakt an diese Abfolge der Formteile halten (und nicht etwa ein oder drei Verse/Chorus-Paare vor der Bridge bringen, s. Tabelle 8 auf S. 104). Erst später beginnen einige Songs (wie zuvor im R\&B) direkt mit dem Chorus oder sie wiederholen ihn nach der Bridge ein zusätzliches Mal, bevor ein weiteres Verse/Chorus-Paar folgt - wodurch seine neu gewonnene Eigenständigkeit als Formsegment noch deutlicher wird. Diese Varianten finden sich bei Leiber und Stoller noch nicht, sondern erst bei ihren etwas jüngeren Kollegen aus dem Brill Building-Umfeld (wo man sie als Vorbilder verehrte) und dann vor allem in England.

Die AABA-Form ist in den meisten dieser Beispiele nur noch auf dem Papier zu erkennen und wird kaum als solche wahrgenommen. Der ehemalige B-Teil wird dabei zum C-Teil, doch die bis heute geläufige Bezeichnung Bridge verweist auf die Abstammung dieses Formteils aus der Popular Song Form. Englische Bands nannten ihn dagegen häufiger »Middle Eight « gleich, wie viele Takte er tatsächlich umfasst. ${ }^{74}$ Der Begriff »Middle Eight « hat dabei den Vorteil, dass er nicht in zwei verschiedenen Bedeutungen verwendet wird: Als Bridge wird häufig nämlich auch der Formteil PreChorus bezeichnet ${ }^{75}$, der freilich eine ganz andere, viel jüngere Geschichte hat.

74 »We used to call everything a middle eight, even if it had thirty-two bars or sixteen bars. George Martin used to point out, >Paul, hasn't this got sixteen bars? > Yes, George, it has. > But you're calling it a middle eight? > Yes, George, we are. $>$ | see. Super! < We called them middle eights, we had heard musicians say >That's a nice middle eight < and we didn't get the significance of the word seight . We just learned the word for it and that was what we called it: there were verses, choruses and middle eights « (Paul McCartney in Miles 1997: 177).

75 So singt Robbie Williams im Song "Strong (Chambers 1999) beim Übergang vom ersten Verse zum PreChorus: »And that's a good line to take it to the bridge Analog kündigt Timberland in Justin Timberlakes Song "SexyBack « (Timberlake/ Mosley/Hills 2006) den Verse und Chorus verbindenden Part mit »Take it to the bridge « an. Beide zitieren vermutlich bewusst James Browns »Get Up (I Feel 


\begin{tabular}{|c|c|c|c|c|c|}
\hline Song & \multicolumn{5}{|c|}{ Form } \\
\hline $\begin{array}{l}\text { »Witch Doctor } \\
\text { (Bagdasarian 1958) }\end{array}$ & & $V(6)-\operatorname{Ch}(8)$ & $\mathrm{V}-\mathrm{Ch}$ & $\operatorname{Br}(8)$ & $\mathrm{V}-\mathrm{Ch}-\mathrm{Ch}$ \\
\hline $\begin{array}{l}\text { "Little Egypt« } \\
\text { (Leiber/Stoller 1961) }\end{array}$ & Intro & $V(12)-C h(8)$ & $\mathrm{V}-\mathrm{Ch}$ & $\operatorname{Br}(8)$ & V - Ch - Coda \\
\hline $\begin{array}{l}\text { »Find Another Fool } \\
\text { (Weil/Mann 1961) }\end{array}$ & Intro & $V(16)-C h(8)$ & $\mathrm{V}-\mathrm{Ch}$ & $\operatorname{Br}(8)$ & V - Ch - Coda \\
\hline $\begin{array}{l}\text { "Roses Are Red (My Love)« } \\
\text { (Evans/Byron 1962) }\end{array}$ & $\mathrm{Ch}^{\prime}(4)$ & $V(7)-\operatorname{Ch}(8)$ & $\mathrm{V}-\mathrm{Ch}$ & $\operatorname{Br}(8)$ & $C h-V-C h$ \\
\hline $\begin{array}{l}\text { "You Can't Compare With } \\
\text { My Baby« } \\
\text { (Weil/Mann 1962) }\end{array}$ & Intro & $V(16)-C h(10)$ & $\mathrm{V}-\mathrm{Ch}$ & $\operatorname{Br}(8)$ & Ch - Coda \\
\hline $\begin{array}{l}\text { "Please Please Me« } \\
\text { (Lennon/McCartney 1963) }\end{array}$ & Intro & $V(8)-\mathrm{Ch}(8)$ & $\mathrm{V}-\mathrm{Ch}$ & $\operatorname{Br}(10)$ & V - Ch - Coda \\
\hline $\begin{array}{l}\text { »Tell Me Why« } \\
\text { (Lennon/McCartney 1964) }\end{array}$ & $\mathrm{Ch}$ & $V(12)-C h(8)$ & $\mathrm{V}-\mathrm{Ch}$ & $\operatorname{Br}(10)$ & $\mathrm{Ch}$ \\
\hline $\begin{array}{l}\text { "When I Get Home } \\
\text { (Lennon/McCartney 1964) }\end{array}$ & $\mathrm{Ch}$ & $V(8)-\operatorname{Ch}(8)$ & $\mathrm{V}-\mathrm{Ch}$ & $\operatorname{Br}(10)$ & $\mathrm{V}-\mathrm{Ch}$ \\
\hline $\begin{array}{l}\text { "Ferry Cross The Mersey« } \\
\text { (Marsden 1964) }\end{array}$ & Intro & $V(8)-\operatorname{Ch}(6)$ & $\mathrm{V}-\mathrm{Ch}$ & $\operatorname{Br}(8)$ & V - Ch - Coda \\
\hline $\begin{array}{l}\text { »Hubble Bubble (Toil And } \\
\text { Trouble)« } \\
\text { (Hugg/Jones/Mann/ } \\
\text { McGuiness/Vickers 1964) }\end{array}$ & $\mathrm{Ch}$ & $\mathrm{V}(16)-\mathrm{Ch}(16+4)$ & $\mathrm{V}-\mathrm{Ch}$ & $\operatorname{Br}(16+4)$ & Ch - Ch - Coda \\
\hline $\begin{array}{l}\text { "Sha La La« } \\
\text { (Mosley/Taylor 1964) }\end{array}$ & $\mathrm{Ch}$ & $V(10)-C h(8)$ & $\mathrm{V}-\mathrm{Ch}$ & $\operatorname{Br}(9)$ & Ch - Coda \\
\hline $\begin{array}{l}\text { "Baby I Need Your Lovin'« } \\
\text { (Holland/Dozier/Holland } \\
\text { 1964) }\end{array}$ & Intro & $V(12)-C h(8)$ & $V(8)-C h$ & $\operatorname{Br}(8)$ & $\mathrm{V}(12)-\mathrm{Ch}$ \\
\hline & & A & A & B & $A^{\mathrm{var}}$ \\
\hline
\end{tabular}

Tabelle 8: Zusammenhang von AABA- und Verse/Chorus/Bridge-Form

Like Being A) Sex Machine « (Brown/Byrd/Lenhoff 1970), der dort mit den Worten »Take 'em to the bridge! « seine Band anweist, in eine Art B-Teil zu wechseln, bei dem diese ihren Vamp nach über zwei Minuten zum ersten Mal verlässt und auf der IV. Stufe einen neuen Vamp spielt. Led Zeppelin parodieren dies in »The Crunge « (Bonham/Jones/Page/Plant 1973), indem Plant am Ende des Funk-beeinflussten Stückes, das keine Bridge enthält, ausruft: »Take it, take it, take it! Oh excuse me! Oh will you excuse me? I'm just tryin' to find the bridge. Has anybody seen the bridge? Please! Have you seen the bridge? I ain't seen the bridge! Where's that confounded bridge?« 


\section{Die Evolution des PreChorus}

Als eigenständiger Formteil tritt der PreChorus verstärkt ab ca. 1962 in Songs der New Yorker Brill Building-Komponistenteams auf. ${ }^{76}$ Vieles deutet darauf hin, dass er nicht, wie Everett (2009: 146) mutmaßt 1964 »erfunden« wurde, sondern dass auch seine Wurzeln in der oben beschriebenen Ausweitung der AABA-Form liegen. Die früheste Vorform ist dann ein Doo Woptypisches Phänomen, bei dem der bereits oben beschriebene Take off-Effekt vom Einsatz der Bridge in die A-Zeile vorverlegt wurde.

\subsection{Take off}

Während die meisten Loop-basierten Doo Wop-Songs mit den typischen wiederholten Harmoniefolgen I-vi-IV-V oder I-vi-ii-V den gesamten A-Teil ausfüllen, gibt es einige Einzelfälle, in denen nach der ersten Wiederholung der Wechsel auf eine neue harmonische Stufe folgt, die durch die vorherige starke Betonung der I. Stufe als Entfernung vom tonalen Zentrum, als »Abheben« (Take off) empfunden wird, um dann für die letzten zwei Takte des A-Teils zur I. Stufe zurückzukehren. Mit dem Take off korrespondieren in der Regel neue, meist diastematisch höhere melodische Phrasen sowie Änderungen in der Backgroundtextur, etwa das Wechseln des Satzgesangs von rhythmisierten Klangsilben zu liegenden Oohs. Somit bildet sich innerhalb

76 Die Organisationsstrukturen des Brill Building (1619 Broadway) und des benachbarten Aldon-Verlags (1650 Broadway) führten die Tin Pan Alley-Struktur in den 1960er Jahren fort (Emerson 2005: 20ff). Wie zuvor in der Tin Pan Alley hatten in diesen beiden Gebäuden zahllose Verleger, Produzenten, Songwriter, Bandleader, Demo-Studios etc. ihre Büros, als Zielgruppe wurden nun allerdings vor allem Teenager anvisiert. Die Veröffentlichungen von Brill Building- resp. Aldon-Firmen werden als Reaktion der Majorlabel auf den Rock ' $n$ ' Roll gedeutet, in dessen Zuge zahlreiche Independent-Label den Marktanteil der Majorlabel stark reduziert hatten. Neben der hochprofessionellen, sehr arbeitsteiligen Organisation liefern auch die Biographien wichtiger Brill Building/Aldon-Autoren direkte Verweise auf die Tin Pan Alley-Ära (und damit indirekt auf die AABAForm): "As a child he [Gerry Goffin, *1939] developed a taste for Broadway musicals and began writing songs of his own in his head. [...] With a plan to one day write a musical of his own« (Patrick 2007: 2, s. auch Emerson 2005: 86f.); "Cynthia Weil was born in 1941, in Manhattan, New York. As a teenager she loved Broadway show tunes and thought that Rock \& Roll was stupid. Cynthia: '[...] When I first saw musical theatre I knew instantly that was what I wanted to do « (Patrick/Baumgart 1999: 10, s. auch Emerson 2005: 93). Leiber und Stoller eröffneten 1961 ein Büro im Brill Building, sowohl Barry Mann und Cynthia Weil als auch Ellie Greenwich und Jeff Barry sowie Phil Spector (Emerson 2005: 137 bzw. 152) sahen sie als Vorbilder an. 
des A-Teils eine eigene aaba'- oder aabc-Struktur aus, bei der der b-Teil das Bekannte verlässt und zugleich lyrisch und harmonisch auf das Ziel, auf die Refrainzeile vorbereitet, die dann über die letzten zwei Takte - zur Rückkehr auf die I. Stufe - gesungen wird. ${ }^{77}$ In diesem Verständnis wird der Take off vom reinen Ereignis zum (Binnen-)Formteil. Tabelle 9 zeigt Beispiele für solch eine Binnengliederung des A-Teils. ${ }^{78}$

\begin{tabular}{|c|c|c|c|c|c|c|c|c|c|c|}
\hline \multirow[b]{2}{*}{$\begin{array}{l}\text { Just For You« } \\
\text { (Davis 1943) }\end{array}$} & \multicolumn{5}{|c|}{ Verse-artig } & & \multicolumn{2}{|c|}{ Take off } & \multicolumn{2}{|c|}{ Refrain } \\
\hline & $I-I_{5}$ & ii $-V$ & $1-$ & & ii - & & IV & ii & ii $-V$ & $\mathrm{I}-\mathrm{V}$ \\
\hline $\begin{array}{l}\text { »Count Every } \\
\text { Star«(Coquatrix/ } \\
\text { Gallop 1950) }\end{array}$ & I - vi & ii $-V$ & I - & & ii - & & $1^{7}$ & IV - iv & I - vi & ii $-V$ \\
\hline $\begin{array}{l}\gg \mid \text { 'm Just A Fool In } \\
\text { Love } \\
\text { (Chessler 1951) }\end{array}$ & I - vi & ii $-V$ & I - & & ii $-\mathrm{i}$ & & vi - iii & IV - iii & $\mathrm{ii}^{7}$ & V \\
\hline $\begin{array}{l}\text { »Since You've Been } \\
\text { Away« (Glover 1951) }\end{array}$ & I - vi & $\mathrm{ii}-\mathrm{V}$ & I - & & ii - & & $1^{7}$ & IV - V & I - vi & ii $-V$ \\
\hline $\begin{array}{l}\text { "Goodnite Sweet- } \\
\text { heart, Goodnite } \\
\text { (Carter/Hudson 1953) }\end{array}$ & I - vi & ii $-V$ & I - & & ii - & & $I-I^{7}$ & IV - iv ${ }^{7}$ & I & I \\
\hline $\begin{array}{l}\text { »Devil Or Angel« } \\
\text { (Carter 1955) }\end{array}$ & I - vi & ii $-V$ & $1-$ & & ii - & & $I^{7}-\# 1^{07}$ & ii $-V$ & I - IV & V \\
\hline $\begin{array}{l}\text { »Adorable« } \\
\text { (Ram 1955) }\end{array}$ & I - vi & ii $-V^{7}$ & I - & & ii - & & $1^{7}$ & IV - iv & I - vi & ii $-V$ \\
\hline $\begin{array}{l}\text { »Since I Don't Have } \\
\text { You« (Rock/Beau- } \\
\text { mont/Martin 1958) }\end{array}$ & 1 & iv $-V^{7}$ & 1 & & iv - & & I & iv & ii & V \\
\hline $\begin{array}{l}\text { "My Last Date« (Crame } \\
\text { Davis/Bryant 1960) }\end{array}$ & & \begin{tabular}{l|l} 
I & IV
\end{tabular} & 1 & IV & I & IV & I-V & I - IV & I-V & $\mathrm{I}-\mathrm{V}$ \\
\hline
\end{tabular}

Tabelle 9: AABA-Songs mit Binnengliederung des (meist) achttaktigen A-Teils in Verse-artig, Take off und Refrain

Stets beginnen diese A-Teile auf der I. Stufe. Mit dem wiederholten harmonischen Pattern, das im Wesentlichen zwischen I. und V. Stufe pendelt,

77 Es gibt auch Beispiele, in denen der Take off nur auf der Ebene der Melodik und/oder des Arrangements stattfindet, während die Akkordschleife unverändert weiterläuft: »Heart And Soul« (Carmichael/Loesser 1938, allerdings ohne Refrain in den letzten zwei Takten); »Diana« (Anka 1957); »A Teenager In Love (Pomus/Shuman 1959). Everett (2009: 140) orientiert sich in seinen Formanalysen stärker an der Melodik als an der Harmonik und bezeichnet die entsprechende Phrasenstruktur als »Statement - Restatement - Departure Conclusion «-Form (SRDC).

78 Dargestellt ist hier jeweils die erste A-Zeile, deren Halbschluss im zweiten und dritten A-Teil durch einen Ganzschluss ersetzt wird. 
korrespondiert eine ebenfalls wiederholte zweitaktige melodische Phrase. Im Take off wird das harmonische Geschehen geöffnet, indem die IV. Stufe angesteuert wird - entweder direkt oder leittönig über die Zwischendominante $\mathrm{I}^{7} .^{79}$ In Takt 7 oder 8 wird dann in fast allen Fällen das tonale Zentrum über eine authentische Kadenz erreicht. Der erste Durchgang des A-Teils endet entsprechend der Tin Pan Alley-Periode offen mit $V^{7}$, um zur I. Stufe des wiederholten A-Teils zu führen. Dieser schließt dann auf der I. Stufe oder er moduliert über eine Zwischendominante zum ersten Akkord des B-Teils.

\subsection{Der Take off als PreRefrain}

Dieses Kompositionsprinzip ist der Ausgangspunkt für ein ähnliches 16-taktiges Modell, das etwa zeitgleich mit der Erweiterung des A-Teils durch einen achttaktigen Refrain entstand (s. Abschnitt 4.2). Statt aber auf die ersten acht Takte direkt den Refrain folgen zu lassen, gliedert sich dieses Modell analog dem achttaktigen Take off-Modell in acht Takte Verse-artigen Charakters, vier Takte mit zum Refrain hinleitenden Charakter und vier Takte Refrain. Besonders häufig wurde es zwischen 1961 und 1963 von Gerry Goffin und Carol King verwendet; unsere frühesten Beispiele stammen allerdings wiederum von Leiber und Stoller (s. Tabelle 10 auf S. 108).

Die harmonische und formale Verwandtschaft mit dem Take off-Modell ist offensichtlich, da die Proportionen erhalten bleiben: Auf die Wiederholung zwei- oder viertaktiger Akkord-Shuttles oder -Loops, die das tonale Zentrum festigen, folgt nach acht Takten ein Take off, in dem die IV. Stufe und (stärker als im früheren achttaktigen Modell) die Nebenstufen zur harmonischen Öffnung genutzt werden. Der Refrain ist mit der »authentischen« Rückkehr zur I. Stufe im 13. oder spätestens 15. Takt verbunden, wobei der Eindruck des Ankommens durch das Verweilen auf dieser Stufe für zwei Takte unterstützt wird. Trotz der Ausweitung auf 16 Takte bleibt auch in diesem Modell die Einheit des A-Teils u.a. durch den harmonischen Bogen deutlich wahrnehmbar. Take off und Refrain erscheinen noch nicht als eigenständige Formteile, kommen durch die Verdopplung ihres Umfangs aber deutlicher zur Geltung. Im Hinblick auf den sich aus diesem Modell später entwickelnden eigenständigen Formteil PreChorus könnte man den

79 Eine bemerkenswerte Ausnahme bildet der Song »'m Just A Fool In Love der Orioles (s. Tabelle 9), der in Hinblick auf Form und Sound klar dem Doo Wop zuzuordnen ist, mit seinen chromatischen Gängen aber dennoch an den Tin Pan Alley-Stil erinnert. 


\begin{tabular}{|c|c|c|c|c|c|c|c|c|c|c|c|c|c|c|c|c|}
\hline & \multicolumn{8}{|c|}{ Verse-artig } & \multicolumn{4}{|c|}{ PreRefrain } & \multicolumn{4}{|c|}{ Refrain } \\
\hline $\begin{array}{l}\text { »It's A Miracle« } \\
\text { (Leiber/Stoller } \\
\text { 1954) }\end{array}$ & 1 & $1^{7}$ & IV & 1 & 1 & $\mathrm{I}^{7}$ & $V \mathrm{ii}$ & V & $1^{7}$ & $1^{7}$ & IV & ii & I-vi & ii V I & I-IV & 1 \\
\hline $\begin{array}{l}\text { "Sorry, But I'm } \\
\text { Gonna Have To } \\
\text { Pass« (Leiber/ } \\
\text { Stoller 1958) } \\
\end{array}$ & I & 1 & V & V & 1 & 1 & V & V & I & $1^{7}$ & IV & V & IV & V & 1 & I \\
\hline $\begin{array}{l}\text { »Dream Lover« } \\
\text { (Darin 1959) }\end{array}$ & I & 1 & vi & vi & 1 & 1 & vi & vi & 1 & V & I & IV & I-vi | & IV V & 1 & $\mathrm{~V}^{7}$ \\
\hline $\begin{array}{l}\text { "I Count The Tears« } \\
\text { (Pomus/Shuman } \\
\text { 1960) }\end{array}$ & I & I & vi & vi & IV & IV & V & V & vi & iii & vi & iii & IV & V & 1 & 1 \\
\hline $\begin{array}{l}\text { »How About That« } \\
\text { (Augustus/Payne } \\
\text { 1960) }\end{array}$ & I & 1 & $\mathrm{~V}^{7}$ & $V^{7}$ & 1 & 1 & $\mathrm{~V}^{7}$ & $V^{7}$ & 1 & $1^{7}$ & IV & IV & 1 & $\mathrm{~V}^{7}$ & I IV & 1 \\
\hline $\begin{array}{l}\text { »First Taste of } \\
\text { Love« (Spector/ } \\
\text { Pomus 1960) }\end{array}$ & I & 1 & $\mathrm{~V}^{7}$ & $V^{7}$ & $\mathrm{~V}^{7}$ & $\mathrm{~V}^{7}$ & 1 & 1 & 1 & $1^{7}$ & IV & IV & 1 & $\mathrm{~V}^{7}$ & 1 & 1 \\
\hline $\begin{array}{l}\text { "Will You Still Love } \\
\text { Me Tomorrow?« } \\
\text { (Goffin/King 1961) }\end{array}$ & I & 1 & IV & V & 1 & 1 & V & V & III & III & vi & vi & IV & V & 1 & 1 \\
\hline $\begin{array}{l}\gg \text { Heaven Is Being } \\
\text { With You« (Goffin/ } \\
\text { King/Weil 1961) }\end{array}$ & I & 1 & I & 1 & 1 & 1 & V & V & 1 & vi & I & vi & IV & V & 1 & 1 \\
\hline $\begin{array}{l}\text { It Might As Well } \\
\text { Rain Until Sep- } \\
\text { tember« (Goffin/ } \\
\text { King 1962) }\end{array}$ & I & $I V_{/ 5}$ & $\left.\right|^{\text {maj7 }}$ & $1 \mathrm{~V}_{/ 5}$ & 1 & $\mathrm{IV}_{/ 5}$ & $\left.\right|^{\text {maj7 }}$ & $\mathrm{I}^{7}$ & IV & iv & I & $\mathrm{vi}^{7}$ & $\mathrm{bVI}^{7}$ & V & 1 & $\mathrm{ii}^{7}$ \\
\hline $\begin{array}{l}\text { Point Of No } \\
\text { Return« (Goffin/ } \\
\text { King 1962) }\end{array}$ & I & $1^{6}$ & Imaj7 $^{\text {maj }}$ & $1^{6}$ & 1 & $1^{6}$ & ii & V & 1 & $1^{7}$ & IV & iv & $\mid \mathrm{I}-\mathrm{IV}$ & I-IV & I-V & 1 \\
\hline $\begin{array}{l}\text { »It Started All Over } \\
\text { Again« } \\
\text { (Goffin/Keller 1963) }\end{array}$ & I & 1 & bVII & V & 1 & 1 & bVII & V & I & i7 & IV & iv & 1 & V & 1 & V \\
\hline $\begin{array}{l}\text { »Then He Kissed } \\
\text { Me« (Spector/ } \\
\text { Greenwich/Barry } \\
\text { 1963) }\end{array}$ & I & V & I & I & I & V & I & I & IV & I & IV & I & 1 & V & 1 & 1 \\
\hline $\begin{array}{l}\text { »The Kind Of Boy } \\
\text { You Can't Forget« } \\
\text { (Greenwich/Barry } \\
\text { 1963) }\end{array}$ & 1 & IV & I & IV & 1 & IV & I & IV & IV & IV & I & vi & V & IV & V & IV \\
\hline $\begin{array}{l}\text { »Things We Said } \\
\text { Today« (Lennon/ } \\
\text { McCartney 1964) }\end{array}$ & $i-v^{7}$ & $\mathrm{i}$ & $i-v^{7}$ & i & $i-v^{7}$ & $\mathrm{i}$ & $i-v^{7}$ & $\mathrm{i}$ & III & $\mathrm{III}^{9}$ & VII & bll & $i-v^{7}$ & $\begin{array}{l}\mathrm{i} \\
\mathrm{i}\end{array}$ & $i-v^{7}$ & $\mathrm{i}$ \\
\hline
\end{tabular}

Tabelle 10: AABA-Songs mit Binnengliederung des 16-taktigen A-Teils in Verse-artig, PreRefrain und Refrain 
Take off hier teleologisch als Proto-PreChorus bezeichnen, denn die Funktion beider Teile ist die gleiche, so auch Everett (2009: 146f.): »In songs that do not contain a chorus [...] the Departure-gesture that precedes each refrain [...] has the same formal function as a prechorus, but clearly the stage is smaller. «Da kein eigenständiger Formteil Chorus folgt, müsste terminologisch korrekt allerdings von einem PreRefrain gesprochen werden - diese Bezeichnung ist jedoch bislang kaum verbreitet. ${ }^{80}$

Da sich in unserer Stichprobe außerhalb der AABA-Form bis 1960 nahezu keine PreRefrains oder PreChoruses finden, liegt der Schluss nahe, dass sich diese Formteile nicht, wie man vermuten könnte, aus der AAA-Form mit Refrain oder aus der Verse/Chorus-Form, sondern auf dem beschriebenen Weg aus der Aufspreizung der AABA-Form entwickelt haben. ${ }^{81}$ Für diese Richtung des Einflusses spricht auch, dass die ab 1958 (vor allem in der Country Music) zu findenden PreRefrain-Beispiele aus anderen als AABAStücken harmonisch ähnlich funktionieren wie oben dargestellt, sie also wie AABA-Songs wirken, bei denen auf die Bridge verzichtet wurde:

\begin{tabular}{|c|c|c|c|c|c|c|c|c|c|c|c|c|c|c|c|c|}
\hline & \multicolumn{8}{|c|}{ Verse-artig } & \multicolumn{4}{|c|}{ PreRefrain } & \multicolumn{4}{|c|}{ Refrain } \\
\hline $\begin{array}{l}\text { »It's Only Make } \\
\text { Believe« (Nance/ } \\
\text { Twitty 1958) }\end{array}$ & tra & I & v & & I & V & 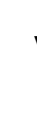 & V & IV & V & $1^{7}$ & IV & V & IV & I-IV & $I-V$ \\
\hline $\begin{array}{l}\text { »Why I'm Walking « } \\
\text { (Endsley/Jackson } \\
\text { 1960) }\end{array}$ & V & V & 1 & 1 & IV & V & I & I & IV & V & IV & IV & V & V & I & I \\
\hline $\begin{array}{l}\text { »'ll Have Another } \\
\text { Cup Of Coffee« } \\
\text { (Brock 1961) }\end{array}$ & 1 & V & 1 & I & 1 & IV & I & I & IV & IV & I & 1 & I & IV & I & I \\
\hline $\begin{array}{l}\text { "Locomotion« } \\
\text { (Goffin/King 1962) }\end{array}$ & I & vi & I & vi & 1 & vi & I & vi & IV & ii & IV & $\mathrm{II}_{3}$ & 1 & V & & \\
\hline $\begin{array}{l}\text { „Six Days On The } \\
\text { Road« } \\
\text { (Montgomery/ } \\
\text { Green 1963) }\end{array}$ & 1 & V & 1 & I & $\mathrm{I}$ & I & V & V & IV & V & I & IV & I & V & I & I \\
\hline
\end{tabular}

Tabelle 11: Dreiteilige Binnenform von A-Teilen in Songs ohne Bridge

80 Fitzgerald (2007: 121f.) benutzt den Begriff »prehook« - seltsamerweise allerdings in der Verbindung »verse-prehook-chorus".

81 Die einzigen Gegenbeispiele mit Chorus vorbereitenden Takten in unserer Stichprobe haben mit dem beschriebenen Take off-Prinzip nichts zu tun, deuten allerdings darauf hin, dass es bereits um 1910 Songs mit eigenständigem PreChorus gab, ohne dass sich dieser Formteil hätte fest etablieren können: »Nur a Bier will i hab'n« (gesungen von August Juncker 1907); »San Antonio « (Van Alstyne 1907), »Has Anybody Seen Kelly« (Murphy/Letters 1909), »I Want A Girl Just Like The Girl That Married Dear Old Dad« (Harry von Tilzer/Dillon 1911). Daneben findet sich ein PreChorus auch in »Do Re Mi« (Guthrie 1940). 


\subsection{Der PreChorus als eigenständiger Formteil}

Nach der Aufspreizung zu 16 Takten mit Verse-, PreRefrain- und Refraincharakter in den späten 1950er Jahren wurden zu Beginn der 1960er Jahre noch umfangreichere A-Teile komponiert. Bei gleichbleibender Verse-Länge wachsen die PreRefrain- und Refrainsektionen z.B. bei »Tell Him« (Berns 1962) auf ebenfalls je acht Takte an, was 24-taktige A-Teile zur Folge hat. In diesen ist der typische einheitstiftende Bogen jedoch kaum noch wahrnehmbar, stattdessen werden die Formelemente Verse, PreChorus und Chorus als eigenständig empfunden. Vor allem der Chorus gewinnt dabei die Bedeutung, die er in Verse/Chorus-Formen immer schon hatte. Wie in den unter 4.2. beschriebenen Beispielen bildet er im Unterschied zum Refrain nicht mehr den kurzen Abschluss einer größeren Einheit, sondern wird zum Mittelpunkt des Songs, der für Wiedererkennbarkeit sorgt. Neben dem größeren zeitlichen Umfang wird diese Wirkung auch hier durch das Hinzukommen neuer Instrumente, mehrfache Text-Wiederholungen, UnisonoBackgroundgesänge, vorangestellte Generalpausen und eine innerhalb des Chorus' geschlossene Harmonik erzielt.

Als eigenständig werden Chorus und PreChorus außerdem (zumindest bei wiederholtem Hören) wahrgenommen, wenn die Formteile auch unabhängig voneinander, also nicht immer in derselben Reihenfolge auftreten. So ist es, wie schon in Abschnitt 4.2. gesehen, üblich, dass ein Chorus direkt der Bridge oder dem Solo folgt, ohne dass zuvor noch Verse und PreChorus erklingen müssten; auch nutzen einige Songs Material des Chorus' als Intro oder beginnen mit dem Chorus. Analog erhöht sich auch die Eigenständigkeit des PreChorus, wenn er ohne einen weiteren Verse direkt nach Solo oder Bridge gespielt wird (»Baby, It's You«, Bacharach/Davis/Williams 1962; »She's Not There«, Argent 1964; »Downtown«, Hatch 1964) oder wenn auf den ersten Durchgang aus Verse und PreChorus ein weiterer Durchgang folgt, bevor der Chorus einsetzt (»She Loves You«, Lennon/McCartney 1963, das zudem mit einer Chorus-Variation beginnt). Der Charakter des PreChorus' verändert sich dabei nicht im Vergleich zu Take off und PreRefrain: durch Entfernung von der I. Stufe sorgt er für Abwechslung, harmonische Instabilität und Spannung, die sich im anschließenden Chorus wieder löst.

Das Anwachsen des A-Teils auf bis zu 26 Takte (»Walking In The Rain«, Mann/Weil/Spector 1964, mit einer 8+8+10 Binnengliederung) führt offenbar dazu, dass der A-Teil allein genug abwechslungsreiches Material für den ganzen Song bietet und so auf den B-Teil - auch durch die damals übliche Begrenzung der Songlänge auf zweieinhalb Minuten - immer häufiger ver- 
zichtet wird. Zwar wurden weiterhin AABA-Formen mit vollständig aufgespreizten A-Teilen komponiert (neben »Tell Him« z. B. »You Beat Me To The Punch (Robinson/White 1962) mit 8+7+7 Takten; »The First Time « (Andrews 1963) mit 8+5+4 Takten; »Baby Baby I Still Love You« (Weil/ Titelman 1964) mit 8+4+8 Takten), doch finden sich (vor allem in den USA) ab 1963 immer häufiger Varianten ohne Bridge:

\begin{tabular}{|c|c|c|c|c|}
\hline Song & V & $\mathrm{PCh}$ & Ch & Form \\
\hline $\begin{array}{l}\text { »He Knows I Love } \\
\text { Him Too Much« } \\
\text { (Goffin/King 1961) }\end{array}$ & 8 & 5 & 8 & Intro - V/PCh/Ch - V/PCh/Ch - Instr(=V/PCh) - Ch \\
\hline $\begin{array}{l}\text { »The Beggar That } \\
\text { Became A King« } \\
\text { (Barry/Powers 1962) }\end{array}$ & 16 & 8 & 8 & Intro - V/PCh/Ch - Solo - V/PCh/Ch \\
\hline $\begin{array}{l}\text { "Baby, It's You« } \\
\text { (Bacharach/ } \\
\text { David/Williams 1962) }\end{array}$ & 8 & 9 & 8 & Intro - V/PCh/Ch - V/PCh/Ch - Solo(=V) - PCh/Ch \\
\hline $\begin{array}{l}\text { "What Do I See In } \\
\text { The Girl« } \\
\text { (Goffin/King 1963) }\end{array}$ & 8 & 6 & 4 & Intro - V/PCh/Ch - V/PCh/Ch - Instr(=V) - PCh/Ch \\
\hline $\begin{array}{l}\text { "She Loves You« } \\
\text { (Lennon/McCartney } \\
\text { 1963) }\end{array}$ & 8 & 8 & 8 & Intro(=Ch') - V/PCh - V/PCh/Ch - V/PCh/Ch \\
\hline $\begin{array}{l}\text { "(Love Is Like A) Heat } \\
\text { Wave« } \\
\text { (Holland/Dozier/ } \\
\text { Holland 1963) }\end{array}$ & 8 & 4 & 8 & $\begin{array}{l}\text { Intro }-\mathrm{V} / \mathrm{PCh} / \mathrm{Ch}-\mathrm{V} / \mathrm{PCh} / \mathrm{Ch}-\text { Inst }(=\mathrm{V} / \mathrm{PCh} / \mathrm{Ch})- \\
\text { V/PCh/Ch - Coda }\end{array}$ \\
\hline $\begin{array}{l}\text { "Be My Baby« } \\
\text { (Spector/Greenwich/ } \\
\text { Barry 1963) }\end{array}$ & 8 & 8 & 8 & $\begin{array}{l}\text { Intro - V/PCh/Ch - V/PCh/Ch - Inst(=V) - Ch - } \\
\text { Break - Ch }\end{array}$ \\
\hline $\begin{array}{l}\text { "Baby I Love You« } \\
\text { (Spector/Greenwich/ } \\
\text { Barry 1963) }\end{array}$ & 8 & 8 & 8 & Intro - V/PCh/Ch - V/PCh/Ch - Instr(=V) - Ch \\
\hline $\begin{array}{l}\text { "Surf City« } \\
\text { (Wilson/Berry) }\end{array}$ & 8 & 5 & 12 & Intro - V/PCh/Ch - V/PCh/Ch - V/PCh/Ch' - Outro \\
\hline $\begin{array}{l}\text { "Downtown« } \\
\text { (Hatch 1964) }\end{array}$ & 8 & $4+5$ & $6+4$ & $\mathrm{~V} / \mathrm{PCh} / \mathrm{Ch}-\mathrm{V} / \mathrm{PCh} / \mathrm{Ch}-\operatorname{Instr}(=\mathrm{V})-\mathrm{PCh} / \mathrm{Ch}$ \\
\hline $\begin{array}{l}\text { Don't Worry Baby« } \\
\text { (Wilson/Christian } \\
1964)\end{array}$ & 8 & 4 & 9 & $\mathrm{~V} / \mathrm{PCh} / \mathrm{Ch}-\mathrm{V} / \mathrm{PCh} / \mathrm{Ch}-\operatorname{Instr}(=\mathrm{V})-\mathrm{V} / \mathrm{PCh} / \mathrm{Ch}$ \\
\hline $\begin{array}{l}\text { »The Girl's Alright } \\
\text { With Me« } \\
\text { (Holland/Kendricks/ } \\
\text { Whitfield 1964) }\end{array}$ & 8 & 8 & 8 & $\mathrm{~V} / \mathrm{PCh} / \mathrm{Ch}-\mathrm{V} / \mathrm{PCh} / \mathrm{Ch}-$ Solo $-\mathrm{V} / \mathrm{PCh} / \mathrm{Ch}$ \\
\hline
\end{tabular}

Tabelle 12: Songs, die der Verse/PreChorus/Chorus-Form folgen 
Diese Entwicklung lässt sich mit Blick auf die Spitzenpositionen der Billboard Hot 100 auch quantitativ belegen: Während 1964 52\% aller Nr.1-Titel der AABA-Form folgten und nur $9 \%$ aus Verses, PreChoruses und Choruses gebaut waren, stieg der PreChorus-Anteil in den Folgejahren deutlich an, während immer weniger AABA-Songs die oberste Position erreichten. ${ }^{82}$

\begin{tabular}{|l|c|c|c|c|c|c|c|}
\hline & 1960 & 1962 & 1963 & 1964 & 1965 & 1966 & 1968 \\
\hline AABA & $35 \%$ & $30 \%$ & $40 \%$ & $52 \%$ & $26 \%$ & $19 \%$ & $15 \%$ \\
\hline V/PC/C & $0 \%$ & $5 \%$ & $5 \%$ & $9 \%$ & $22 \%$ & $19 \%$ & $20 \%$ \\
\hline & $\mathrm{n}=20$ & $\mathrm{n}=20$ & $\mathrm{n}=20$ & $\mathrm{n}=23$ & $\mathrm{n}=27$ & $\mathrm{n}=27$ & $\mathrm{n}=20$ \\
\hline
\end{tabular}

Tabelle 13: Anteil an AABA- und Verse/PreChorus/Chorus-Formen in Nr.1-Hits der 1960er Jahre

\section{Renaissance und Rückgang der AABA-Form}

Während sich so in den USA die AABA-Form durch die umfangreiche Aufspreizung des A-Teils selbst "abschaffte «, blieb sie in England - und zwar meist in ihrer klassischen 32-taktigen Form - noch einige Jahre die erste Wahl (was sich durch die »British Invasion« der Jahre 1964/65 auch in den Billboard-Charts niederschlägt, vgl. den 1964er Peak der AABA-Formen in Tabelle 13 u. Abb. 2, S. 116); alle sieben AABA-Nr.1-Hits des Jahres 1965 stammen von britischen Bands!).

Selbst in Anbetracht der Tatsache, dass sich das frühe Live-Repertoire der Beatles zu einem nicht unerheblichen Anteil aus Songs in der AABA-Form speist ${ }^{83}$, erstaunt es doch, wie stark dieses Formmodell die Eigenkompositionen John Lennons und Paul McCartneys lange Zeit prägte. Obwohl die frühen Beatles laut Everett (2001: 54) mindestens 54 Songs mit zwölftaktigem Blues-

82 Nicht berücksichtigt wurden bei der Auswertung rein instrumentale Titel. Erreichten in einem Jahr weniger als 20 Titel die Top-Position, wurden, um auf eine Stichprobe von mindestens 20 Titeln zu kommen, die bestplatzierten Songs der Billboard Year End Charts hinzugezogen.

83 Darunter z.B. Songs von Leiber/Stoller (»Kansas City«, »Young Blood«), Goffin/King (»Don't Ever Change«, »Take Good Care Of My Baby«, »Chains«, »Will You Still Love Me Tomorrow«), Felice und Boudelaux Bryant (»All I Have To Do Is Dream«, »Raining In My Heart«), Buddy Holly (»Crying, Waiting, Hoping «, »Everyday«) oder aus der Tin Pan Alley-Zeit (»Red Sails In The Sunset«, "Ain't She Sweet«, »Over The Rainbow«, »Till There Was You«). Laut Everett (2001: 50) enthalten mindestens 46 der von den Beatles bis 1960 gecoverten Stücke eine kontrastierende Bridge, die auf der V. Stufe endet. Inventuren des Beatles-Repertoires bis 1960 bzw. 1962 finden sich bei Everett (ebd.: 86-90) und Laing (2009: 27-32). 
schema im Programm hatten, findet es sich unter den bis inkl. 1964 veröffentlichten Lennon/McCartney-Kompositionen nur zweimal - und auch dann stets nur im Rahmen der AABA-Form (»You Can't Do That « und »Can't Buy Me Love«, beide 1964). Stattdessen weisen Fitzgerald (1996: 42) zufolge 76\% der 34 USTop 40-Hits von Lennon/McCartney aus den Jahren 1963-66 die AABA-Form auf (die restlichen 24\% folgen einer Verse/Chorus-Form). Lennons Ausspruch »Paul and I wanted to be the Goffin and King of England« (zit. n. Inglis 2003: 221) findet in diesen Zahlen in Bezug auf die Songform einen überzeugenden Beleg. Tatsächlich nutzen Lennon/McCartney die AABA-Form noch viel häufiger als Goffin/King (54\%) oder Barry/Greenwich (47\%) im selben Zeitraum (Fitzgerald 1996: 42). Unsere Analyse aller bis 1966 veröffentlichten Beatles-Eigenkompositionen kommt zu ähnlichen Ergebnissen, wobei allerdings deutlich wird, dass im Laufe der Zeit auch bei den Beatles die AABA-Form etwas an Bedeutung verlor: ${ }^{84}$

\begin{tabular}{|c|c|c|c|c|}
\hline & AABA & AAA & Verse/Chorus & Sonstige \\
\hline 1963 (22 Songs) & $73 \%$ & $0 \%$ & $14 \%$ & $14 \%$ \\
1964 (24 Songs) & $67 \%$ & $0 \%$ & $29 \%$ & $4 \%$ \\
1965 (29 Songs) & $48 \%$ & $14 \%$ & $31 \%$ & $7 \%$ \\
1966 (16 Songs) & $50 \%$ & $13 \%$ & $31 \%$ & $6 \%$ \\
\hline
\end{tabular}

Tabelle 14: Formmodelle aller zwischen 1963 und 1966 offiziell veröffentlichten Beatles-Eigenkompositionen

Bei den Rolling Stones verhält es sich dagegen gegensätzlich. Obwohl sie stärker Blues-beeinflusst waren als die Beatles, funktionieren zwar auch die ersten Jagger/Richards-Kompositionen fast alle nach dem AABA-Prinzip - nur veröffentlichten die Rolling Stones keines dieser Stücke unter ihrem Namen. Stattdessen wurden alle AABA-Songs an andere Interpreten weitergereicht ${ }^{85}$, sodass sich im Repertoire der Band zu Beginn ausschließlich Blues- und Verse/Chorus-Formen finden ${ }^{86}$ - während die Beatles diese zwar ständig live spielten, aber nicht für ihre eigenen Stücke nutzten. Der Song »| Wanna Be

84 Vertiefend zur Form der Beatles-Songs und zu ihren Brill Building-Bezügen s. Fitzgerald 1996 und Everett 2001 (v.a. 48-51).

85 »It Should Be You« und »Will You Be My Lover Tonight« wurden von George Bean, "Shang A Doo Lang « von Adrienne Posta, "So Much In Love« von The Mighty Avengers und "That Girl Belongs To Yesterday « von Gene Pitney interpretiert (alle 1964). Das ebenfalls dem AABA-Schema folgende »We Were Falling In Love« blieb unveröffentlicht.

86 Umso bemerkenswerter ist ihre Aufnahme einer der seltenen Chicago-BluesNummern mit Bridge, Muddy Waters' »I Just Want To Make Love To You« (Dixon 1954), die die Stones durch Vereinheitlichung der A-Zeilen und Umstellung des Solos - nun als instrumental wiederholte Bridge - gänzlich auf AABA BA-Form trimmen. 
Your Man«, den Lennon/McCartney 1963 den Rolling Stones zur Erstveröffentlichung überließen, ist nicht zufällig einer der wenigen frühen BeatlesSongs ohne Middle Eight. ${ }^{87}$

Erst 1966 finden sich dann AABA-Formen in Stücken der Rolling Stones (»| Am Waiting«, »Long Long While« und »Mothers Little Helper«, alle Jagger/ Richards).

\begin{tabular}{|c|c|c|c|c|}
\hline Rolling Stones & AABA & AAA & Verse/Chorus & Sonstige \\
\hline $\begin{array}{c}1963-1967 \\
\text { (60 Songs) }\end{array}$ & $10 \%$ & $43 \%$ & $40 \%$ & $7 \%$ \\
\hline
\end{tabular}

Tabelle 15: Formmodelle in 60 zwischen 1963 und 1967 veröffentlichten Eigenkompositionen der Rolling Stones

Jagger und Richards assoziierten AABA also offensichtlich mit einer MusikTradition, mit der sie ihre Band zunächst bewusst nicht in Verbindung bringen wollten (was sie nicht daran hinderte, solche Musik für andere zu komponieren): »We wrote loads of airy-fairy silly love songs for chicks and stuff that didn't take off. We'd give them to Andrew [Loog Oldham, Manager] and, amazing to us, he got most of them recorded by other artists. Mick and I refused to put this crap we were writing with the Stones. We'd have been laughed out of the goddamn room« (Richards 2010: 143).

Dieser musikalische Kontrast zwischen den Beatles und den Rolling Stones, der sich schon auf formaler Ebene so deutlich zeigt, findet sich ähnlich zwischen anderen englischen Bands der Zeit wieder: Bei den eher Pop-orientierten Bands kam die AABA-Form in Coverversionen, Fremd- und Eigenkompositionen sehr häufig zum Einsatz ${ }^{88}$, die stärker Blues-orientierten

87 Kurios ist vor diesem Hintergrund folgende Entstehungsgeschichte, die Miles/ Badman (2001: 107) kolportieren: Nach einem zufälligen Treffen der Bands hätten Lennon und McCartney sich bereit erklärt, den Rolling Stones einen Song zu überlassen: »There was only one problem: the song didn't have a middle eight. After a quick conference John and Paul told them that if they really liked the song, they would finish it off for them. They disappeared into a side room and reappeared a few minutes later. >Forget something? asked Bill Wyman. >No,< said Paul. >We've just finished the middle eight.« Ob die Rolling Stones (wie dann später auch die Beatles in ihrer Version) die Bridge bewusst wegließen oder ob es nie eine gegeben hat (oder ob die ganze Story erfunden wurde), ist unbekannt.

88 AABA-Formen finden sich z.B. bei: Freddie \& The Dreamers (»I'm Telling You Now«, Garrity/Murray,1964; »I Understand (Just How You Feel)«, Best 1964 (1953)), Gerry \& The Pacemakers (»How Do You Do It « und »I Like It«, beide Murray 1963; »Ferry Cross The Mersey« und »'m The One«, Marsden 1964), Billy J. Kramer \& The Dakotas (»Bad To Me«, »'ll Keep You Satisfied« (beide Lennon/McCartney 1963; »From A Window« (Lennon/McCartney 1964), »Little Children«, McFarland/Shuman 1964), Dave Clark Five (»Can't You See She's Mine«, Clark/Smith 1964), Herman's Hermits (»l'm Into Something Good«, 
Gruppen wie die Yardbirds, die Animals und die Kinks mieden dieses Modell dagegen weitgehend, aber nicht vollständig. ${ }^{89}$ Sie hatten im Blues etwas gefunden, womit sie sich vom Pop-Mainstream der Zeit absetzen konnten: »Wir hatten genug von den Croonern. Gute Sänger, aber ihre Stücke waren exakt zwei Minuten lang mit einem Mittelteil von acht Takten, das ganze war ziemlich kitschig. Selbst Leute wie Tommy Steele und Cliff Richard waren nur ein müder Abklatsch von echter Musik. Mir reichte das emotional nicht aus« (Yardbirds-Gitarrist und -Bassist Chris Dreja in Priestley 2010: 28 '23"). ${ }^{90}$

Mit negativer Bedeutung aufgeladen war die AABA-Form auch im USamerikanischen Folk-Revial der 1950er und 1960er Jahre, weshalb sie dort tabu war. AABA signalisierte den Folk-Sängerinnen und -Sängern offenbar standardisierte kommerzielle Unterhaltungsware und entsprach damit nicht den Ansprüchen an Authentizität, denen sie sich verpflichtet sahen. Stattdessen hielten sie ihre Songs in der Tradition der narrativen Balladen, des Blues und frühen Country in der AAA- oder "simple verse «-Form. ${ }^{91}$ Schaut man sich die von Bob Dylan gewählten Songformen der Jahre 1961 bis 1964 an, so entsteht der Eindruck, dass selbst Verse/Chorus-Formen als zu kommerziell verpönt waren, da er in dieser Zeit zwar häufig an den Verse gebundene Refrainzeilen, aber niemals eigenständige Choruses schrieb. Erst 1965, als er auch das E-Gitarren-Tabu brach und mit Rock-Besetzung auftrat, begann Dylan Verse/Chorus-Songs aufzunehmen (»Mr. Tambourine Man«, »Like A Rolling Stone«, »Tombstone Blues«, »Can You Please Crawl Out Your Window«). 1965 findet sich auch erstmals eine Art Bridge bei Dylan, dies allerdings in einer AAABAAA-Form, die keinerlei Assoziationen an den Tin Pan Alley-Stil weckt (»Ballad Of A Thin Man«).

Goffin/King 1964), Peter \& Gordon (»A World Without Love«, Lennon/ McCartney 1964), Searchers (»When You Walk In The Room«, De Shannon 1964), Hollies (»Yes I Will«, Goffin/Titelman 1965).

89 Der AABA-Form folgen u.a. Yardbirds: »I Ain't Got You« (Carter 1964); Animals: »Don't Let Me Be Misunderstood« (Benjamin/Caldwell/Marcus 1965), The Kinks: »I Took My Baby Home« (Davies 1964).

90 Das englische Originalzitat wird durch die deutsche Synchronisation übertönt und ist nicht eindeutig zu transkribieren: »We'd had a diet of crooners. Y'know, good singers, but their singles [...] two minutes with a middle eight, it was really kitsch, kitsch [...] I mean and even people like Tommy Steele and Cliff Richards were just poor pastiches of the real thing, y'know, it just didn't, for me, it didn't, y'know... [Original-Zitat wird hier abgeschnitten].«

91 Gegen dieses Tabu verstießen The Brothers Four mit ihrem Nr. 2-Hit "Greenfields « (Gilkyson/Dehr/Miller 1959). 


\begin{tabular}{|c|c|c|c|c|}
\hline Bob Dylan & AABA & AAA & Verse/Chorus & Sonstige \\
\hline $\begin{array}{c}1962-1967 \\
84 \text { Songs }\end{array}$ & $4 \%$ & $81 \%$ & $10 \%$ & $5 \%$ \\
\hline
\end{tabular}

Tabelle 16: Formmodelle in 84 Kompositionen Bob Dylans der Jahre 1962-1967

Spätestens 1966 hatte die AABA-Form ihre dominierende Bedeutung in der Popmusik - und erst recht in der Rockmusik - weitgehend verloren, wenngleich Lennon und McCartney sie bis zum Ende der Beatles und darüber hinaus gern für langsame Stücke verwendeten, z.B. in »| Will« und »Hey Jude« (beide 1968), »The Long And Winding Road« (1970), »Imagine« (Lennon 1971) oder »My Love« (McCartney 1973). Zu finden war sie vereinzelt auch noch in den letzten Atemzügen der Brill Building-Ära, in Songs der Monkees, der Schöpfung des Brill Building-Moguls Don Kirshner, aber selbst dort eher selten (»Pleasant Valley Sunday«, Goffin/King 1967). In der Folgezeit gab es zwar immer wieder auch Billboard Nr.1-Hits im AABA-Format ${ }^{92}$, das Verse/Chorus-Format war nun jedoch eindeutig die Norm. ${ }^{93}$

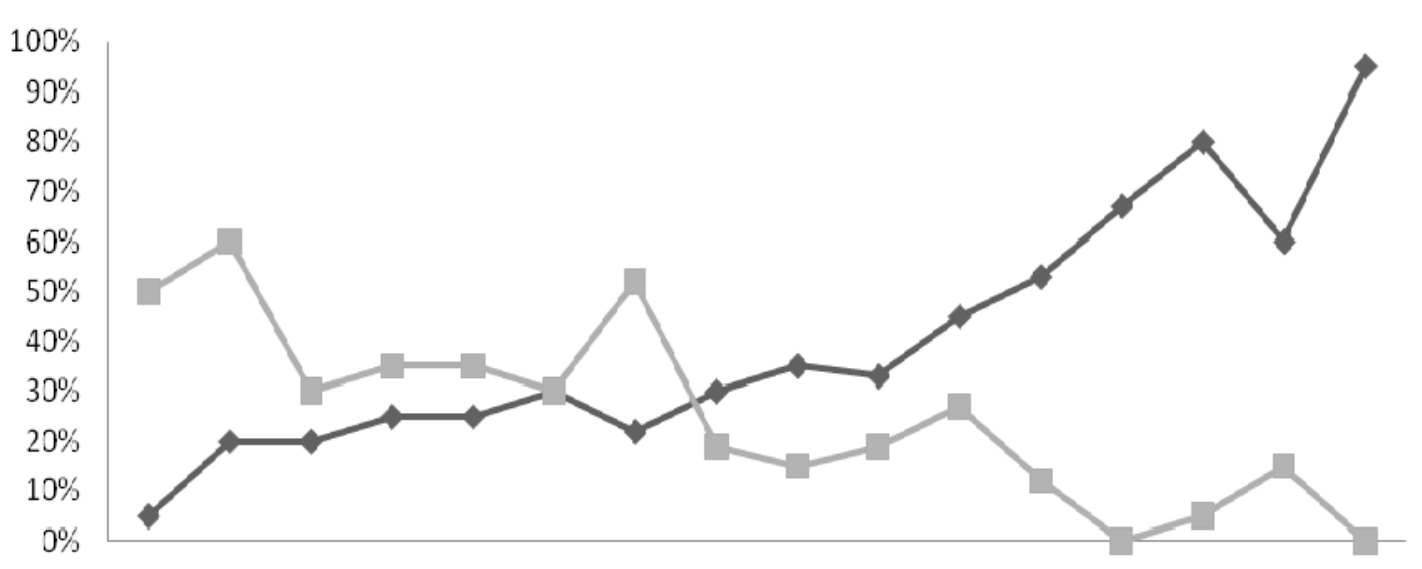

1952195419561958196019621964196619681970197219741976197819801982 $\neg \mathrm{V}-\mathrm{Ch} \leftrightharpoons-\mathrm{AABA}$

Abbildung 2: Anteil der AABA- und Verse/Chorus-Formen an Nr. 1-Hits der Billboard Top 100 der Jahre 1952 bis $1982(n=342)$

92 etwa »Raindrops Keep Fallin' On My Head« (David/Bacharach 1969), Sammy Davis Jr.s »The Candy Man« (Bricusse/Newley 1971), Michael Jacksons »Ben« (Black/Scharf 1972) oder Billy Swans »I Can Help« (Swan 1974).

93 Bemerkenswert ist, dass ausgerechnet das von John Phillips 1967 zur Bewerbung des Monterey-Festivals geschriebene »San Francisco (Be Sure To Wear Flowers In Your Hair)«, welches zumindest Außenstehenden als Hymne der Hippie-Bewegung galt und gilt, mit seiner nun anachronistischen AABA'-Form völlig untypisch für die Musik der Psychedelic-Szene Kaliforniens war, die antikonventionell sein wollte, Wurzeln in der Folk-Ideologie hatte und von musikalischer (und gesellschaftlicher) Experimentierlust geprägt war. 
Dass die AABA-Form in den späten 1960ern nicht mehr den popmusikalischen Alltag bestimmte, zeigt sich auch daran, dass sie zu dieser Zeit bereits gezielt ironisch, nostalgisch und parodistisch eingesetzt wurde - dass sie also zumindest für Insider mit einer Bedeutung aufgeladen war, die sie in den Zeiten ihrer größten Verbreitung noch nicht gehabt hatte. Schon die Music Hall-Pastiche »Winchester Cathedral« (Stephens), mit der die New Vaudeville Band 1966 in den USA erfolgreich war, nutzt die AABA-Form für eine nostalgische Stilkopie. Die 1920er Jahre-Pastiche »Honey Pie« (Lennon/ McCartney 1968) eröffnet die AABA-Form sogar stilgerecht mit einem einleitenden Verse. Auch in Frank Zappas Doo Wop-Parodie »Fountain Of Love (Zappa/Collins) darf neben Genre-typischen Lyrics, BackgroundGesängen und Akkordpattern die AABA-Form nicht fehlen (wenn auch mehrfach ironisch gebrochen). Und Bob Dylan konnte sein Publikum in den ausgehenden 1960ern kaum stärker schocken als mit Country-Songs im von der Gegenkultur verhassten Gewand und Format (»l'll Be Your Baby Tonight « 1968, und »Tonight I'll Be Staying Here With You« 1969) oder Tin Pan AlleyStandards (»Blue Moon«, Rodgers/Hart 1935, auf Self Portrait 1970).

Ähnlich normbrechend setzen Punk- und New Wave-Musiker die AABAForm (oder zumindest Anklänge daran) ein, um durch diesen Rückgriff ihre Gegenposition zu den musikalischen Trends ihrer Zeit deutlich zu machen und zwar genau in dem Moment, in dem AABA endgültig passé war (1976 war das erste Jahr, in dem kein Billboard-Spitzenreiter mehr der AABA-Form folgte). Während die AABA-Form oder die aus ihr hervorgegangenen Bridges in Hard Rock, Progressive Rock oder Disco nicht verwendet werden, eignet sie sich bestens für die bewusst simplen Songs der Ramones (»Blitzkrieg Bop«, Dee Dee und Tommy Ramone 1976; »I Wanna Be Well«, Joey Ramone 1977) oder die Assoziationen an die Girl Group-Zeit evozierenden Songs von Blondie (»(I'm Always Touched) By Your Presence Dear«, Valentine 1978; »Sunday Girl«, Stein 1979 ${ }^{94}$ ). Auch stark an AABA erinnernde Verse/ChorusFormen mit Bridge finden sich im Punk häufiger, z.B. auf der ersten britischen Punk-Single, The Damneds »New Rose« (James 1976), die neben der Form auch mit dem einleitenden Zitat aus »Leader Of The Pack« von den Shangri-La's (1964) und der Coverversion von »Help!« auf der B-Seite klar auf die Musik der 1960er verweist, oder in The Boys' »First Time« (Plain 1977).

Der Disco-Song »December 1963 (Oh, What A Night)« (Gaudio/Parker 1975) der Four Seasons nutzt eine um einen C-Teil erweiterte Variante der

94 Vgl. auch die AABA-Coverversionen »I'm Gonna Love You Too« (1978, orig. Mauldin/Petty/Sullivan 1958), »Denis« (1978, orig. »Denise«, Levenson 1963) und »Out In The Streets« (1999, orig. Greenwich/Barry 1965). 
im Disco völlig unüblichen AABA-Form dagegen nicht als symbolischen Normenbruch, sondern mit semantischem Hintergedanken - verweist doch so neben dem Songtext auch die Form auf eine nostalgische Erinnerung an die frühen 1960er Jahre.

Ein AABA-Revival gab es offenbar noch einmal im Jahr 1980, als drei Songs mit diesem Formmodell die Billboard Hot 100 anführten. Alle drei Queens »Crazy Little Thing Called Love« (Mercury), Billy Joels »It's Still Rock And Roll To Me« und John Lennons »(Just Like) Starting Over« - verweisen mit ihren Rockabilly- bzw. Doo Wop-Anklängen musikalisch klar auf die 1950er Jahre.

Soweit wir sehen, müssen diese und spätere Verwendungen der AABAForm $^{95}$ also als bewusste Rückgriffe aufgefasst und analysiert werden. Aufgabe der Analyse ist es hier, nach den Motiven und Botschaften solcher Rückgriffe (Zitat, Parodie, Nostalgie, Hommage, Normverletzung etc.) zu fragen.

\section{Und dann? Formenvielfalt}

Seit dem Ende der Vorherrschaft der AABA-Form gibt es kein einheitliches Formmodell mehr, das ähnlich dominant wäre, wie AABA es über vierzig Jahre lang gewesen ist.

Verses und Choruses in variabler Anzahl, Länge und Reihenfolge bilden nun das Rückgrat der meisten Songs. Bei sporadisch zu findenden vokalen Intros stellt sich die Frage, inwiefern hier der alte Tin Pan Alley-Verse noch fortwirkt; Gospelintonationen oder die textierten Vamps des Doo Wop kommen als weitere Vorbilder in Betracht. ${ }^{96}$ Andere Parts wie PreChoruses, Bridges - die nun auch instrumental sein können ${ }^{97}$ - und Soli stehen

95 Z.B. Bruce Springsteen (»Fire« 1978), Tom Waits (»Singapore« und »Clap Hands«, beide 1985) und Ron Sexsmith (»Tomorrow In Her Eyes« und »For The Driver«, beide 2004) sowie aktuell bei Magnetic Fields: „California Girls" (Merritt 2008; mit formalem wie textlichem Bezug auf die Beach Boys-Zeit); Vampire Weekend: »Holiday« (Baio/Thomson/Koenig/Batmanglij 2010); The Black Keys: »Everlasting Light« (Auerbach/Carney 2010).

96 Z.B. »| Do« (Pauling 1954), "Shop Around " (Gordy/Robinson 1960), »That Child Is Really Wild« (Gordy/Robinson 1960), »Itsy Bity, Pity Love« (Bradford/Wylie 1960), »Take Good Care Of My Baby« (Goffin/King 1961), Twistin' Postman« (Bateman/Holland/Stevenson 1961), »It Might As Well Rain Until September « und "Keep Your Hands Off My Baby « (beide Goffin/King 1962), »My Boyfriend's Back« (Feldman/Goldstein/Gottehrer 1963), »If I Fell« (Lennon/McCartney 1964).

97 Instrumentale Bridges waren vor allem im Soul der 1960er Jahre beliebt: »Respect« (Redding 1965; in Otis Reddings Uraufnahme noch vokal, bei Aretha 
optional zur Verfügung, ohne dass sie zwingend an der Position eingesetzt werden müssten, für die sie ursprünglich intendiert waren. ${ }^{98}$

So wird z.B. mit dem PreChorus reichlich experimentiert: Mal erscheint er erst nach zwei aufeinander folgenden Verses (»Congratulations«, Jagger/ Richards 1964), mal erst in der zweiten Verse/Chorus-Kombination (»I Can See For Miles«, Townshend 1967). Andere Stücke verzichten im letzten Verse/Chorus-Durchgang auf den PreChorus (»Your Good Thing (Is About To End)«, Hayes/Porter 1966), häufiger folgt er ohne Verse direkt auf Solo oder Bridge (»I'm A Believer«, Diamond 1966; »Fool On The Hill«, Lennon/McCartney 1967). Auch gibt es Stücke mit zwei unterschiedlichen PreChoruses (Lou Christies »Lightnin' Strikes«, Christie/Herbert 1965) oder Songs, die (nach einem »instrumentalen Verse « als Intro) mit dem PreChorus beginnen (Diana Ross' »Love Child«, Taylor/Wilson/Sawyer/Richards 1968).

Covachs Behauptung, die Musik der 1970er würde verstärkt Verse/ Chorus-Modelle mit Bridges nutzen (Covach 2005: 75), trifft zumindest hinsichtlich der bestplatzierten Billboard-Singles nicht zu. In einer Stichprobe von $121 \mathrm{Nr} .1$-Hits der Jahre 1970-1978 folgen zwar 67 dem Verse/ Chorus-Modell, aber nur 12 Songs verbinden es mit einer Bridge und nur 22 haben einen PreChorus.

Originelle und innovative Wege der Formbildung ging man Mitte der 1960er Jahre bei Motown, wo die AABA-Form nie großes Ansehen genossen hatte: Brian Holland/Lamont Dozier/Eddie Holland und auch William Stevenson komponierten zwischen 1963 und 1966 (der Blütezeit von AABA bei den Beatles) keinen einzigen Chart-notierten Song in diesem Format, während Smokey Robinson es in etwa einem Viertel seiner damaligen Hits einsetzte. ${ }^{99}$ Stattdessen wurde mit vielen verschiedenen Formen experimentiert, die sich in keine festen Schemata mehr ordnen lassen:

Franklin 1967 instrumental), »In The Midnight Hour« (Cropper/Pickett 1965), »Knock On Wood« (Cropper/Floyd 1966).

98 Zak (2008) untersucht den ab 1965 aufkommenden und dann in den 1970ern weit verbreiteten Trend zu Rocksongs mit »epischen« Längen und »episodischem « Aufbau, wie sie sich im Hard Rock (Led Zeppelin, Queen), bei Singer/ Songwritern (Bruce Springsteen, Billy Joel) und im Progressive Rock (Genesis, Yes) finden. Spicer (2004) führt Beispiele für Stücke aus unterschiedlichen Stilbereichen an, die sich »kumulativ« aufbauen. Osborn (2010) befasst sich mit der seit 2000 in »Post-Rock«, »Art-Rock«, »Math-Metal« und »Neo-Prog « verbreiteten Tendenz, Songs mit einem Part enden zu lassen, der kein Material aus Verse oder Chorus enthält, oder sie (ohne Material zu wiederholen) »durchzukomponieren «.

99 Eine entsprechende Statistik hat Fitzgerald (2007: 122f.) aufgestellt. Demnach enthielten auch nur 12 Prozent der Holland/Dozier/Holland-Songs eine Bridge. Mitverantwortlich waren Brian Holland und Mickey Stevenson allerdings für die kuriose Form des Marvelettes-Songs »Playboy« (B. Holland/Bateman/Horton/ 
Im Supremes-Hit »You Keep Me Hanging On« (Holland/Dozier/Holland 1966) tritt der Chorus in drei verschiedenen Varianten auf: Bei der Songeröffnung und der ersten Wiederholung hat er 12 Takte, bei der zweiten Wiederholung acht und bei der dritten, über die zudem ein neuer Text gesungen wird, 16 Takte. Der PreChorus folgt nur auf den ersten und dritten Verse, im zweiten Durchlauf wird er ausgelassen. In »Come See About Me« (Holland/Dozier/Holland 1964), ebenfalls von den Supremes, ist der PreChorus mit 12 Takten der längste Formteil.

Martha \& The Vandellas' »Dancing In The Street« (Stevenson/Gaye/ Hunter 1964) beginnt nach kurzem Intro mit einem Verse $(A=8+6$ Takte). Der Wechsel von der I. auf die IV. lässt dann einen PreChorus (B) oder ein Bluesderivat vermuten, doch wird nach vier Takten für weitere vier Takte zum Vamp des Verses zurückgewechselt $\left(A^{\prime}\right)$, der dann mit der Titelzeile endet. Es folgt ein achttaktiger Part mit erhöhter harmonischer Dichte, der als Chorus gehört werden könnte (C), doch erklingt die Titelzeile erst anschließend, wiederum über dem Vamp des Verses (A"). Der ganze Ablauf wird dann noch einmal identisch wiederholt. Insgesamt entsteht ein kontinuierlicher, fließender Ablauf, der den Tanz-Gedanken des Songtextes unterstützt.

Ähnlich unkonventionell verläuft »Stop! In The Name Of Love« (Holland/ Dozier/Holland 1965) von den Supremes: Nach einem achttaktigen Verse $(A)$, der offen auf der V. Stufe endet, scheint ein zweiter zu folgen ( $\left.A^{\prime}\right)$, in dem allerdings die Harmonien verändert werden und der bereits nach vier Takten in einen weiteren viertaktigen Teil (B) mündet, über den die Refrainzeile »Think it over « wiederholt wird. Es beginnt dann mit der Titelzeile und ihrer Wiederholung eindeutig der achttaktige Chorus (C), der allerdings wiederum in den Refrain »Think it over « (B) mündet. Nach identischer Wiederholung dieser gesamten Struktur endet das Stück mit einem weiteren Verse $(A)$ und - diesmal ohne $A^{\prime}$ und $B$ - einem direkt angeschlossenen Chorus.

»You Can't Hurry Love« (Holland/Dozier/Holland 1966) von den Supremes beginnt mit einem Verse (A) und einem Chorus (B), der sich harmonisch nicht vom Verse unterscheidet. Statt eines zweiten Verses folgt mit einem Wechsel auf die iii. Stufe dann schon ein Teil mit BridgeCharakter $(C)$, der wie viele andere Bridges mit $V^{7}$ endet. Diese Kombination aus Chorus und Bridge wird noch einmal wiederholt, erst dann kommt der Verse-Teil (A) wieder zum Einsatz, allerdings nicht achttaktig wie zu Beginn,

Stevenson 1962): Chorus - AABA - Chorus - BA - Chorus, mit ungewöhnlicher 4+6-Aufteilung des A-Teils. 
sondern über spannungssteigernde 24 Takte, wobei die Band - die Verzögerung nicht abwarten könnend - bereits nach acht Takten ihre ChorusBegleitung spielt und somit den Text »| keep on waiting, anticipating « illustriert - bevor dann endlich der erwartete Chorus den Song beendet: ein Beispiel dafür, dass die Songform Träger semantischer Bedeutung sein kann.

Neben diesen jeweils einmalig bleibenden Formen entwickelten andere Motown-Songwriter zeitgleich eine später sehr einflussreich werdende Formcharakteristik: In Songs wie Jr. Walker \& The All Stars' »Shot Gun« (DeWalt 1965), The Miracles' »Going To A Go-Go« (Robinson/Moore/Tarplin/ Rogers 1965) und Stevie Wonders »Uptight (Everything's Alright)« (Cosby/Moy/Wonder 1966) ist über die Form nicht mehr anhand der Harmonik zu entscheiden, da ihre Vamps bzw. Riffs ohne harmonische Wechsel während des gesamten Stückes durchlaufen. Formabschnitte ergeben sich nurmehr dadurch, dass der (Background-)Gesang zwischen Verse-artigen Parts und Sektionen, in denen als Hook mehrfach die Titelzeile skandiert wird, wechselt, sowie durch Soli oder durch kurze Breaks:

\begin{tabular}{|l|c|c|c|c|c|c|c|c|c|c|c|c|c|c|c|}
\hline \multicolumn{10}{|c|}{ "Going To A Go-Go (Robinson/Moore/Tarplin/Rogers 1965) } \\
\hline Intro & Ch & $V^{1}$ & Ch & Break & Ch & $V^{2}$ & Ch & Break & Solo & Break & Ch & $V^{3}$ & Ch & Break & Ch \\
\hline $4+4$ & 4 & 8 & 4 & 4 & 4 & 8 & 4 & 4 & 8 & 4 & 4 & 8 & 4 & 4 & $\begin{array}{c}8 \\
\text { (fade) }\end{array}$ \\
\hline
\end{tabular}

Verse- und Chorus-artige Teile treten in diesen Stücken in variierenden Längen und verschiedenen Abfolgen auf, sodass die Form improvisiert, abwechslungsreich, fließend und nicht vorhersehbar erscheint, was aber nicht desorientierend wirkt, da die Unterschiede zwischen den einzelnen Abschnitten bewusst gering gehalten sind. Mögliche Vorbilder für solches Verharren auf dem harmonischen sNull-Niveau sind etwa in John Lee Hookers Boogies (z.B. »Boogie Chillen«, Hooker 1948) bzw. darüber hinaus in bestimmten Formen des Pre War-Country Blues zu sehen - die AABAForm bleibt hier genealogisch außen vor.

Dieses Formmodell, in dem nicht mehr die Harmonik die einzelnen Abschnitte markiert, stellt die Grundlage für die weitere Entwicklung verschiedener Tanz-orientierter Musikstile von Funk und Dub über Disco und HipHop bis zur Electronic Dance Music dar. Sie ist damit auch als Vorläufer der Track-Form zu sehen, in der Begriffe wie Verse und Chorus oft nicht mehr sinnvoll anzuwenden sind, da die wesentlichen formbildenden Unterschiede im zeitlichen Verlauf nur durch den Gesang oder durch Hinzufügen und Weglassen einzelner Spuren (»Tracks«) und andere Texturänderungen entstehen. In den Mainstream-Charts hat dieses Modell jedoch nur wenige 
Spuren hinterlassen. ${ }^{100}$ Wer den größten ökonomischen Erfolg sucht, der kann auch heute nicht auf einen Chorus verzichten. ${ }^{101}$

\section{Schluss}

Die Untersuchung hat gezeigt, wie wichtig eine historische Betrachtung der verschiedenen Songformen-Modelle für die wissenschaftliche Begriffsbildung ist. Um mit der herrschenden terminologischen Verwirrung umgehen zu können, ist es notwendig, ihre Genese zu kennen; um sie nicht zu verschlimmern, sollte man die entsprechenden Begriffe sehr bewusst einsetzen. Zudem ist deutlich geworden, wie wichtig das Wissen um das jeweils Allgemeine und Besondere einer Zeit für die Analyse konkreter Songs ist. Nur mit diesem Hintergrund ist es möglich, Songformen auch semantisch zu deuten und ihre jeweilige kulturelle Bedeutung im Kontext ihrer Entstehungszeit zu interpretieren. Die Beobachtung und Beschreibung der Form ist keine analytische Pflichtübung, sondern lohnender Ausgangspunkt für viele nicht nur musik-, sondern auch kulturanalytische Fragestellungen. So ließe sich fragen, wo das offensichtlich gewachsene Mitteilungsbedürfnis herrührte, das Ende der 1950er Jahre zur Ausdifferenzierung der A-Zeile zum A-Teil und damit auch zu textreicheren neuen Verses führte. Im Gegenzug wäre beispielsweise die These zu prüfen, ob die kontinuierliche Zunahme von Refrains und Choruses in Zusammenhang steht mit dem zunehmenden medialen Informationsangebot und kürzer werdenden Aufmerksamkeitsspannen.

100 Erste Billboard-Plätze erreichten u.a. »Tighten Up« (Bell/Buttier 1967), »Thank You (Fallettinme Be Mice Elf Agin« (Stone 1969), »'ll Take You There (Bell 1972), »Papa Was A Rolling Stone« (Whitfield/Strong 1972). »Disco Lady« (Scales/Vance/Davis 1976), "Le Freak « (Edwards/Rodgers 1978), "Miss You« (Jagger/Richards 1978; mit kontrastierender Bridge) oder in jüngerer Zeit »| Gotta Feeling «, Adams/Pineda/Gomez/Ferguson/Guetta/Rieserer 2009).

101 Besser noch sind zwei Choruses: In den letzten Jahren zeichnet sich der Trend $\mathrm{ab}$, dem eigentlichen Chorus einen ebenfalls eingängigen Post-Chorus folgen zu lassen, in dem den Hörern bei nachlassender harmonischer Spannung der TitelHook mehrfach eingebläut wird (z.B. Rihannas »Umbrella (Jay-Z/Harrell/ Nash/Stewart 2007), Lady Gagas »Pokerface« (Germanotta/Khayat 2008) oder Beyoncés »Halo« (Bogart/Knowles/Tedder 2009). Wann diese Entwicklung begonnen hat, wäre noch zu untersuchen. Mögliche Vorläufer mit zweigeteilten Choruses wären die Motown-Songs »I Heard It Through The Grapevine« (Whitfield/Strong 1967), "I Want You Back« (Gordy/Perren/Mizell/Richards 1969) und $\gg A B C$ « (dies. 1970) sowie »Friday On My Mind « (Young/Vanda 1966), "Summer In The City« (Sebastian/Boone 1966) und »Born To Be Wild« (Bonfire 1968). 


\section{Literatur}

Beatles, The (2000). The Beatles Anthology. London: Cassell.

Covach, John (2005). »Form in Rock Music: A Primer. «In: Engaging Music: Essays in Music Analysis. Hg. v. Deborah Stein. Oxford: Oxford University Press, S. 65-76.

Covach, John (2010). "Leiber and Stoller, the Coasters, and the >Dramatic AABA Form. « In: Sounding Out Pop. Analytical Essays in Popular Music. Hg. v. Mark Spicer und John Covach. Ann Arbor: University of Michigan Press, S. 1-17.

Emerson, Ken (2005). Always Magic in the Air. The Bomp and Brilliance of the Brill Building Era. New York u. a.: Viking.

Everett, Walter (2001). The Beatles as Musicians. The Quarry Men through Rubber Soul. Oxford, New York: Oxford University Press.

Everett, Walter (2009). The Foundations of Rock. From Blue Suede Shoes To Suite: Judy Blue Eyes. Oxford: Oxford University Press.

Fitzgerald, Jon (1996). "Lennon-McCartney and the >Middle Eight<.«In: Popular Music and Society 20, Nr. 4, S. 41-52.

Fitzgerald, Jon (2007). »Black Pop Songwriting 1963-1966: An Analysis of U.S. Top Forty Hits by Cooke, Mayfield, Stevenson, Robinson, and Holland-DozierHolland. «In: Black Music Research Journal 27, Nr. 2, S. 97-140.

Forte, Allen (1995). The American Popular Ballard of the Golden Era 1924-1950. Princeton, NJ: Princeton University Press.

Fritsch, Markus / Lonardoni, Andreas / Kellert, Peter (2010). Harmonielehre und Songwriting. Neusäß: Leu (6. Aufl.).

Hamm, Charles (1979). Yesterdays. Popular Song in America. New York u. London: W.W. Norton.

Hoerburger, Felix (1998). »Refrain.«In: Die Musik in Geschichte und Gegenwart. Sachteil, Bd. 8. Hg. v. Ludwig Finscher. Kassel, Stuttgart: Bärenreiter / Metzler (2. Aufl.), Sp. 121-126.

Inglis, lan (2003). » Some Kind of Wonderful:: The Creative Legacy of the Brill Building. «In: American Music 21, Nr. 2, S. 214-235.

Laing, Dave (2009). »Six boys, six Beatles: the transformative years, 1950-1962.« In: The Cambridge Companion to the Beatles. Hg. v. Kenneth Womack. Cambridge: Cambridge University Press, S. 9-32.

Leiber, Jerry / Stoller, Mike (with David Ritz) (2009). Hound Dog. The Leiber and Stoller Autobiography. New York u. a.: Simon \& Schuster.

Middleton, Richard (2003). »Form. «In: Continuum Encylopedia of Popular Music of the World. Hg. v. John Shepherd et al. London: Continuum, S. 503-520.

Miles, Barry (1997). Paul McCartney: Many Years From Now. New York: Holt.

Miles, Barry / Badman, Keith (2001). The Beatles Diary: The Beatles Years. London: Omnibus.

Osborn, Bradley T. (2010). Beyond Verse and Chorus: Experimental Formal Structures in Post-Millennial Rock Music. Dissertation, University of Washington, Online unter: https//digital.lib.washington.edu/researchworks/handle/1773/ 15910 (Zugriff am 14.8.2011).

Pastras, Phil (2001). Dead Man Blues. Jelly Roll Morton Way Out West. Berkeley, Los Angeles: University of California Press.

Patrick, Mick (2007). Liner Notes zur CD Goffin \& King. A Gerry Goffin \& Carole King Song Collection 1961-1967. Ace CDCHD 1170. 
Patrick, Mick / Baumgart, Malcolm (1999). Liner Notes zur CD On Broadway. Hit Songs and Rarities from the Brill Building Era. Westside WESD 216.

Richards, Keith (2010). Life. London: Weidenfeld \& Nicolson.

Shaw, Arnold (1983). Die Geschichte des Rhythm und Blues. Honkers und Shouters. Frankfurt/M.: Zweitausendeins.

Spicer, Mark (2004). »(Ac)cumulative Form in Pop-Rock Music.« In: twentiethcentury music 1 , Nr. 1, S. 29-64.

Stephenson, Ken (2002). What to Listen for in Rock. A Stylistic Analysis. New Haven und London: Yale University Press.

Tagg, Philip (2009). Everyday Tonality. Towards a Tonal Theory of What Most People Hear. New York, Montreal: The Mass Media Music Scholars' Press.

Tawa, Nicholas E. (1990). The Way to Tin Pan Alley. American Popular Song, 18661910. New York, London: Schirmer.

Townsend, Peter (2007). Pearl Harbor Jazz: Changes in Popular Music in the Early 1940s. Jackson, MS: University Press of Mississippi.

Zak, Albin (2008). »Rock and Roll Rhapsody. Pop Epics of the 1970s.«In: Expression in Pop-Rock Music. Critical and Analytical Essays. Hg. v. Walter Everett. New York, London: Routledge (2. Aufl.), S. 345-360.

\title{
Filmquelle
}

Priestley, Philip (2010). British Blues Explosion. Als in England der Rock ausbrach [Dokumentarfilm, 59 Min.]. Gesendet auf arte am 12.9.2010 um 5:00 Uhr.

\begin{abstract}
This paper deals with different dimensions of the formal construction of songs in $20^{\text {th }}$ century popular music. First, it proposes that the form of songs is not only an obligatory (albeit formalistic) starting point for analysis but is actually itself a worthwhile object of interpretation. It explains how the analysis of the formal song structure can produce meaningful insights on a semantic, symbolic, and functional level. Secondly, the authors provide a critical discussion on the use of prevalent terms such as chorus, refrain, verse, bridge, etc. They show that a study of the historical evolution both of constituent song parts, and of song forms in general, is necessary to overcome the internal contradictions and incompatibilities of the current terminology.

This approach is the center of this paper. It refers to the authors' analysis of c. 2500 songs spanning the whole $20^{\text {th }}$ century with a focus on the decisive years 1920 to 1970. Illustrating the results with a large number of examples, the authors trace the development of the AABA-form, various verse/chorus-forms, the evolution of the pre-chorus and various other song parts, and song form models. The findings are supported by statistical data based on the US Billboard Top 100, and show the prevalence of certain models as well as specific trends in historic change.

Finally, the paper shows that the awareness of formal conventions and particularities can be an essential pre-condition for the analysis of popular music's cultural meanings.
\end{abstract}

